\title{
Daily physical activity, energy expenditure and physical fittness: assessment and implications
}

Citation for published version (APA):

Plasqui, G. (2004). Daily physical activity, energy expenditure and physical fittness: assessment and implications. [Doctoral Thesis, Maastricht University]. Datawyse / Universitaire Pers Maastricht. https://doi.org/10.26481/dis.20050121gp

Document status and date:

Published: 01/01/2004

DOI:

10.26481/dis.20050121gp

Document Version:

Publisher's PDF, also known as Version of record

\section{Please check the document version of this publication:}

- A submitted manuscript is the version of the article upon submission and before peer-review. There can be important differences between the submitted version and the official published version of record.

People interested in the research are advised to contact the author for the final version of the publication, or visit the DOI to the publisher's website.

- The final author version and the galley proof are versions of the publication after peer review.

- The final published version features the final layout of the paper including the volume, issue and page numbers.

Link to publication

\footnotetext{
General rights rights.

- You may freely distribute the URL identifying the publication in the public portal. please follow below link for the End User Agreement:

www.umlib.nl/taverne-license

Take down policy

If you believe that this document breaches copyright please contact us at:

repository@maastrichtuniversity.nl

providing details and we will investigate your claim.
}

Copyright and moral rights for the publications made accessible in the public portal are retained by the authors and/or other copyright owners and it is a condition of accessing publications that users recognise and abide by the legal requirements associated with these

- Users may download and print one copy of any publication from the public portal for the purpose of private study or research.

- You may not further distribute the material or use it for any profit-making activity or commercial gain

If the publication is distributed under the terms of Article $25 \mathrm{fa}$ of the Dutch Copyright Act, indicated by the "Taverne" license above, 


\section{Daily physical activity, energy expenditure and physical fitness}

Assessment and implications 


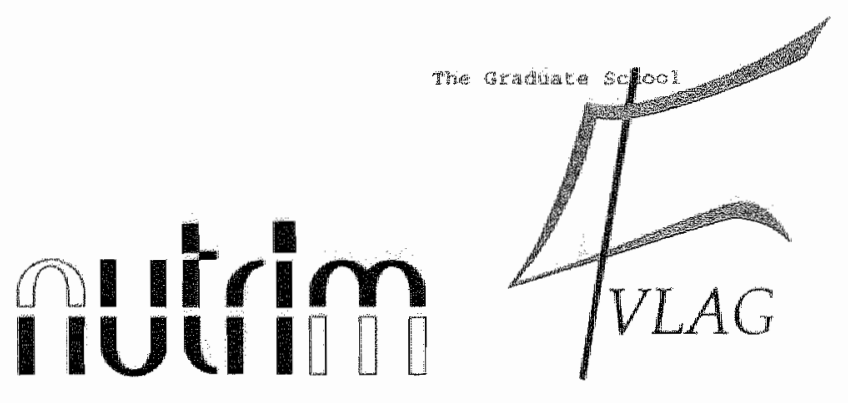

The studies presented in this thesis were perforned at the Nutrition and Toxicology Research Institute Maastricht (NUTRIM), which participates in the graduate school VLAG (Food Technology, Agrobiotechnology, Nutrition and Health Sciences), accredited by the Royal Netherlands Academy of Arts and Sciences.

\author{
Cover design: Guy Plasqui \\ Cover Photo: adopted from S. Rossner \\ Layout: Guy Plasqui \\ Printed by: Datawyse, Universitaire Pers Maastricht \\ C Guy Plasqui, Mastricht 2004-09-03 \\ ISBN $\quad 90-5278-432-9$
}




\title{
Daily physical activity, energy expenditure and physical fitness
}

\section{Assessment and implications}

\author{
PROEFSCHRIFT
}

ter verkrijging van de graad van doctor

aan de Universiteit Maastricht

op gezag van de Rector Magnificus

Prof.mr G.P.M.F. Mols

volgens het besluit van het College van Decanen

in het openbar te verdedigen

op vrijdag 21 januari 2005 on 14.00 uur

door

\section{Guy Plasqui}

geboren te Bonheiden op 2 juni 1976

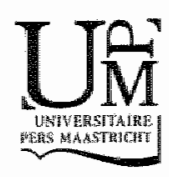




\section{Promotor}

Prof.dr. K.R. Westerterp

\section{Beoordlelingseommissie}

Prof.dr H. Kuipers (voorzitter)

Prof. dr. W. Th. Hermens

Prof. dr. T. Piersma (Rijksuniversiteit Groningen)

Prof. dr. ir. W.H.M. Saris

Prof. ar. ir. P.H. Veltink (Universiteit Twente)

Financial support by the Netherlands Heart Foundation and the Netherlands Association for the Study on Obesity (NASO) for the publication of this thesis is gratefully acknowledged. 


\section{Contents}

\section{Chapter 1}

General introduction

\section{Chapter 2}

Seasonal variation in sleeping metabolic rate, thyroid activity and leptin

\section{Chapter 3}

Seasonal variation in total energy expenditure, and physical activity in Dutch young adults

Chapter 4

Measuring free-living energy expenditure and physical activity with trimaxial accelerometry

\section{Chapter 5}

Accelerometry and heart rate as a measure of physical fitmess: proof of concept

\section{Chapter 6}

Accelerometry and heart rate monitoring as a measure of physical fitness: crossvalidation

Chapter 7

Daily physical activity in patients with heart failure before and after cardiac resynchronisation therapy

\section{Chapter 8}

General discussion

Appendix 1

Summary

Samenvatting

Dankwoord

List of publications 

Chapter 1

General introduction 


\section{Introduction}

A large proportion of the Western population is physically inactive. A sedentary lifestyle, often adopted during adolescence and continued in adulthood, is a major concern for public health. Where at the age of nine, $97 \%$ of the children meet the activity recommendations, only $82 \%$ of the boys and $62 \%$ of the girls meet these recommendations at the age of $15(58)$. Individuals who are regularly physically active enjoy better health and have a greater degree of independence than those who are sedentary (66). Physical inactivity is associated with several diseases such as cardiovascular disease $(12,51)$, diabetes mellitus type II $(19,20,26,41)$, osteoporosis $(23,46)$ and obesity $(21,72,78)$. The dramatic increase in the prevalence of overweight and obesity over the past decades $(13,49,71)$ is related with, and possibly caused by lower levels of physical activity (21).

Physical activity (PA) can be defined as body movement, produced by skeletal muscles, resulting in energy expenditure (9). It is a complex behaviour including sports as well as non-sports activities. Sports are often planned, structured and repetitive with the objective to improve or maintain physical fitness (9) while non-sports activities can be subdivided into different categories such as occupational, leisure time and household activities but also personal care or transportation. From this definition, it is clear that physical activity has an impact on energy expenditure and physical fitness. The extent to which body movement leads to energy expenditure is dependent on body size and body composition. The extent to which physical activity improves physical fitness is dependent on the amount and type of activity performed. Different aspects of physical activity will influence different aspects of physical fitness.

Physical activity is a behaviour that can be influenced by the environment. Season is an environmental factor that modulates climatic features such as ambient temperature and day length. These changes in climatic conditions can affect one or more aspects of physical activity and energy expenditure. Figure I schematically displays the relation between physical activity and energy expenditure, physical fitness and body composition with season as a modulating environmental factor. Changing one factor has consequences on the others. The different aspects mentioned in figure 1 will be elucidated below. 


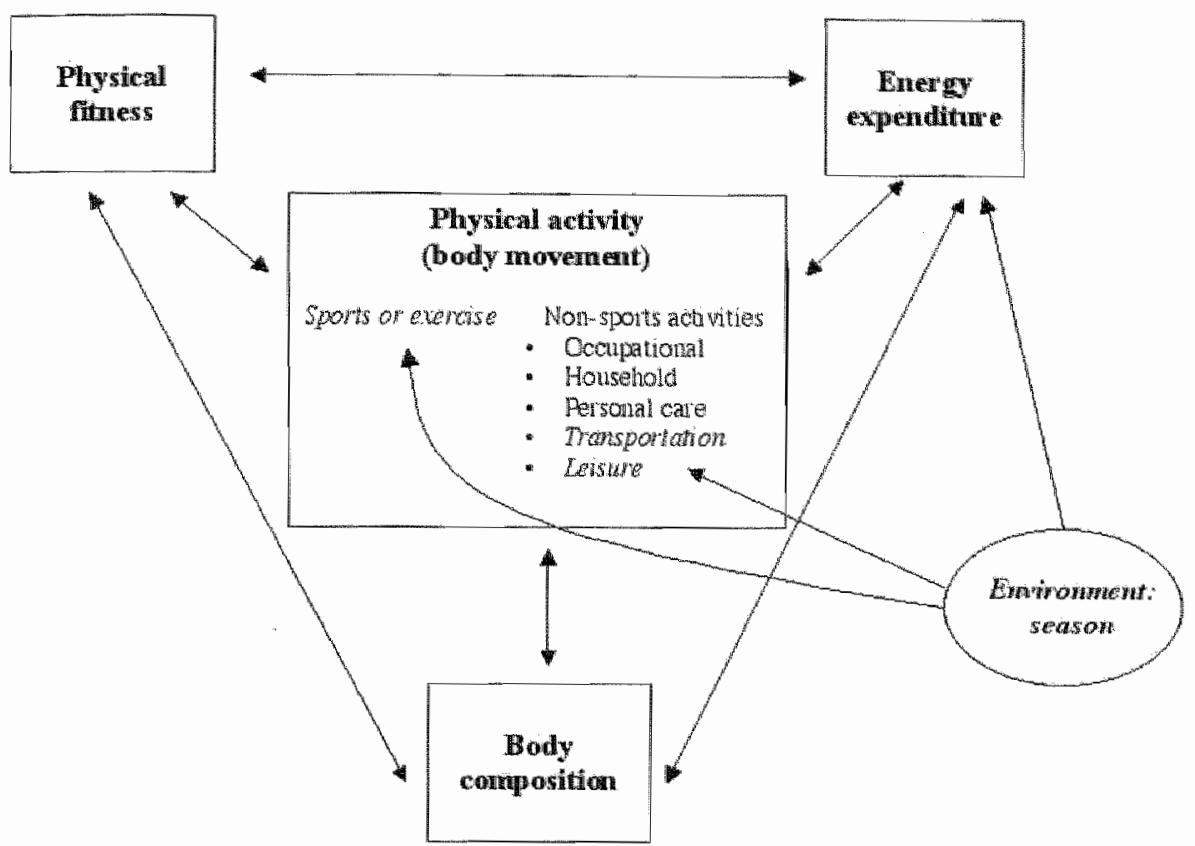

Figure 1: A model to display the relation between physical activity and energy expenditure, physical fitness and body composition and the influence of season. Season and the main aspects of physical activity that are influenced by season are printed in italic.

\section{Components of total energy expenditure}

Total energy expenditure (TEE) consists of three major components: basal metabolic rate (BMR), diet induced thermogenesis (DIT) and activity related energy expenditure (AEE). BMR consists of sleeping metabolic rate (SMR) and the energy cost of arousal. The contribution of the different components to TEE in a moderately active, average male is presented in Figure 2.

On average, BMR accounts for the largest proportion of TEE. It is defined as the daily rate of energy metabolism an individual needs to maintain and preserve the integrity of vital functions (1). SMR is the metabolic rate measured during sleep. When SMR is defined as the lowest metabolic rate during sleep, it is about 5\%-10\% lower than BMR, but when overnight metabolic rate is used, SMR and BMR are equivalent $(15,65)$. A major determinant of BMR is body composition or fat free mass more particularly (75).

DIT is the energy cost of the digestion, absorption and conversion of ingested food and is assumed to be $10 \%$ of TEE in subjects consuming an average mixed diet and being in energy balance ( 75 ). 


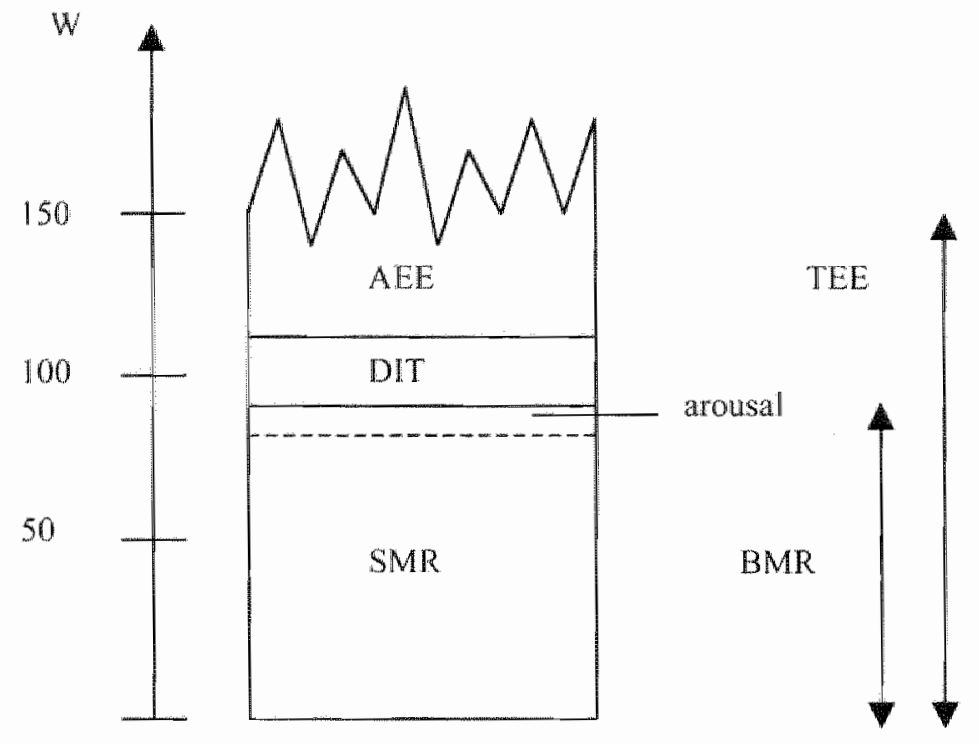

Figure 2: Components of total energy expenditure (TEE): sleeping metabolic rate (SMR), energy cost of arousal, basal metabolic rate (BMR), diet induced energy expenditure (DIT) and activity related energy expenditure (AEE). Data for a moderately active adult male weighing $70 \mathrm{~kg}$, with $15 \%$ body fat (74).

AEE is the energy spent on physical activity and is the most variable component between subjects. To compare AEE between subjects, a correction for body mass or better, body composition should be made. Although there is no consensus on how to correct for body size $(54,75)$, A.EE is often expressed as $\mathrm{kJ} / \mathrm{kg}$ body mass or as $\mathrm{kJ} / \mathrm{kg}$ fat free mass. Physical activity can also be quantified by the physical activity level (PAL), which is TEE divided by $B M R$.

\section{Environment: season}

The reguation of energy balance and thus body weight involves many physiological and biochemical mechanisms and is influenced by both genetic and environmental Pactors. Changes in envirommental factors can result in changes in ingestive behaviour, metabolism and physical activity. Season is an important environmental fatcor regarding energy homeostasis, as thas extensively been studied in amimals and has asso gained interest in humans. Seasonal variation in body weight, present in many animals, has also been shown in humans $(30,53,70,76)$. The mechanism behind seasonality in body weight in humans is still umevealed and data are rather scarce. In developing countries, energy intake and energy expendiure (EE) can vary considerably between harvest and non-harvest season, resulting in changes in body weight $(45,52,55)$. In industrialized countries, food availability is guaranteed throughout the year and workload is usually independent of season. Studies investigating seasonall changes in 
energy intake have shown contradictory results $(30,53,70)$. The lack of an accurato method to detamine energy intake in humans probably accounts for the inconsistent results. EE and its different components can be measured more accurately and is therefore our primary interest.

There are two main climatic features that change with the season, i.e. photoperiod (hours of daylight) and enwirommental temperature. Both of these factors might have sn influence on one or more components of energy expenditure. In many animals. photoperiod is essential for the regulation of energy balance. Photoperiod is transduced into a hommonal signal, melatonin, within the pineal gland (44). Seasonal vatiation in melatonin is also present in humans, and although the endocrine pathways and the physiological effects are beyond the scope of this thesis, it might have an effect on energy metabolism.

Environmental temperature has been related to seasonal variation in BMR $(24,32,50)$, possibly through an effect on thyroid activity (50). Thyrotd activity is known to be related with BMR $(2,50,68)$ and is up regulated in a cold enwiromment $(10,68)$, which makes it a potential regulating factor in seasonal BMR changes. Beside effects on homone concentrations, climate might have a direct effect on EE through an effect on AEE. The substantial shorter photoperiod and adverse weather conditions in winter season, in a country like The Netherlands, might directly affect physical activity and thus $\mathrm{AEE}$. Changes in physical activity might also induce changes in body composition which than in turn affect BMR. Season could therefore infuence energy expenditure throngh several pathways and the impact on the different components of BE should be elucidated.

\section{Assessment of energy expenditure}

EE can be measured with both direct and indirect calorimetry. Substrate oxidation results in heat production. Direct calorimetry measures the heat output per se while indirect calorimetry measures the gas exchange $\left(\mathrm{O}_{2}\right.$-consumption and $\mathrm{CO}_{2}$-production) as a conseguence of substrate turnover. When a subject is at rest, both direct and indirect calorimetry measure the same EE. Whem physical activity is performed, contraction of the muscles results in heat output and external work. Gxternal work is only measured with indirect and not with direct calorimetry. Measuring the $\mathrm{O}_{2}$ consumption, $\mathrm{CO}_{2}$ production and urine nitrogen loss allows the calculation of $\mathrm{EE}$. The energy equivalent of oxygen and carbon dioxide varies with the nutrient (carbohydratte, fat, protein) oxidized. Since, in the case of a normal protein oxidation of $10.15 \%$ of the daily energy production, the protein correction for the calculation of FE is about $1 \%$, urine nitrogen loss is often not measured and $\mathrm{EE}$ is calculated from $\mathrm{O}_{2}$-consumption and $\mathrm{CO}_{2}$-production (74) (see also appendix I for a more detailed description). The techniques described below are all based on indirect calorimetry.

\section{Venrilated hood}

The most frequently used method to measure BMR is the yentilated bood. The subject lies supine on a bed with a transparent ventilated canopy over the head. Airlow through the hood as well as the $\mathrm{O}_{2}$-and $\mathrm{CO}_{2}$-concentration in both in-and out-flowing air is measured contimously. BMR is measured in the moming after an overnight fast, in a thermo-neutral enviromment and the subject being awake. Subjects are instructed to 
awoid exercise before testing, including the day prior to the measurement day. The best reproducibility is found when BMR is measured over $30 \mathrm{~min}_{\mathrm{r}}$ where the first 10 -min interval is removed because of habituation to the testing procedure (1).

When used over longer intervals, the ventilated hood also allows measurement of DIT. However, since for the accurate determination of DIT, EE must be measured up to 6 hours after a meal (67), restlessness of the subject becomes a probllem.

\section{Whole-room calorimeters}

The principle of measuring $\mathrm{EE}$ in a whole-room calorimeter or respiration chamber is the same as with a ventilated hood system except that the measurement interval is much longer dwe to the large dilution space of the chamber. The chamber used in this thesis measures $14 \mathrm{~m} 3$ and is equipped with a bed, table, chair, freeze tollet, washing bowl, radio, television and computer (62). Respiration chambers allow measurement of TEE and its different components, although $\mathrm{AEE}$ in the chamber is not representative for AEE in daily life due to the limited space.

\section{Dowbly labelled water}

The doubly labelled water method is the only technique available to accurately assess TEE in daily life. Subjects are given a dose of water labelled with the stable isotopes ${ }^{18} \mathrm{O}$ and ${ }^{2} \mathrm{H}$. $\mathrm{H}$ will be eliminated from the body as ${ }^{2} \mathrm{H}_{2} \mathrm{O}$ while ${ }^{18} \mathrm{O}$ will be eliminated as $\mathrm{H}_{2}{ }^{12} \mathrm{O}$ and $\mathrm{C}^{18} \mathrm{O}_{2}$. Concentrations of both isotopes can be measured in urine, saliva or blood samples and the difference between both elimination rates is a measure of $\mathrm{CO}_{2}$ production. By assuming an average respiratory quotient ( $\mathrm{RQ}, \mathrm{CO}_{2}$-production $/ \mathrm{O}_{2}$ consumption) of 0.85 , EE can be calculated. Depending on the administration dose and energy tumover, TEE can be measured over intervals of 2.5 days in extremely active subjects to 30 days in sedentary elderly (77). The method is accurate to $1-2 \%(61)$ and is considered the golden standard for the measurement of TEE in daily life.

\section{Physical activity assessment}

The complex nature of PA makes it difficult to accurately measure all its aspects and assess the impact on EE. Different measuring techniques avalable can be grouped into five categories: behavioural observation, self-1eport (questionnaires and activity diaries), physiological markers (heart rate, body temperature, ventilation), motion sensors (pedometers, accelerometers) and calorimetry (direct and indirect) $(28,64,73$ ). Ideally. PA should be assessed during daily life, over periods long enough to be representative for the habitual activity level and with minimal discomfort to the subject. Furthemore, it is important to identify physical activity patterns (frequency, duration, intensity) as well as AEE.

\section{Activity related enesgy expenditure and the physical acrivity level}

By combining a measurement of TEE by means of doubly labelled water with BMR by a ventilated hood (or SMR with a respiration chamber), AEE [(0.9.TEE) BMIR] and the plysical activity level (PAL $=\mathrm{TEE} \cdot \mathrm{BMR} \mathrm{R}^{-1}$ ) can be calculated. Since the doubly labelled water technique is expensive, this method is only applicable for small study populations. Furthemore, this technique provides an accurate measure of TEE but no information on physical activity patterns in terms of frecuency, duration and intensity is available. 
Therefore, several other techniques for the measurement of PA in the field have been developed, ideally with doubly labelled water as the reference. Two of these techniques, heart rate registration and accelerometry, will be described in further detail.

\section{Heart rate registration}

Heart rate registration is a frequenty used method to estimate free-living energy expenditure. Under controlled laboratory conditions, there is good linear relation between heart rate and $\mathrm{O}_{2}$-consumption, although there is a deviation from linearity in the upper and lower part of the curve. It is therefore a reasonable approach to use heart rate as a physiological marker of $\mathrm{O}_{2}$-consumption and thus physical activity $(14)$. A disadvantage is that the relation between heart rate and $O_{2}$-consumption waries between subjects, requiring individual calibration during a standardized activity protocol. Further disadvantages are that: heart rate is also influenced by other factors but activity, stuch as ambient temperature and emotional stress $(40,42)$; the relation between heart rate and $\mathrm{O}_{2}$-consumption is affected by the relative size of the exercising muscle mass $(59)$; hear: rate remains elevated after $\mathrm{O}_{2}$-consumption has retumed to baseline, resulting in an overestimation of energy expenditure (59).

\section{Morion sensors}

Motion sensors are probably the oldest tools available to measure body movement or physical activity. They have evolved from mechanical pedometers to electronic uniaxial and tri-axial accelerometers. The first pedometer was probably invented by Leonardo da Vinci, about 500 years ago (42). lit was designed to count steps by responding to vertical acceleration, moving a lever arm up and down, resulting in rotation of a gear. Another mechanical motion sensor, the actometer, was developed by Schulman and Reisman (63). They used a modified wristwath to transform vertical accelerations into rotation of an internal rotor. Movement of the rotor is then registered as a change in position of the clock hands and the resulting change in time displayed is used as the activity measure (40). In the seventies, the electronic large-scale integrated motor activity monitor (LSI) was developed (29). The device is slightly larger than a wristwatch and can be worn at various body locations. The sensor consists of a cylinder containing a ball of mercury. Tilting of the instrument causes the ball of mercury to roll down the cylinder, making contact with a mercury switch at the end of the cylinder. The number of closures of the mercury switch is recorded and used as a measure of physical activity $(29)$.

Currently, several electronic pedometers are commercially available (60). Pedometers. can be used to count steps and, when the step-length is known, walking distance and thus provide information about total walking andor running activity. Since only the total amount of steps is monitored there is no information on frequency, duration and intensity of physical activity (5). Due to the complex nature of different activities in daily life, their applicability to assess free-living activity is linuted.

Accelerometers are electronic motion sensors that exist of piezoresistive or piezoelectric sensors. Piezoresistive accelerometers respond to accelerations by a change in resistance of sillicon resistors, which is then transfomed to a voltage proportional to the amplitude and frequency of the acceleration of the small mass in the sensor. Piezoresistive accellerometers require an external power source and respond to a constant acceleration such as gravity (6). Piezo-electric accelerometers generate an 
clectric charge in response to a mechanical force and thus acceleration (6). They do not respond to constant acceleration and their major advantage is that no power supply is required, except for data-storage, resulting in a considerable reduction of size and weight of the device.

Over the past decades, advances in techology have resulted in the development of small and light instruments that are able to collect data at a high frequency and store minute by minute data over several days or weeks. Uni-axial accelerometers measure accelerations in one direction, usually in the vertical plane, whereas tri-axial accelerometers measure accelerations in the anterior-posterior, medio-lateral and vertical direction. With the wide range of activities a subject can perform, tri-axial accelerometers provide more information and show a better relation with $\mathrm{AEE}$ than uniaxial (8). A number of uni-axial ICSA (Computer Science and Application's Inc., Shalimar, FL) currently known as the MTI (Manufacturing Technology Inc., Fort Walton Beach, FL); Caltrac (Hemokinetics, Madison, WI); Lifecorder (Suzuken Co. Ltd, Nagoya, Japan)] and tri-axial [the Mini Motionlogger actigraph (Ambulatory monitoring Inc., Ardsley, NY): Tritrac-R3 D (Hemokinetics, Madison, WI); Physillog (BioAGM, Switzerland)] accelerometers are currently avalable. The accelerometer used for this thesis is not conmercially available and will be discussed in detal below.

\section{Triaxial Accelerometer for Mowement Registration}

The Trimaxial Accelerometer for Movement Registration (Tracmor) was developed at our laboratory about fifteen years ago. Originally, the sensor weighed about $20 \mathrm{~g}$ and consisted of a piezo-electric element, defomed by a small mass on a lever, bent from one comer to the opposite comer, making it sensitive in three directions $(38,39)$. The semsor was connected to a unit $(40 \times 60 \times 80 \mathrm{~mm} ; 350 \mathrm{~g})$ for data acquisition and storage, and power supply $(38,39)$. Bouten et al. (6) then developed a tri-axial accelerometer based on three uni-axial piezoresistive accelerometers mounted orthogonally onto a cube made of Celeron. The result was a small sized tri-axial accelerometer $(50 \times 30 \times 8 \mathrm{~mm}, 16 \mathrm{~g})$ connected to a portable data unit $(110 \times 70 \times 35$ $\mathrm{mm}, 250 \mathrm{~g}$ including batteries) allowing minute by minute data storage for intervals up 108 days (6). In the next version of the Tracmor (Philips Research, Eindhoven, The Netherlands), piezo-electric accelerometers were used, accelerometer and data unit were combined in one small casing $(69 \times 28 \times 9 \mathrm{~mm}, 30 \mathrm{~g})$ and the memory and power supply were able to store data for up to three weeks $(16,18,35-37)$. The current Tracmor consists of three separate uni-axial piezo-electric accelerometers, measures 71 $\times 26 \times 7$ mm and weighs $22 \mathrm{~g}$ battery included. The acceleration signal is high-pass fillered at $1 \mathrm{~Hz}$ and low-pass filtered at $7.2 \mathrm{~Hz}$ and the amplitude range is approximately $-5 \mathrm{~g}$ to $5 \mathrm{~g}$. Accelerations are sampled at a frequency of $75 \mathrm{~Hz}$. Accelerometer signals are summed and stored minute by minute for each axis $X$ (medio-lateral), $Y$ (longitudinal or vertical) and Z (antero-posterior) separately. Battery power (one lithium battery, $3 \mathrm{~V}, \mathrm{CR} 2032$ ) and storage capacity allow contimuous data acquisition for periods of up to three weeks after which data can be downloaded into a computer.

Ideally, an accelerometer should be small, light, unobtrusive, sensitive within the right frequencies and amplitudes, and able to store data over longer periods of time. The size of the device is important in order not to interfere with nomal daily activity patterns. Bouten et al. have summarized the frequency and amplitude range required to accurately measure human movement (6). For accelerometers placed at waist level, a frequency band between 0.3 and $3.5 \mathrm{~Hz}$ and an amplitude range of $-6 \mathrm{~g}$ to $6 \mathrm{~g}$ should 
suffice to capture daily physical activity. Within these ranges, accelentions during low intensity activities, like sedentary activities or walking, as well as high intensity activities or exercise, like running and jumping, can be measured (6). Low-and highpass filters can be used to elminate those frequencies that are unlikely to arise from human movement, such as high frequencies due to transportation.

To test the capability of accelerometers to predict energy expenditure, validation against indirect calorimetry is necessary. Many accelerometers have been tested under laboratory conditions during standardized activities $(8,33,43,47,48,69)$, in field settings against portable calorimeters $(4,17)$ or in the controlled environment of a whole room calorimeter $(3,27,56)$. Most accelerometers show good to very good correlations $(\mathrm{r}=0.74-0.95)$ with energy expenditure during walking and running on a treadmill or with other defined activities $(8,33,43,47,48)$. An increasing number of accelerometers has also been validated against doubly labelled water under unconfined conditions in daily life $(7,11,16,18,22,31,34,35,57)$. Conelations between accelerometer output and DLW derived energy expenditure measures, such as AEE or TEE are often very poor and mainly determined by subject's characteristics such as body mass, age, sex and height $(22,31,57)$. Significant correlations between activity counts and PAL. TEE and AEE were found for the CSA (Computer Science and Application"s Inc., Shalimar, FL) accelerometer $(11,34)$ and the various models of the Tracmor (Philps Research, Eindhoven, The Netherlands). So far, of all the accelerometers tested, the Tracmor seems to correlate best with DLW derived energy expenditure measures with correlations between PAL and activity counts of 0.73 in healthy young adults (7), 0.78 in elderly (35) and 0.79 in children (18) and between TEE, adjusted for BMR, and activity counts of $0.95(16)$.

Piezo-electric accelerometers, such as the Tracmor, are unable to detect static activities such as for keeping posture or carrying weights. The amount of energy expended per unit of accelerometer output is also dependent on body size and composition as well ass on the type of activity performed. For example, cycling will result in a lower accelerometer output than running while the energy expenditure during cycling might be equally high. Given these shortcomings, the correlations between the Tracmor and energy expenditure are considerably high.

\section{Physical Fitness}

Just as plysical activity, physical fitness is a complex tom with many aspects. Figure 3 summarizes how a variety of parameters can contribute to a person"s fitness. Depending on the type and objective of study, one or more of these components can be measured. In health and sports related research, physical finess is often refered to as cardiorespiratory endurance expressed as maximal oxygen uptake $\left(\mathrm{VO}_{2 \mathrm{nax}}\right)$ of the maxtmal capacity of the cardiovascular system to provide $O_{2}$ to the muscle cell during sustained exercise. VO $\mathrm{V}_{\text {max }}$ can be accurately measured under laboratory condivions using an incremental exercise protocol usually on a bicycle ergometer or treadmill (25). 


physical fitness $\begin{cases}\text { health related fitness } & \left\{\begin{array}{l}\text { cardiorespiratory endurance } \\ \text { muscular endurance } \\ \text { muscular strength } \\ \text { body composition } \\ \text { flexibility }\end{array}\right. \\ \text { skill related fitness } & \left\{\begin{array}{l}\text { agility } \\ \text { balance } \\ \text { coordination } \\ \text { speed } \\ \text { power } \\ \text { reaction time }\end{array}\right.\end{cases}$

Figure 3: Aspects of physical finess. Adopted from Caspersen et al. (9).

Using an incremental bicycle test, maximal mechanical performance or peak working capacity $\left(W_{\max }\right)$ and $\mathrm{VO}_{2 \max }$ are measured simultaneously. $W_{\text {max }}$ refers to the extemal power reached at the time of exhaustion of the subject. $W_{\max }$ and $\mathrm{VO}_{2 \max }$ are linearly related, with only a deviation in the upper part of the curve, and are therefore often used interchangeably. In this thesis, physical fitness will be defined as either $W_{\text {max }}$ or VOImax.

\section{Outline of the thesis}

The first wo studies (chapters 2 and 3 ) investigated the impact of season, as a dominant envirommental factor, on the components of TEE and on physical finess. Accurate techniques were used to assess SMR. TEE and the maximal mechanical power of the body ( $\left.W_{\text {max }}\right)$. The doubly labelled water (DLW) technique is the only one available to measure TEE under daily life conditions but only provides a measure of the overall activity level and not about activity patterns. Accelerometers provide information about the lotal amount, intensity, frequency and duration of physical actiwity and when combined with subjects" physical characteristics such as body mass, a prediction of TEE can be made. Since only a few accelerometers have been validated against DLW, and they often show poor relations with DLW derived energy expenditure, chapter 4 focused on the validation of the new version of the Tracmor under daily lite conditions. VOtman the most widely used measure of physical fimess, can be directly measured under laboratory conditions using an incremental exercise test. These tests require a specific protocol, expensive equipment and maximal exertion of the subject. Therefore, various alternative tests have been developed to predict $\mathrm{VO}_{2 \mathrm{~m} n}$ instead of the direct measurement. Chapters 5 and 6 describe the potential use of a new fitness-index, based 
on the combined use of accelerometry and heart rate registration, as a measure of physical fitness.

In chapter 7, the Tracmor was used to measure daily physical activity in patients with heart failure, a population with low physical activity levels due to cardiac impaiment. This study amed to investigate whether the implantation of a pacemaker positively affected physical activity.

Chapter 8 combines the different studies and puts the results in perspective. 
1. Adriacns, M. P. P. F. Schoffelen, and K. R. Westerterp. Intra-individual variation of basal metabolic rate and the influence of darly habitual physical activity before testing. Br J Nutr. 90:419-423, 2003.

2. al-Adsani, H., L. J. Hoffer, and I. E. Silva. Resting energy expenditure is sensitive to small dose changes in patients on chronic thyroid hormone replacement. J Clin Endocrinol Metab. 82:1118.1125., 1997.

3. Avons, P., P. Garthwaite, H. L. Davies, P. R. Murgatroyd, and W. P. James. Approaches to estimating physical activity in the communty: calorimetric validation of actometers and heart rate monitoring. Eur J Clin Nutr. 42:185-196, 1988.

4. Bassett, D. R., B.A. Ainsworth, and A. M. Swartz. Validity of four motion sensors in measuring moderate intensity physical activity. Med.Sci.Sports Exerc. $32.5471,2000$

5. Bassert, D. R., Jr. Validity and rellability issues in objective monitoring of physical activity. Res Q Exerc Sport. 7 I:S30-36, 2000

6. Bouten, C. V., K. T. Koekkoek, M. Verduin, R. Kodde, and J. D. Janssen. A triaxial accelerometer and portable data processing unit for the assessment of daily physical activity. 1EEE Trans Biomed Eng. 44:136-147, 1997

7. Bouten, C. V., W. P. Verboeket van de Venne, K. R. Westerterp, M. Verduin, and J. D. Janssen. Daily physical activity assessment: comparison between movement registration and doubly labeled water. J Appl Physiol. 81:1019-1026, 1996.

8. Bouten, C. V., K. R. Westerterp, M. Verduin, and J. D. Janssen. Assessment of energy expenditure for physical activity using a triaxial accelerometer. Med Sci Sports Exerc. 26:15॥6-1523, 1994.

9. Caspersen, C. J., K. E. Powell, and G. M. Christenson. Physical actiwity, exercise, and physical fitness: definitions and distinctions for health-related research. Public Health Rep. 100:126-131,1985.

10. Eastman, C. J., R. P. Ekins, I. M. Leith, and E. S. Williams. Thyroid homone response to prolonged cold exposure in man. J Physiol. 241:175-181., 1974.

11. Ekelund, U., M. Sjostrom, A. Yngve, E. Poortvliet, A. Nilsson, K. Froberg, N. Wedderkopp, and K. Westerterp. Physical activity assessed by activity monitor and doubly labeled water in children. Medicine And Science In Sports And Exencise. Feb. 33:275-281, 2001.

12. Fang, J., J. Wylie-Rosett, H. W. Cohen, R. C. Kaplan, and M. H. Alderman. Exercise body mass index, caloric intake, and cardiovascular mortality. Am J Prev Med. 25:283-289,2003.

13. Flegal, K. M. M. D. Carroll, C. L. Ogden, and C. L. Johnson. Prevalence and trends in obesity among US adults, 1999-2000. Jama, 288:1723-1727, 2002.

14. Freedson, P. S. and K. Miller. Objective monioring of physical activity using motion sensors and heart late. Res Q Exere Sport. 71:21-29, 2000. 
15. Goldberg, G. R., A. M. Prentice, H. L. Davies, and P. R. Murgatroyd. Overnight and basal metabolic rates in men and women. Eur J Clin Nutr. 42:137-144, 1988.

16. Goris, A. H., E. P. Meijer, A. Kester, and K. R. Westerterp. Use of a triaxial accellerometer to validate reported food intakes. Am J Clin Nutr. 73:549-553, 2001 .

17. Hendelman, D., K. Miller, and C. Baggett. validity of accelerometry for the assessment of moderate intensity physical activity in the freld. Med.Sci.Sports Exerc. $32: \$ 442,2000$.

18. Hoos, M. B., G. Plasqui, W. J. Gerwer, and K. R. Westerterp. Physical activity level measured by doubly labeled water and accelerometry in children. Eur J Appl Physiol. 89:624-626, 2003.

19. Hu, F, Bi, T. Y. Li, G. A. Colditz, W. C. Willet, and J. E. Manson Television watching and other sedentary behaviors in relation to risk of obesity and type 2 diabetes mellitus in women. Jama. 289:1785-1791, 2003.

20. Hu, G., Q. Qiao, K. Silventoinen, J. G. Eriksson, P. Jousilahti, J. Lindstrom, T. T. Valle, A. Nissinen, and J. Tuomilehto. Occupational, commuting, and leisure-time physical activity in relation to risk for Type 2 diabetes in middle-aged Finnish men and women. Diabetologia. 46:322-329, 2003.

21. Jebb, S. A. and M. S. Moore Contribution of a sedentary lifestyle and inactivity to the etiology of overweight and obesity: current evidence and research issues. Med Sci Sports Exerc. 31:\$534-541, 1999.

22. Jolhnson, R. K., J. Russ, and M. 1. Goran. Physical activity related energy expenditure in children by doubly labeled water as compared with the Calltrac accelerometer: Int.J.Obes. 22:1046-1052, 1998.

23. Kai, M. C., M. Anderson, and E. M. Lau. Exereise interventions: defusing the world's osteoporosis time bomb. Bull World Health Organ. 81:827-830, 2003.

24. Kashiwazaki. H. Seasonal fluctuation of BMR in populations not exposed to limitations in food avalabillity: reality or illusion? Eur J Clin Nutr. 44:85-93., 1990.

25. Keren, G., A. Magazanik, and Y. Epstein. A comparison of various methods for

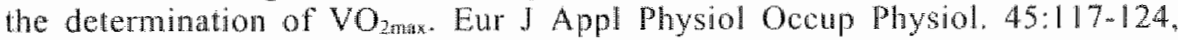
1980.

26. Kriska, A. M., A. Saremi, R. L. Hanson, P. H. Bennet, S. Kobes, D. E. Willams, and W. C. Knowler. Physical activity, obesity, and the incidence of type 2 diabetes in a highrisk population. Am J Epidemiol. 158:669-675, 2003.

27. Kumahara, H., Y. Schutz, M. Ayabe, M. Yoshioka, Y. Yoshilake, M. Shindo, K. Ishii, and H. Tanaka. The use of uniaxial accelerometry for the assessment of physical-activity-related energy expenditure: a vallidation study against wholebody indirect calorimetry. Br J Nutr. 91:235-243, 2004. 
28. Lamonte, M. J. and B. E. Ainsworth. Quantifying energy expenditure and physical activity in the context of dose response. Med Sci Sporis Exerc. 33:5370-378; discussion S419-320,2001.

29. LaPorte, R. E. L. H. Kuller, D. J. Kupfer, R. I. McPartland, G. Matthews, and C. Caspersen. An objective measure of physical activity for epidemiologic research. Am I Epidemiol. 109:158-168, 1979.

30. Lee, C. J., G. S. Lawler, M. Panemangalore, and D. Street. Nutritional status of middle-aged and elderly females in Kentucky in wo seasons: Part 1. Body weight and related factors. J Am Coll Nutr. 6:209-215, 1987 .

31. Leenders, N. Y., W. M. Sherman, H. N. Nagaraja, and C. L. Kien. Evaluation of methods to assess physical activity in free-liwing conditions. Med Sci Sports Exerc. 33:1233-1240., 2001.

32. Leonard, W. R., M. V. Sorensen, V. A. Galloway, G. J. Spencer, M. I. Mosher, L. Osipova, and V.A. Spitsyn. Climatic infuences on basal metabolic rates among circumpolar populations. Am J Human Biol. 14:609-620, 2002.

33. Levine, J. A., P. A. Baukol, and K. R. Westerterp. Validation of the Tracmor triaxial accelerometer system for walking. Med Sci Sports Exerc. 33:1593 1597. 2001.

34. Masse, L. C., J. E. Fulton, K. L. Watson, M. T. Mahar, M. C. Meyers, and W. W. Wong. Influence of body composition on physical activity validation studies using doubly labeled water. J Appl Physiol. 96:1357-1364, 2004.

35. Meijer, E. P., A. H. Goris, L. Wouters, and K. R. Westerterp. Physical inactivity as a determinant of the physical activity level in the elderly. Int $J$ Obes Relat Metab Disord. 25:935-939,2001.

36. Meijer, E. P., K. R. Westerterp, and F. T. J. Verstappen. Effect of exercise training on physical activity and substrate utilization in the elderly. International Journal Or Sports Medicine. Oct. 21:499-504, 2000.

37. Meijer, E. P., K. R. Westerterp, and F. T. J. Verstappen. Effect of exercise training on total daily physical activity in elderly humans. Eur.J.Appl.Physiol. 80:16-21, 1999

38. Meijer, G. A., K. R. Westeterp, H. Koper, and F. ten Hoor. Assessment of energy expendiure by recording heart tate and body acceleration. Med Sci Sports Exere. $21: 343-347,1989$

39. Meijer, G. A. L., K. R. Westerterp, and F. M. H. Verhoeven. Methods to assess physical activity with special reference to motion sensors and accelerometers. IEEE Trans. Biomed.Eng. 38:221-229, 1991.

40. Melanson, E. L., Jr, and P. S. Freedson. Physical activity assessment: a review of methods. Crit Rev Food Sci Nutr. 36:385-396, 1996.

41. Mensink, M., E. J. Feskens, W. H. Saris, T. W. De Bruin, and E. E. Blaak. Study on Lifestyle Intervention and Impaired Glucose Tolerance Mastricht (SLIM): 
preliminary results after one year. Int J Obes Relat Metab Disord. 27:377-384, 2003.

42. Montoye, H. J., H. C. G. Kemper, W. H. M. Saris, and R. A. Washburn. Measuring physical activity and energy expenditure, 1996, 191.

43. Montoye, H. J., R. Washburn, S. Servais, A. Ertl, I. G. Webster, and F. J. Nagle. Estimation of energy expenditure by a portable accelerometer. Med.Sci.Sports Exerc. $15: 403-407,1983$.

44. Morgan, P. J. and J. G. Mercer. The regulation of body weight: lessons from the seasonal animal. Proc Nutr Soc. 60:127-134, 2001.

45. Murayama, N. and R. Ohtsuka. Sexsonal fluctuation in encrgy balance anong farmers in Northeast Thailand; the lack of response of energy intake to the change of energy expenditure. Eur J Clin Nutr. 53:39-49, 1999.

46. Neville, C. E., L. J. Murray, C. A. Boreham, A. M. Gallagher, J. Twisk, P. I. Robson, J. M. Savage, H. C. Kemper, S. H. Ralston, and G. Davey Smith. Relationship between physical activity and bone mineral status in young adults: the Northern Ireland Young Hearts Project. Bone. 30:792-798, 2002.

47. Nichols, J. F., C. G. Morgan, L. E. Chabot, J. F. Sallis, and K. I. Callas. Assessment of physical activity with the computer science and applications, Inc., accelerometer: laboratory versus field validation. rqes. 71:36-43, 2000.

48. Nichols, J. F., C. G. Morgan, J. A. Sarkin, J. F. Sallis, and K. J. Calfas, Validity, reliability, and calibration of the Tritrac accelerometer as a measure of physicall activity. Med.Sci.Sports Exerc. 31:908-912, 1999.

49. Ogden, C. L., K. M. Flegal, M. D. Carroll, and C. L. Johnson. Prevalence and trends in overweight among US children and adolescents, 1999-2000. Jama. 288:1728-1732, 2002.

50. Osiba, S. The seasonal variation of basal meabolism and activily of thyroid gland in man. Jap.J.Physiol. 7:355-365, 1957.

51. Panagiotakos, D. B., C. Chrysohoou, C. Pitsavos, A. Menoti, A. Dontas, I. Skoumas, C. Stefanadis, and P. Toutouzas. Risk factors of stroke mortality: a 40. year follow-up of the Corfu cohori from the Seven-Countries Study. Neuroepidemiology. $22: 332-338,2003$.

52. Panter-Brick, C. Inter-individual and seasonal weight variation in rural nepali women. J.Biosoc.sci. 27:215-233, 1995.

53. Pasquali, R., G. Baraldi, F. Casimirri, L. Mattioli, M. Capelli, N. Melchionda, F. Capani, and G. Labo. Seasonal variations of total and free thyroid homones in healthy men: a chronobiological study. Acta Endocrinol Copenh, 107:42-48, 1984.

54. Prentice, A. M., G. M. Goldberg, P. R. Murgatroyd, and T. I. Cole. Physical "activity and obesity." problems in correcting expenditure for body size. Int l. Obes. $20: 688-691,1996$. 
55. Prentice, A. M., R. G. Whitehead, S. B. Roberts, and A. A. Paul. Long-term energy balance in child-bearing Gambian women. An I Clin Nutr. 34:2790-2799, 1981 .

56. Puyau, M. R., A. L. Adolph, F. A. Vohra, and N. F. Butte. Validation and calibration of physical activity monitors in children. Obes Res. 10:150-157,2002.

57. Rafamantanantsoa, H. H., N. Ebine, M. Yoshioka, H. Higuchi, Y. Yoshitake, H. Tanaka, S. Satoln, and P. J. Jones. Validation of three alternative methods to measure total energy expenditure against the doubly labeled water method for older Japanese men. INutr Sci Vitaminol (Tokyo). 48:517-523, 2002.

58. Riddoch, C. J., L. Bo Andersen, N. Wedderkopp, M. Harro, L. Klasson-Heggebo, L. B. Sardinha, A. R. Cooper, and U. Ekelund. Physical activity levels and pattems of 9 - and 15-yr-old European children. Med Sci Sports Exere. 36:86-92. 2004.

59. Rowlands, A. V., R. G. Eston, and D. K. Ingledew. Measurement of physical activity in chiddren with particular reference to the use of heart rate and pedometry. Sports Med. 24:258-272, 1997.

60. Schneidar, P. L., S. E. Crouter, and D. R. Bassett. Pedometer measures of freeliving physical activity: comparison of 13 models. Med Sci Sports Exerc. 36:331$335,2004$.

61. Schoeller, D. A. and J. M. Hnillicka. Reliability of the doubly labeled water method for the measurement of total daily energy expenditure in free-living subjects. I Nutr. 126:348S-354S, 1996.

62. Schoffelen, P. F., K. R. Westerterp, W. H. Saris, and F. Ten Hoor. A dualrespiration chamber system with automated calibration. I Appl Physiol. 83:2064$2072,1997$.

63. Schulman, J. L. and J. M. Reisman. An objective measure of hyperactivity. Am J Ment Defic. 64:455-456, 1959.

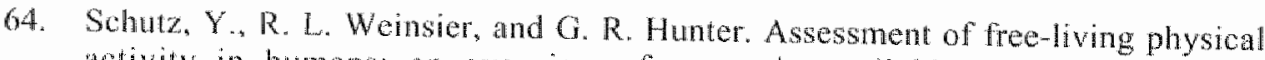
activity in humans: an overview of currently available and proposed new measures. Obes Res. 9:368-379., 2001

65. Seale, J. L. and J. M. Conway. Relationship between ovemight energy expenditure and BMR measured in a roonm-sized calorimeter. Eur J Clin Nutr. 53.107-111.
1099.

66. Seefoldt, V., R. M. Malina, and M. A. Clark. Factors affecting levels of physical activity in adults. Sports Med. 32:143-168, 2002.

67. Segal, K. R., A. Edano, and M. B. Tomas. Thermic effect of a meal over 3 and 6 hours in lean and obese men. Metabolism. 39:985-992, 1990.

68. Silva, I. E. Thyroid hormone control of thermogenesis and energy balance. Thyroid. $5: 481-492,1995$.

69. Terrier, P., K. Aminian, and Y. Schutz. Can accelerometry accurately predict the energy cost of uphill/downhill walking? Ergonomics. 44:48-62., 2001. 
70. Van Staveren, W. A., P. Deurenbery, J. Burema, L. C. De Groot, and J. G. Hautvast. Seasonal variation in food intake, pattern of physical activity and change in body weight in a group of young adult Dutch women consuming selfselected diets. Int I Obes. 10:133-145, 1986.

71. Visscher, T. L., D. Kromhout, and J. C. Seidell. Long-term and recent time trends in the prevalence of obesity among Dutch mern and women. Int $J$ Obes Relat Metab Disord. 26:1218-1224, 2002.

72. Weinsier, R. L., G. R. Hunter, R. A. Desmond, N. M. Byme, P. A. Zuckerman, and $B$. E. Danell. Free-living actiwity energy expenditure in women successful and unsucessful at maintaining a nomal body weight. Am J Clin Nutr. 75:499$504 ., 2002$.

73. Westerterp, K. R. Assessment of physical activity level in relation to obesity: current evidence and research issues. Med.Sci.Sports Exerc. 31 S522-S525, 1999.

74. Westerterp, K. R. Energy expenditure. In: Food intake and energy expenditure. M. S. Westerterp-Plantenga, E. W. H. M. Fredrix, and A. B. Steffens (Eds.): CRC Press, 1994, pp. 235-257.

75. Westerterp, K. R. Energy metabolism and body composition: general principles. Eur Respir Mon. 24:1-10,2003.

76. Westerterp, K. R. Seasonal variation in body weight: an experimental case study. J.Thermai Biol, 26:525-527, 2001.

77. Westerterp, K. R., L. Wouters, and W. D. v. Marken-Lichtenbelt. The Maastricht protocol for the measurement of body composition and energy expenditure with llabeled water. Obes.Res. 3:49-57, 1995.

78. Williams, P. T. Vigorous exercise and the population distribution of body weight. Int J Obes Relat Metab Disord. 28:1120-128, 2004. 

Chapter 2

\section{Seasonal variation in sleeping metabolic rate, thyroid activity and leptin}

Guy Plasqui, Arnold D.M. Kester and Klaas R. Westerterp

Am J Physiol Endocrinol Metab 285: E338-E343, 2003 


\begin{abstract}
Objective We investigated seasonal variation in sleeping metabolic rate and the possible relation with body composition, thyroid activity and leptin.

Methods 25 healthy volunteers, were examined four times during the year: in spring (April, May), summer (July, Aagust), autumn (October, November) and winter (Jantary, Fubruary). Body composition was determined using a three-compartment model based on underwater weighing and the deuterium dilution method. Sleeping netabolic rate (SMR) was measured during an overnight stay in a respiration chamber. A blood sample was taken for the analysis of free and total T4, TSH and leptin.

Results SMR showed a significant seasonal variation $(\mathrm{p}<0.01)$ with a maximum in winter $(4.54 \mathrm{~kJ} / \mathrm{min})$ and a minimum in summer $(4.34 \mathrm{~kJ} / \mathrm{min})$. The amplitude was $0.10 \pm 0.02 \mathrm{~kJ} / \mathrm{min}$ and the phase was November the 5 th. Season explained $17 \%$ of the intra-individual wariation in SMR. The circannual thythm in SMR could not be explained by changes in body composition, thyroid activity or leptin. Inter-individual variation in SMR was explained by fat free mass $($ FFM $(p<0.001)$ and leptin $(p<0.001)$.
\end{abstract}




\section{Introduction}

Resting metabolic rate ( $R M R$ ), mainly determined by fat free mass (FFM), is the nain component of total energy expenditure (TEE) and therefore an important factor in the sudy of energy metabolism and obesity. One aspect influencing RMR is environmental temperature where RMR is higher in a cold environment (32). Environmental temperature includes room temperature as well as ambient temperature. If ambient temperature regulates $\mathbb{R M R}$, one expects a seasonal variation in $R M R$. Osiba (20) measured four Japanese male adults monthly under standard conditions and found a distinct seasonal variation in sleeping metabolic rate (SMR) with a summer low, winter high difference of $16.3 \%$ of the mean. Kashiwazaki (11) re-analyzed the literature about seasonal fluctuations in RMR in populations not exposed to limitations in food avalability. It was stated that both indoor as well as outdoor temperature at the lime of measurement influence RMR and that seasonal influences persisted after controlling for indoor temperatures. On the contrary, a more recent study from Haggarty (6) revealed no summer-winter differences in the RMR of adult mates in the UK. The latter was one of the few studies including data on body composition, to eliminate the possibility that the seasonal changes in RMR are due to changes in FFM.

Thyroid activity is known to be related with $\operatorname{RMR}(1,20,28)$ and is up regulated in a cold environment $(4,28)$, which makes it a potential regulating factor in seasonal RMR changes. Osiba (20) measured the protein-bounded iodine in serum as a measure of the thyroxin content and found a seasonal variation with the peak in January. Other studies measuring free, reverse or total T3 (triodothyronin), free or total T4 (thyroxin) or TSH (thyroid stimulating hormone) showed contradictory results regarding seasonal influences or the moment of peak concentrations $(15,18,24,29)$.

The recently discovered hormone leptin, produced by adipocytes, could also influence RMR and has been suggested as a local autocrine/paracrine regulator of TSH release ( 7 , 19). Very little is known about seasonal influences on leptin. Donahoo et al. (3) found no effect of the season on leptin concentrations in normal weight men and women. Perry et all. (22) found a circannual rhythm for leptin in older African American men but the data were cross-sectional.

Despite a wide interest in seasonal variation in RMR, there are quite some contradictory results and questions to be solved. To our knowledge, there is no study on seasonal variation in $R M R$ including repeated measures of sleeping metabolic rate (SMR), body composition and homonal influences in both men and women, not subject to limitations in food-availability. This study was designed to investigate 1) a possible seasonal variation in SMR 2) whether or not this variation is due to a change in body composition 3) seasonal variation in thyroid runction, represented as $T S H$, free $\mathbb{4}$ and total $\mathbb{T} 4$, and its relation with $S M R$ 4) a possible seasonal variation in leptin and its relation with SMR.

\section{Methods}

Subjects.

Subjects were 25 healthy volunteers ( 10 males and 15 females) between the age of 20 and 30 , most of them working at the university. Detailed information about the objective and the protocol of the study was provided. Written informed consent was 
obtained and the sudy was approved by the Ethics Committee of Maastricht University. Most subjects were working at the university, performing comparable activities. Sleeping metabolic rate (SMR), body composition and a blood sample were obtained at subsequent time points: in spring (April, May), summer (July, August), Autumn (October, November) and winter (January, February). The subjects were not measured within 14 days before or after their vacations. Subjects" physical characteristics at baseline are shown in Table 1.

Table 1: Subject characteristics at baseline as mean $\pm \mathrm{SD}$.

\begin{tabular}{lcc}
\hline $\mathrm{N}$ & Women & Men \\
Age $(\mathrm{y})$ & 15 & 10 \\
Height $(\mathrm{m})$ & $25 \pm 2$ & $26 \pm 2$ \\
Body mass $(\mathrm{kg})$ & $1.72 \pm 0.07$ & $1.82 \pm 0.08$ \\
BMI $\left(\mathrm{kg} / \mathrm{m}^{2}\right)$ & $64.4 \pm 5.9$ & $69.2 \pm 9.6$ \\
Body fat $(\%)$ & $21.9 \pm 1.9$ & $20.9 \pm 2.0$ \\
\hline
\end{tabular}

\section{Sheping metobolic rate}

SMR was measured during an overnight stay in a respiration chamber. The chamber measured $14 \mathrm{~m}^{3}$ and was equipped with a bed, table, chair, freeze toilet, washing bowl, radio, television and computer (26). Subjects entered the room at $21 \mathrm{~h}$ in the evening and left the room at $7: 30$ in the moming. Energy expenditure was calculated from $\mathrm{O}_{2}$. consumption and $\mathrm{CO}_{2}$-production according to Weir's formula (33). SMR was defined as the average metabolic rate during at least $3 \mathrm{~h}$ of sleep with the lowest activity measured by Doppler radar, usually between 3:00 and 6:00 AM. Subjects were asked to consume their normal evening meal at home between 18:00 and 19:00. The meals were not standardized, in order not to interfere with the subjects' nomal feeding behaviour and thus with energy balance. Since SMR was measured at least $6 \mathrm{~h}$, in general 8 to $11 \mathrm{~h}$ after the meal, the effect of diet-induced themogenesis is assumed to be minimal $(27)$.

The respiratory quotient (RQ) was determined as a measure of substrate oxidation. Room temperature was held constant at $20 \pm 1{ }^{\circ} \mathrm{C}$ every season to investigate whether the seasonal effect is present when short-term effects of temperature changes are controlled for.

\section{Body Composition}

Anthropometric measurements were taken in the morning after leaving the respiration chamber. Body mass was measured on an electronic scale (Mettler Toledo IDI Plus, Germany) to the nearest $0.0 \rrbracket \mathrm{kg}$. Height was measured to the nearest $0.1 \mathrm{~cm}$ (SECA Mod.220, Germany). Body volume was measured with underwater weighing. Residual lung volume was simultaneously measured with the helium dilution technique. Total body water (TBW) was measured with deuterium dilution according to the Matastricht
protocol (34). Body composition was calculated from body density and TBW using siri's three-
compartment model 30 ). 


\section{Blood sample}

After the anthropometric measurements before the consumption of any food or drinks, a blood sample was taken for the analysis of leptin, total thyroxine (totalT4), free thytoxine (free T4) and thyroid stimulating hormone (TSH).

Ambient temperature. Data on 24 average ambient temperature was supplied by the Royal Dutch Meteorological Institute and was collected at a location near the university (Maastricht, Beek; $51^{\circ}$ North, $6^{\circ}$ East).

\section{Siatistics}

All variables were tested for normal distribution and were log transformed if necessary. A general sinusoidal model was used to investigate a within-subjects seasonal variation in SMR and homone levels.

$$
\begin{gathered}
\mathrm{Y}=\mathrm{c}+\mathrm{A} \cdot \sin \left[\left(\mathrm{d}-\mathrm{d}_{0}\right) / 365 \cdot 2 \pi\right] \\
\mathrm{Y}=\mathrm{c}+\underbrace{\mathrm{A} \cdot \cos \left(2 \pi d_{0} / 365\right)}_{\mathrm{b}_{1}} \cdot \underbrace{\sin (2 \pi \mathrm{d} / 365)}_{\mathrm{X}_{1}}-\underbrace{\mathrm{A} \cdot \sin \left(2 \pi d_{0} / 365\right)}_{\mathrm{b}_{2}} \cdot \underbrace{\cos (2 \pi \mathrm{d} / 365)}_{\mathrm{X}_{2}}
\end{gathered}
$$

With $\mathrm{c}=$ a constant, $\mathrm{A}=$ the amplitude, $\mathrm{d}=$ day of the year the measurement was done, d0 = the phase. ANOVA was used to determine $b_{1}$ and $b_{2}$ and an F-test was used to determine the significance of the sinusoidal model. The amplitude and the phase were then calculated as:

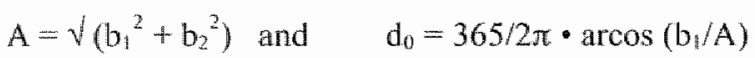

To correct for the menstrual cycle, the phase of the menstrual cycle was put into the model. Measurements for women in the post ovulation phase were coded 1 , while those for men and for women in the pre ovulation phase were coded 0 .

A multiple regression analysis with a backward selection procedure was performed to identify the determinants of inter-individual variation in SMR. All analyses were done with SPSS 10.0 for Macintosh (SPSS Inc., Chicago, llinois) and Statview 5.0 for Macintosh (SAS Institute lnc, North Carolina). The statistical significance level was set at $p<0.05$.

\section{Results}

\section{1) Seasonall variation}

SMR and FFM

Mean values for SMR and FFM for men and women in each season are presented in Table 2 . 
Table 2: Average ambient temperature, SMR, FFM, FM, TSH, total T4, free T4 and leptin in different seasons; results presented as mean $2 \mathrm{SD}$.

\begin{tabular}{|c|c|c|c|c|}
\hline & Spring & Summer & Autumn & Winter \\
\hline $\begin{array}{l}\text { Ambient temperature ( } \mathrm{C}) \\
\text { Men }\end{array}$ & $11 \pm 4$ & $21 \pm 3$ & $8 \pm 4$ & $6 \pm 3$ \\
\hline SMR $(\mathrm{kJ} / \mathrm{min})$ & $4.80 \pm 0.70$ & $4.56 \pm 0.53$ & $4.72 \pm 0.58$ & $4.85 \pm 0.55$ \\
\hline FFM $(\mathrm{kg})$ & $58.4 \pm 8.6$ & $58.6=7.6$ & $58.2 \pm 8.4$ & $58.5=8.3$ \\
\hline FM (kg) & $10.8 \pm 2.6$ & $10.5 \pm 4.3$ & $10.7 \pm 3.5$ & $11.4 \pm 3.1$ \\
\hline $\mathrm{TSH}(\mathrm{mU} / \mathrm{l})$ & $1.4 \pm 0.6$ & $1.7 \pm 1.3$ & $1.3 \pm 0.7$ & $1.2 \pm 0.5$ \\
\hline Trotal T4 (nmol/1) & $104 \pm 11$ & $105 \pm 15$ & $108 \pm 12$ & $101 \pm 9$ \\
\hline Freet4 (pmolll) & $13.8 \pm 1.6$ & $14.0 \pm 1.0$ & $14.2 \pm 1.9$ & $13.1 \pm 1.1$ \\
\hline Leptin $(\mathrm{ng} / \mathrm{ml})$ & $2.5 \pm 1.2$ & $2.5 \pm 0.8$ & $2.3 \pm 0.6$ & $2.6 \pm 1.0$ \\
\hline \multicolumn{5}{|l|}{ Women } \\
\hline $\mathrm{SMR}(\mathrm{kI} / \mathrm{min})$ & $4.27 \pm 0.28$ & $4.14 \pm 0.30$ & $4.31 \pm 0.38$ & $4.29 \pm 0.29$ \\
\hline FFM (kg) & $47.5 \pm 4.3$ & $47.4 \pm 4.5$ & $47.3 \pm 4.4$ & $47.7 \pm 4.4$ \\
\hline FM (kg) & $17.0 \pm 4.4$ & $17.3 \pm 4.1$ & $17.4 \pm 4.2$ & $17.1 \pm 4.7$ \\
\hline TSH (mU/) & $1.9 \pm 0.8$ & $2.0 \pm 0.8$ & $1.9 \pm 1.0$ & $1.7 \pm 0.5$ \\
\hline Tolal T/4 (nmol/d) & $112 \pm 17$ & $116 \pm 22$ & $112 \pm 18$ & $111 \pm 23$ \\
\hline FreeT4 $(\mathrm{pmol} / 1)$ & $12.6 \pm 2.1$ & $12.1 \pm 1.9$ & $12.2 \pm 1.4$ & $12.6 \pm 2.0$ \\
\hline Leptin (ng/ml) & $11.2 \pm 5.6$ & $10.4 \pm 5.5$ & $13.2 \pm 7.2$ & $11.5 \pm 6.7$ \\
\hline
\end{tabular}

SMR, sleeping metabolic rate; FFM, fat free mass; FM, fat mass; ]SH, thyroid stimulating hormone; T4, thyroxine

There were no significant differences in FFM over the year, not for women nor for men. SMR showed a significant seasonal variation with a summer minimum (August) winter naximum (February) ( $p<0.01)$. Figure 1 shows mean SMR in the four seasons and the calculated sinusoidal curve. The mean value over the year was $4.44 \pm 0.50 \mathrm{~kJ} / \mathrm{min}$, the amplitude was 0.10 to $0.02 \mathrm{kl} / \mathrm{min}(2.2+0.5 \%)$ and the phase was November 5 th. Mean SMR over the year was lower for women $(4.25 \pm 0.29 \mathrm{~kJ} / \mathrm{min})$ than for men $(4.73 \pm 0.58$ $\mathrm{kJ} / \mathrm{min})(p=0.01)$ but the cmplitude $(0.08 \pm 0.03 \mathrm{~kJ} / \mathrm{min}$ or $1.9 \pm 0.7 \%$ for women versus $0.1410 .04 \mathrm{~kJ} / \mathrm{min}$ or $3.0 \pm 0.8 \%$ for men) and the phase (October 13 th for women, November 25 th for men) were not significantly different between sexes. There was no significant effect of the menstrual cycle on SMR over the year.

Figure I also shows the mean ambient temperature for each season and the sinusoidal curve for ambient temperature over the year. The seasonal pattern in ambient temperature was almost the exact opposite of the pattern in SMR and the descending part of the temperature curve crosses the mesor (average value over the year) one week before the phase of the SMR curve, suggesting a causal relationship.

Overnight, the respiratory quotient, as a measure of substrate oxidation, was not significantly different between seasons, being $0.83 \pm 0.03$ in spring, $0.84 \pm 0.04$ in summer, $0.8 \| \mathrm{d}=0.04$ in autumn and $0.82 \pm 0.03$ in winter. 


\section{Thyroid activity}

Mean values $\pm \mathrm{SD}$ for women and men separately for each season are summarized in Table 2. Taking both men and women together, no seasonal variation in free T4, total T4 or LN(TSH) was observed. Analyzing men and women separately, a significant seasonal variation in freeT4 was observed for men $(p<0.05)$. The amplitude was $0.49 \pm 0.18 \mathrm{pmol} / 1(3.6 \pm 1.3 \%)$ and the phase was November 6 th. The seasonal variation in free $\mathrm{T} 4$ was not related with SMR. In women, there were no seasonal effects.

\section{Leptin}

Mean values \pm SD for men and women for each season are presented in Table 2 . There was no seasonal variation in Ln(leptin) for women nor for men.

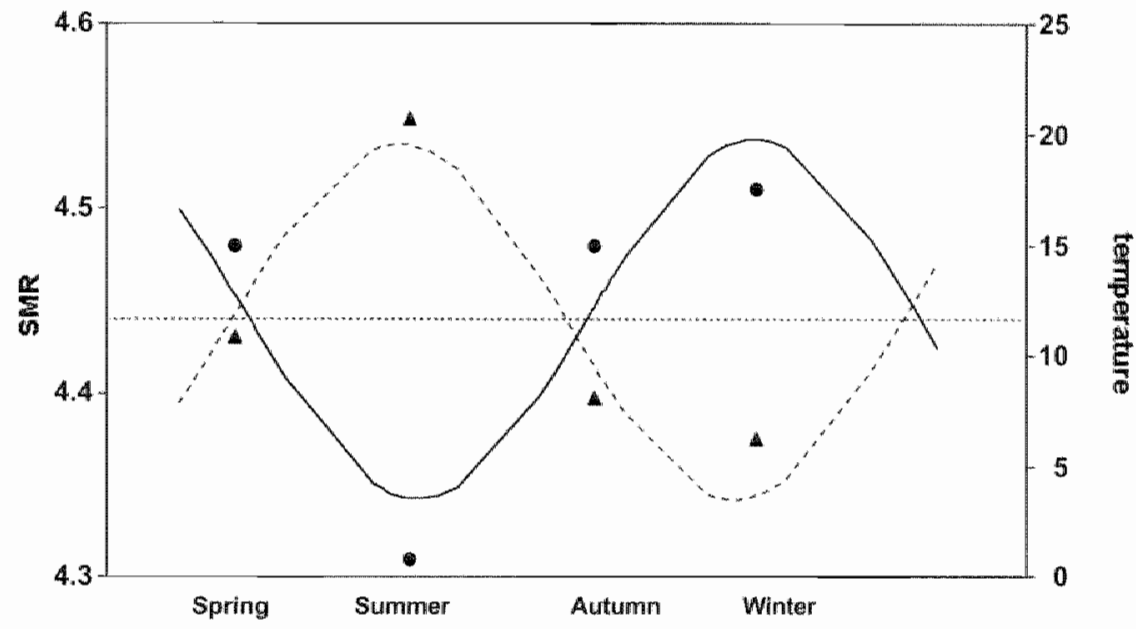

Figure 1: Sinusoidal curve of sleeping metabolic rate (kJ/min) (full line) and ambiand temperature $\left({ }^{\circ} \mathrm{C}\right.$ ) (dashed line) and average values for each season for sleeping metabolic rate (SMR) (circles) and ambient temperature (triangles). For the calculation of the sinusoidal curves see methods, "statistics" section.

\section{Determinants of SMR}

\section{Intra-individual variation}

For women and men together, season explained $17 \%$ of the intra-individual variation in SMR over the year (12\% for women and $25 \%$ for men). Ambient temperature also explained 17\% and made the seasonal effect disappear. None of the measured horinones contributed significantly to the explanation of the seasonal wariation in SMR. However" 
in men, there was an additional effect of total $\mathrm{T} 4$, which was negatively correllated with SMR and explained another $8 \%$ of the intra-individual variation in SMR.

\section{Inter-individual wariation}

To explain inter-individual variation in SMR, average values of the four repeated measures were used in a multiple regression analysis with SMR as the dependant variable and sex, FFM, FM, total T4, free T4, LN(TSH) and LN(leptin) as the independent variables. Only FFM ( $<<0.001)$ and LN(leptin) $(p<0.001)$ were significant predictors of $S M R\left(R^{2}=0.91\right)$. Coefficients, significance levels, partial and semi partial correlations and $\mathrm{R}^{2}$ of the model are presented in Table 3 .

Table 3: Significant predictors of SMR, determined with stepwise regression analysis using backward selection, with SMR as the dependant and sex, FFM, FM, total T4, free T4, LN(TSH) and LN(leptin) as independent variables; coefficients, standard error (SE). significance (D), partial and semi-partial correlation (part $R$ ) and $R$ squared of the model $\left(\mathrm{R}^{2}\right)$.

\begin{tabular}{lcccccc}
\hline & Coefficients & $\mathrm{SE}$ & $\mathrm{P}$ & Partial $\mathrm{R}$ & Part $\mathrm{R}$ & $\mathrm{R}^{2}$ (modal) \\
\hline Constant & 0.58 & 0.31 & 0.079 & & & 0.91 \\
FFM & $6.75 \cdot 10^{-2}$ & $0.50 \cdot 10^{-2}$ & $<0.001$ & 0.95 & 0.88 & \\
LN(leptin) & 0.21 & 0.05 & $<0.001$ & 0.69 & 0.28 & \\
\hline
\end{tabular}

FFM, fat free mass

\section{Discussion}

The results show a seasonal variation in SMR with a minimum in summer and a maximum in winter. The seasonal changes were not due to changes in FFM or any of the measured hormones. In men, there was a significant seasonal variation in free T4, which was not related with SMR, while total T4 did not show a seasonal pattem but did explain an additional $8 \%$ of the intra-individual variation in SMR. FFM and leptin rather than FM explained between-subject variation in SMR.

The seasonal variation in SMR was highly significant $(\mathrm{p}<0.01)$ with an amplitude of $0.10 \mathrm{~kJ} / \mathrm{min}$ or $2.3 \%$ of the mean for women and men together. The summer low winter high difference is two times the amplitude or $4.5 \%$ of the mean. There was a difference in ambient temperature of $15^{\circ} \mathrm{C}$ between summer and winter (Table 2). Kashiwazaki (11) Calculated that, at a constant room temperature of $20^{\circ} \mathrm{C}$, which was the case in this study, an increase in ambient temperature from $5^{\circ} \mathrm{C}$ to $20^{\circ} \mathrm{C}$ would cause a drop in BMR of $4.2 \%$ for an average male subject $(1,68 \mathrm{~m}, 65 \mathrm{~kg}, 40$ years $)$. His calculation was based on data of 123 subjects from 6 different studies and is very close to the results found in this study. Osiba (20) calculated a change of $6.6 \%$ in BMR per $10^{\circ} \mathrm{C}$ based on the data of 9 Japanese males. He also found a higher BMR in spring than in autumn despite the same environmental temperature and suggested that it takes some time for the adaptive changes in BMR to take place. In this study no significant differences in SMR between spring and autumn were found but there were indications for a direct relation between environmental temperature and SMR. Both, 'season' and ambient temperature explained the same amount of variation in SMR within subjects. Furthermore, the descending part of the temperature curve crossed the mesor one week 
before the phase of the SMR curve, in other words, the SMR-curve lagged one week behind the temperature-curve. These results suggest that ambient temperature has a long-term metabolic effect.

The understanding of the mechanism behind these adaptive changes in SMR to season is still incomplete. Thyroid activity is known to be up regulated in a cold environment, but it is not clear whether this is due to the drop in temperature itself or to an increased food intake as a result of the cold exposure $(4,5,9,31)$. Furthermore, increased thyroid activity is able to increase basal metabolism (28), which makes the thyroid gland a possible regulator for seasonal changes in SMR. Studies on seasonal changes in thyroid hormones showed contradictory results. Seasonal variations in $\mathrm{T} 3$ and/or $\mathrm{T} 4(13,15,21)$ have been documented by some authors but contradicted by others (24). TSH was found to be higher in winter in middle-aged and older men and women (29) and in hyperthyroid patients treated with T4 (12) but not in young adults (29). Our data showed a seasonal variation in free T4 for men only. TSH, and total T4 did not significantly change over the year not for women nor for men. However, the seasonal wariation in free T4 did not explain the obserwed seasonal trend in SMR. Total T4 did not show a seasonal pattern but was negatively correlated with SMR and explained an additional $8 \%$ of the intra-individual variation in SMR in men. The negative correlation might be due to a high turnover from T4 into T3, the metabolic active form of $[4$. Osiba (20) combined his measures of serum protein-bounded iodine with measures of BMR and found peak values for both in winter, which might indicate a causal relationship. He stated that the correlation between protein-bounded iodine and BMR was 0.77 . However, he based his equation on the data of four persons each measured twelve times. Thus, he included both intra- and inter-variability in the regression analysis, which might lead to the wrong conclusion that the seasonal variation in BMR is due to changes in thyroid activity. Konno and Morikawa (12) found higher TSH concentrations in winter than in summer but BMR remained unchanged. The fact that we did not find a significant relation between thyroid hormones and seasonal BMR changes, does not necessarily mean that there is none. Blood levels of TSH display diurnal variation with a noctumal rise. Despite the fact that the blood sample was taken at approximately the same time in the morning each season, a more continuous sampling might be recommended.

This is the first study investigating leptin in relation with seasonal changes in RMR. There was no seasonal variation in leptin and leptin was not related with the circannual rhythm in SMR. However, linear regression revealed FFM and leptin as the significant determinants of between subject variation in SMR. Studies investigating the relation between leptin and RMR showed contradictory results. Mackintosh et al. (14) found no effect of leptin administration on RMR in normal weight men. Hukshorn et al. (8) treated obese with pegylated recombinant native human leptin (PEG-OB) or placebo, both in combination with a hypocaloric diet, and found no differences in delta RMR (pre and post intervention) between groups. Some studies found a positive relation between RMR and leptin but no corrections for FM were made $(10,17)$. When both FFM and FM were corrected for, no correlation $(16,25)$ or even a negative correlation was found (2). A positive correlation was found in anorectics, where leptin is suggested to play a role in the energy sparing response to exposure to chronic energy deficiency (23). Despite the difficulty in comparing the different studies because of the wide variety in sex, age and BMII of the study populations and the different approaches to 
correct for FFM andor FM, the general conclusion seems to be that leptin is not related with RMR when subjects are in energy balance. We used a stepwise regression approach and found that after FFM $(p<0.001)$, leptin $(\mathrm{p}<0.001)$ was a stronger predictor of RMR than FM ( $\mathrm{p}=\mathrm{NS})$, resulting in a prediction of $91 \%$ of $\mathrm{RMR}$. This indicates that in this population of normal weight males and females, leptin is an important factor in the regulation of resting energy expenditure.

To our knowledge, this is the first study investigating seasonal variation in RMR including both an accurate measurement of body composition and hormonal influences in both men and women. The study provides additional prove for an up-regulation of RMR in winter. This supports the theory of an energy producing mechanisn as a protection against cold, even in the long term. We were unable to demonstrate a relation of these seasonal SMR changes with activity of the thyroid gland. We took a single blood sample in the moming for the analysis of free and total T4 and TSH as a measure of thyroid function. Perhaps a more frequent and/or continuous sampling would provide a better picture of the thyroid activity. Furthermore, other hormones, such as sexual steroids or melatonin, might be important and interesting to investigate. Another possibility is to include measurements of body temperature. Current technologies allow accurate registration of rectal and/or intestinal temperature over 24 h or even longer.

We were unable to reveal the mechanism behind seasonal RMR changes, which makes it an interesting topic for future research. When doing so it is, in our opinion, crucial to include an accurate measurement of body composition.

In conclusion, we found a distinct seasonal variation in SMR for both men and women, possibly triggered by environmental temperatume. Furthemore, FFM and leptin were the only predictors of between-subject variability in SMR, indicating an important role for leptin in the regulation of $R M R$. 
1. al-Adsani, H., L. J. Hoffer, and J. E. Silva. Resting energy expenditure is sensitive to small dose changes in patients on chronic thyroid hormone replacement. I Clin Endocrinol Metab. 82:1118-1125., 1997.

2. Bobbioni-Harsch, E, F. Assimacopoulos-Jeannet, T. Lehmann, R. Munger, A. F. Allaz, and A. Golay. Leptin plasma levels as a marker of sparing-energy mechanisms in obese women. Int J Obes Relat Metab Disord. 23:470-475, 1999.

3. Donahoo, W. T., D. R. Jensen, T. Y. Shepard, and R. H. Eckel. Seasonal variation in lipoprotein lipase and plasma lipids in physically active, normal weight humans. J Clin Endocrinol Metab. 85:3065-3068., 2000.

4. Eastman, C. J., R. P. Ekins, I. M. Leith, and E. S. Williams. Thyroid homone response to prolonged cold exposure in man. J Physiol. 241:175-181., 1974.

5. Evans, S. E. and D. L. Ingram. The effect of ambient temperature upon the secretion of thyroxine in the young pig. J Physiol. 264:511-521., 1977.

6. Haggarty, P., G. McNeill, M. K. Manneh, L. Davidson, E. Milne, G. Duncan, and J. Ashton. The influence of exercise on the energy requirements of adult males in the UK. Br J Nutr. 72:799-813., 1994.

7. Hsich, C. J., P. W. Wang, S. T. Wang, R. T. Liu, S. C. Tung, W. Y. Chien, Y. C. Lu, J. F. Chen, C. H. Chen, and M. C. Kuo. Serum leptin concentrations of patients with sequential thyroid function changes. Clin Endocrinol (Ox) , 57:2934., 2002.

8. Hukshorn, C. J., W. H. Saris, M. S. Westerterp-Plantenga, A. R. Farid, F. J. Smith, and $L$. A. Campfield. Weekly subcutaneous pegylated recombinant native human leptin (PEG-OB) administration in obese men. J Clin Endocrinol Metab. 85:40034009., 2000 .

9. Ingram, D. L. and H. Kaciuba-Uscilko. The influence of food intake and sumbient temperature on the rate of thyroxine utilization. J Physiol. 270:431-438, 1977.

10. Jorgensen, J. O., N. Vahl, R. Dall, and J. S. Christiansen. Resting metabolic late in healthy adulis: relation to growth hormone status and leptin levels. Metabolism. 47:1134-1139., 1998.

11. Kashiwazaki, H. Seasonal fuctuation of BMR in populations not exposed to limitations in food availability: reality or illusion? Eur $J$ Clin Nutr. 44:85-93., 1990.

12. Konno, N. and K. Morikawa. Seasonal variation of serum thyrotropin concentration and thyrotropin response to thyrotropinareleasing hormone in patients with primary hypothyroidism on constant replacement dosage of thyroxine. J Clin Endocrinol Metab. 54:1 118-1124., 1982.

13. Levine, M., L. Duffy, D. C. Moore, and L. A. Matej. Acclimation of a nonindigenous sub-Arctic population: seasonal wariation in thyroid function in interior Alaska. Comp.Biochem. Physiol. 111A:209-214,1995. 
14. Mackintosh, R. M and J. Hirsch. The effects of leptin administration in non-obese human subjects. Obes Res. 9:462-469-, 2001.

15. Maes, M., K. Mommen, D. Hendrickx, D. Peeters, P. DHondt, R. Ranjan, F. De Meyer, and S. Scharpe. Components of biological variation, including seasonality, in blood concentrations of TSH, TT3, FT4, PRL, cortisol and testosterone in healthy volunteers. Clin Endocrinol (Oxf). 46:587-598., 1997.

16. Newhauser-Berthold, M., B. M. Herberi, P. M. Luhnann, A. A. Sultemeier, W. F. Blum, J. Frey, and J. Hebebrand. Resting metabolic rate, body composition, and serum leptin concentrations in a free-living elderly population. Eur I Endocrinol. $142: 486-492,2000$.

17. Nicklas, B. J., M. J. Toth, and E. T. Poehman. Daily energy expenditure is related to plasma leptin concentrations in older African-American women but not men. Diabetes. 46:1389-1392, 1997.

18. Nicolau, G. Y., E. Haus, L. Plinga, L. Dumitriu, D. Lakatua, M. Popescu, E. Ungureanu, L. Sackett-Lundeen, and E. Petrescu. Chronobiology of pituitarythyroid functions. Rom J Endocrinol. 30:125-148, 1992.

19. Orliga-Carvalho, T. M., K. J. Oliveira, B. A. Soares, and C. C. Pazos-Moura. The role of leptin in the regulation of TSH secretion in the fed state: in vivo and in vitro studies. J Endocrinol. 174:121-125, 2002.

20. Osiba, $\mathrm{S}$. The seasonal variation of basal metabolism and activity of thyroid gland in man. Jap.J. Physiol. 7:355-365, 1957.

21. Pasquali, R., G. Baraldi, F. Casimirri, L. Mattioli, M. Capelli, N. Melchionda, F. Capani, and $\mathrm{G}$. Labo. Seasonal variations of total and free thyroid homones in heathy men: a chronobiological study. Acta Endocrinol Copenh. 107:42-48, 1984.

22. Perry, H. M., 3rd, D. K. Miller, P. Patrick, and J. E. Morley. Testosterone and leptin in older African-American men: relationship to age, strength, function, and season. Metabolism. 49:1085-1091., 2000.

23. Polito, A., A. Fabbri. A. Ferro-Luzzi, M. Cuzzolaro, L. Censi, D. Ciarapica, E. Fabbrini, and D. Giannini. Basal metabolic rate in anorexia nervosa: relation to body composition and leptin concentrations. Am J Chin Nutr. 71:1495-1502.,
2000 .

24. Postmes, T. J., J. C. Van Hout, G. Saat, P. Willems, and J. Coenegracht. A radioimmunoassay study and comparison of seasonal variation in plasma triodothyronine and thyroxine concentrations in nommal healthy persons. Clinica Chimion Acta. 50:189-195, 1974.

25. Rosenbaum, M., M. Nicolson, J Hirsch, E. Murphy, F. Chu, and R. I. Leibel. Effects of weight change on plasma leptin concentrations and energy expenditure.
JClin Endocrinol Metab. $82: 3647.3654 ., 1997$.

26. Schoffelen, P. F. M., K. R. Westerterp, and W. H. M. Saris. A dual-respiration chamber system with automated calibration. J.Appl. Physiol. 83:2064-2072, 1997. 
27. Segal, K. R., A. Edano, and M. B. Tomas. Thermic effect of a meal over 3 and 6 hours in lean and obese men. Metabolism. 39:985-992, 1990.

28. Silva, J. E. Thyroid homone control of themogenesis and energy balance. Thyroid. 5:481-492, 1995.

29. Sinnoni, M. A. Velando, V. Montanini, M. Faustini Fustini, S. Seghedoni, and P. Marrama. Circannual rhythm of plasma thyrotropin in middle-aged and old euthyroid subjects. Horm Res. 33:184-189, 1990.

30. Siri, W. E. Body composition from fluid spaces and density: analysis of methods. Washington, DC: Natl.Acad.Sci.Natl.Res.Council, 1961, 223-224.

31. Tomasi, T. E. and B. A. Horwitz. Thyroid function and cold acclimation in the hamster, Mesocricetus auratus. Am J Physiol. 252:E260-267., 1987.

32. Warwick, P. M. and R. Busby. Influence of mild cold on 24 h energy expenditure in "normally" clothed adults. Bu" J Nutr. 63:481-488, 1990.

33. Weir, J. B. d. V. New methods for calculating metabolic rate with special reference to protein metabolism. J.Physiol. 109:1-9, 1949.

34. Westerterp, K. R., L. Wouters, and W. D. w. Marken-Lichtenbelt. The Masistricht protocol for the measurement of body composition and energy expenditure with labeled water. Obes.Res. 3:49-57, 1995. 

Chapter 3

Seasonal variation in total energy expenditure, and physical activity in Dutch young adults

Guy Plasqui and Klaas R. Westerterp

Obes Res. 2004:12:688-694 


\begin{abstract}
Objective The impact of season on energy expenditure and physical activity is not well quantified. This study focused on summer-winter differences in total energy expenditure (TEE) and physical activity.

Methods 25 bealthy Dutch young adults (10 males, 15 females), living in an urban environment, were measured in summer season (July, August) and winter season (January. February). TEE was measured using doubly labeled water and sleeping metabolic rate (SMR) was measured during an overnight stay in a respiration chamber. Subsequently, the physical activity level (PAL $=$ TEE/SMR) and activity related energy expenditure (AEE $=[0.9 \cdot T E E]-S M R$ ) were calculated. Maximal mechanical power $\left(W_{\text {max }}\right)$, as a measure of physical fitness, was determined with an incremental test on a cycle ergometer. Body composition was measured with hydrostatic weighing and deuterium dilution, using Siri's three-compartment model.

Results There was no difference in TEE between seasons. PAL was higher in summer than in winter $(1.87 \pm 0.22$ vs. $1.76 \pm 0.18 ; p<0.001)$ and the difference was higher for men than for women $(0.20 \pm 0.14$ vs. $0.05 \pm 0.16 ; \mathrm{p}=0.04)$. The difference in PAL between seasons was dependent on the initial activity level. There was a strong linear relation $\left(\mathrm{R}^{2}=0.48\right.$ ) between $\mathrm{PAL}$ and physical finess ( $W_{\text {max }} / \mathrm{FFM}$ ), but $W_{\text {nax }} / \mathrm{FFM}$ did not change between seasons in response to the lower PAL in winter.

Discussion The extent of the changes in PAL is of physiological significance and seasonality in physical activity should be taken into account when studying PA patterns itself or relationships between PA and health.
\end{abstract}




\section{Introduction}

Physical activity is the most variable component of total energy expenditure (TEE) between subjects and therefore important in the regulation of energy balance. Seasonal changes in physical activity might influence energy balance and as a consequence body mass. The impact of season on energy metabolism has been investigated in developing countries where both energy intake and energy expenditure can vary considerably between harvest and non-harvest season, resulting in changes in body weight $(19,20$, 23). Studies in industrialized countries also show changes in body weight $(14,21,29$, 33) over the year implying a change in energy intake, energy expenditure or both. Studies investigating seasonal changes in energy intake have shown contradictory results $(14,21,29)$. The lack of an accurate method to determine energy intake probably accounts for the inconsistent results. TEE and its different components, resting metabolic rate (RMR), diet induced thermogenesis (DIT) and activity related energy expenditure (AEE), can be measured much more accurately. The gold standard for measuring TEE is the doubly labeled water method. In combination with a measure of RMR, the doubly labeled water method allows one to calculate the physical activity level $(\mathrm{PAL}=\mathrm{TEE} / \mathrm{RMR})$ and activity related energy expenditure (AEE). Because of the high cost of ${ }^{18} \mathrm{O}$, this method is not applicable for large studies. Therefore, most seasonality studies assessed physical activity by means of self-report $(16,17,21,29)$, pedometry (14) or accelerometry (16). These studies indicate a lower physical activity during winter season but the impact on energy metabolism is not well quantified. Schoeller et al did measure TEE with doubly labeled water and found no difference in TEE between summer and winter in six females (24). A study of Haggarly et al. (10) also included measurements of TEE and RMR in 9 adult males. They found no significant differences in TEE, BMR or PAL. They did suggest however, that individuals with the highest activity level in summer exhibit the greatest decrease in activity in winter.

If season causes significant changes in physical activity this might also be reflected in a change in physical fitness. Ingemann-Hansen et al. (11) found a higher maximal oxygen uptake $\left(\mathrm{VO}_{2 \mathrm{max}}\right)$ for subjects measured in summer than in winter but these data were cross sectional.

Several studies have demonstrated seasonality in blood pressure (18) as well as plasma lipids, with higher levels of cholesterol $(5,36)$, LDL (or apoB) $(7,36)$ and HDL $(36)$ in winter than in summer. In addition, cardiovascular disease and mortality show a winter peak $(1,6,8)$. In this regard, information on seasonal variations in physical activity is highly relevant.

Because of the wide interest in seasonal influences on physical activity and the small number of data available in terms of energy expenditure, we were interested in intratand inter-individual changes in TEE, PAL and AEE between seasons in both men and women. Furthermore, we aimed to investigate seasonality in physical fitness and the relation between physical activity and physical fitness.

\section{Methods}

\section{Subjects}

Subjects were 25 healthy volunteers ( 10 males and 15 females) between the age of 20 and 30 , most of them working at the university. Detailed information about the 
objective and the protocol of the study was provided to each subject. Written informed consent was obtained and the study was approved by the Ethics Committee of Maastricht University. Subjects were participating in a study investigating seasonality in body weight and the underlying mechanism. Combined measurements of sleeping metabolic rate, body weight, body composition, $W_{\operatorname{man}}$ and $T E E$, were done in summer (duly, August) and winter (January, February).

One subject was excluded from all analyses due to illness and subsequent weight loss in winter season. One subject was excluded from the analyses regarding physical finess. due to an incomplete test on the cycle ergometer in summer season, caused by pain in the knee.

Subject characteristics at the time they entered the study are shown in Table 1.

Table 1: Subject characteristics at baseline as mean $\pm \mathrm{SD}$.

\begin{tabular}{lcc} 
& Women & Meth \\
\hline N & 15 & 9 \\
Age (y) & $25 \pm 2$ & $26 \pm 2$ \\
Height (m) & $1.72 \pm 0.07$ & $1.83 \pm 0.08$ \\
Body mass $(\mathrm{kg})$ & $64.4 \pm 5.9$ & $70.1 \pm 9.8$ \\
BMI $\left(\mathrm{kg}^{2} \mathrm{~m}^{2}\right)$ & $21.9 \pm 1.9$ & $20.8 \pm 2.1$ \\
Body fitt $(\mathrm{m})$ & $26.1 \pm 5.5$ & $15.0 \pm 2.7$ \\
\hline
\end{tabular}

\section{Sleeping metrabolic rate}

SMR was measured during an overnight stay in a respiration chamber. The chamber measured $14 \mathrm{~m}^{3}$ and was equipped with a bed, table, chair, freeze toilet, washing bowl, radio, television and computer (25). Subjects entered the room at $21: 00 \mathrm{~h}$ in the evening and left the room at 7:30 $\mathrm{h}$ in the morning. Energy expenditure was calculated from $\mathrm{O}_{2}$ consumption and $\mathrm{CO}_{2}$-production according to Weir's formula (30). SMR was defined as the average metabolic rate during at least 3 h of sleep wh the lowest activity measured by Doppler radar. Subjects were asked to consume their nomal evening meal at home between 18:00 and 19:00. The meals were not standardized, in order not to interfore with the subjects" normal feeding behaviour and thus with energy balance. Since SMR was measured at least $6 h$, in general 8 to 11 h after the meal, the effect of diet-induced thermogenesis is assumed to be minimal (27). Subject's were instructed to refrain from intensive exercise the day prior to the respiration chamber stay. Room temperature was held constant at $20 \pm 1{ }^{\circ} \mathrm{C}$ every season. SMR was used for the calculation of PAL and $A E_{\text {. }}$ exicnsive results about SMR are discussed elsewhere (22).

\section{Body Composition}

Anthropometric measurements were taken in the moming after leaving the respiration chamber. Body mass was measured on an electronic scale (Mettler Toledo IDI Plus, Germany) to the nearest $0.01 \mathrm{~kg}$. Height was measured to the nearest $0.1 \mathrm{~cm}$ (SECA Mod.220, Germany). Body volume was measured with underwater weighing. Residual lung volume was simultaneously measured using the helium dilution technique. Total body water (TBW) was measured with deuterium dilution according to the Maastricht
protocol (34). 
Body composition was calculated from body density and TBW using Siri"s threecompartment model (28).

\section{Total energy enpenditure}

TEE was measured with doubly labeled water according to the Maastricht protocol (34). In short, after the collection of a baseline urine sample (day 0), subjects drank a weighed amount of ${ }^{3} \mathrm{H}_{2}$ " $\mathrm{O}$ resulting in an initial excess body water enrichment of 150 ppm for deuterium and $300 \mathrm{ppm}$ for oxygen 18 . Subsequent urine samples were collected in the momings of day 1 , day 8 , day 15 and the evenings of day 1 , day 7 and day 14.

\section{Marimal mechanical power}

$W_{\max }$ was determined during an incremental test on a cycle ergometer according to the protocol of Kuipers et al. (13). After a warm up of 5 min at 100 Watt (W) for men and $75 \mathrm{~W}$ for women, workload was increased with $50 \mathrm{~W}$ every 2.5 min. When heart rate (HR) exceeded 160 beats per min (bpm) or the respiratory quotient (RQ) exceeded I workload was increased with $25 \mathrm{~W}$ every 2.5 min until exhaustion.

$W_{m i k} / F F M$ was used as a measure of physical fitness.

\section{Statistics}

Differences between summer and winter were tested using ANOVA repeated measures with sex as a 'between subjects' factor. To investigate the relation between physical activity and physical fitness, linear regression analysis was performed. Statistical significance was set at $\mathrm{p}<0.05$. All analyses were done with Stalview 5.0 for Macintosh (SAS Institute Inc., North Carolina).

\section{Results}

There was no difference in TEE (M.J/d) between summer and winter season, neither for men $(13.43 \pm 2.73 \mathrm{vs} .12 .77 \pm 2.39)$ nor for women $(10.71 \pm 1.48 \mathrm{vs} .10 .77 \pm 1.65)$ (ligure 1). There was a significant seasonal effect on PAL, with thigher PAL-lovels in summer and lower levels in winter $(1.87 \pm 0.22 \mathrm{vs} .1 .76 \pm 0.18 ; p<0.001)$. The average PAL was not different between sexes $(\mathrm{p}=0.07)$, but the difference between seasons was significantly higher for men than for women $(0.20 \pm 0.14 \mathrm{vs} .0 .05 \pm 0.16 ; p=0.04)$. The

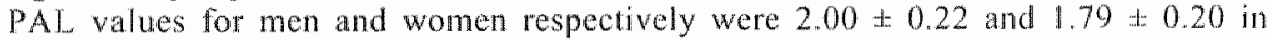
summer and $1.80 \pm 0.18$ and $1.74 \pm 0.17$ in winter. The higher PAL was also reflected in a higher AEE (MV/d) in summer compared to winter $(4.33+1.63 \mathrm{vs} .3 .86 \pm 1.35 ; \mathrm{p}=$ 0.02). Mean AEE was significantly higher for men than for women $(p=0.02$; figure 1$)$ and the difference between seasons was higher for men than for women $(p=0.03$; Figure 1). When AEE was corrected for BM (AEE/BM), the difference between seasons $(p<0.01)$ was still present and the difference was higher for men than for women ( $p<$ $0.01)$. The average $\mathrm{AEE} B \mathrm{BM}$ was also higher for men $(\mathrm{p}=0.04)$. When $\mathrm{AEE}$ was corrected for FFM (AEEFFM), the sex difference disappeared The seasonal difference was still present $(p<0.01)$ but the difference was no longer higher for men than for women $(\mathrm{p}=0.08)$. 
The difference in PAL between seasons was dependent on the initial (summer) activity level. The more active subjects were in summer, the greater the reduction in activity in winter, while those who were inactive in summer remained inactive in winter (figure 2).

There was a strong linear relation between PAL and $W_{\text {tmax }} / F F M(W / k g)(R=0.64, p=$ 0.001 in summer; $R=0.57, p=0.005$ in winter) and $A E E$ and $W_{\text {max }} / F F M(R=0.62, p=$ 0.002 in summer; $R=0.60, p=0.003$ in winter) in both seasons. Because intercept and slope were not significantly different between seasons, the average values of both seasons were used in a simple regression analysis resulting in a correlation of $0.69\left(\mathrm{R}^{2}=\right.$ $0.48, \mathrm{p}<0.001)$ between PAL and $\mathbb{W}_{\text {max }} / F F M$ (figure 3) and a correlation of $0.66\left(\mathrm{R}^{2}=\right.$ $0.43, \mathrm{p}<0.001$ ) between $\mathrm{AEE}$ and $\mathrm{W}_{\text {max }} /$ FFM. Despite the lower PAL and AEE in winter, physical fitness did not change between seasons $(4.76 \pm 0.64$ in summer vs. 4.78 \pm 0.58 in winter).

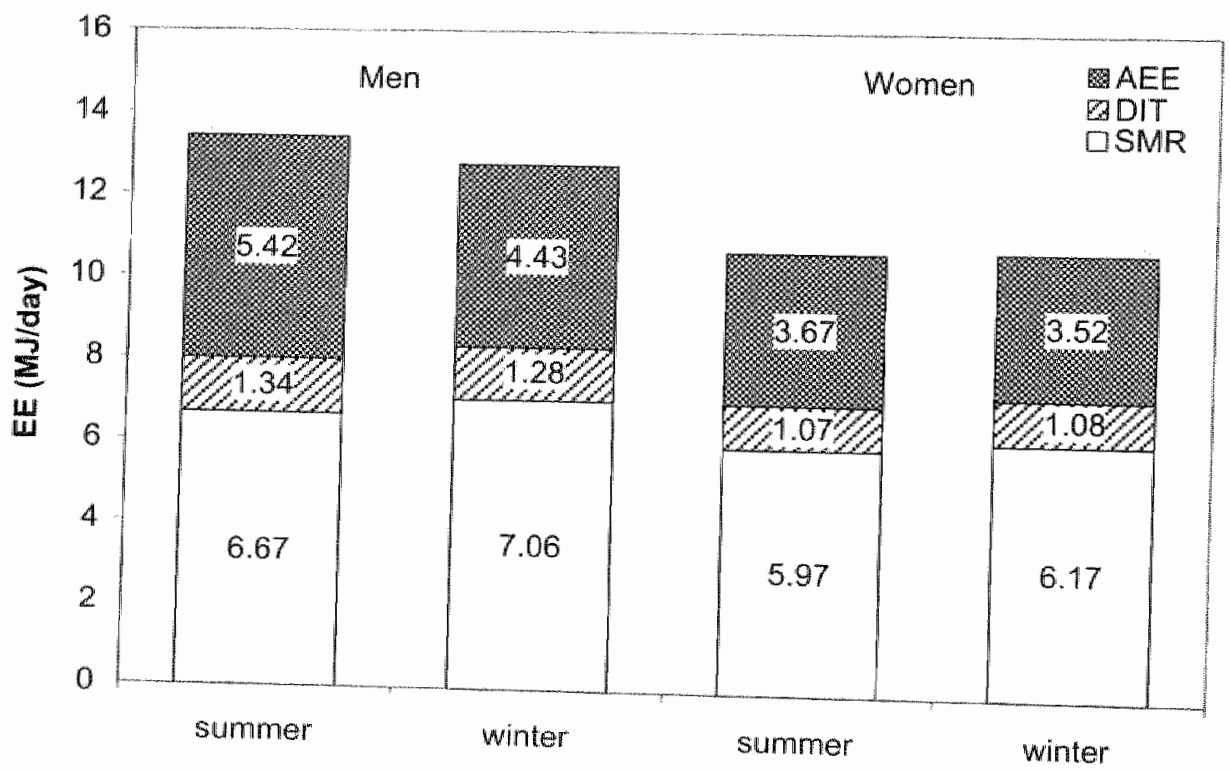

Figure 1: TEE and its components, SMR, DIT (10\% of TEE) and AEE for men and women in summer and winter season. 


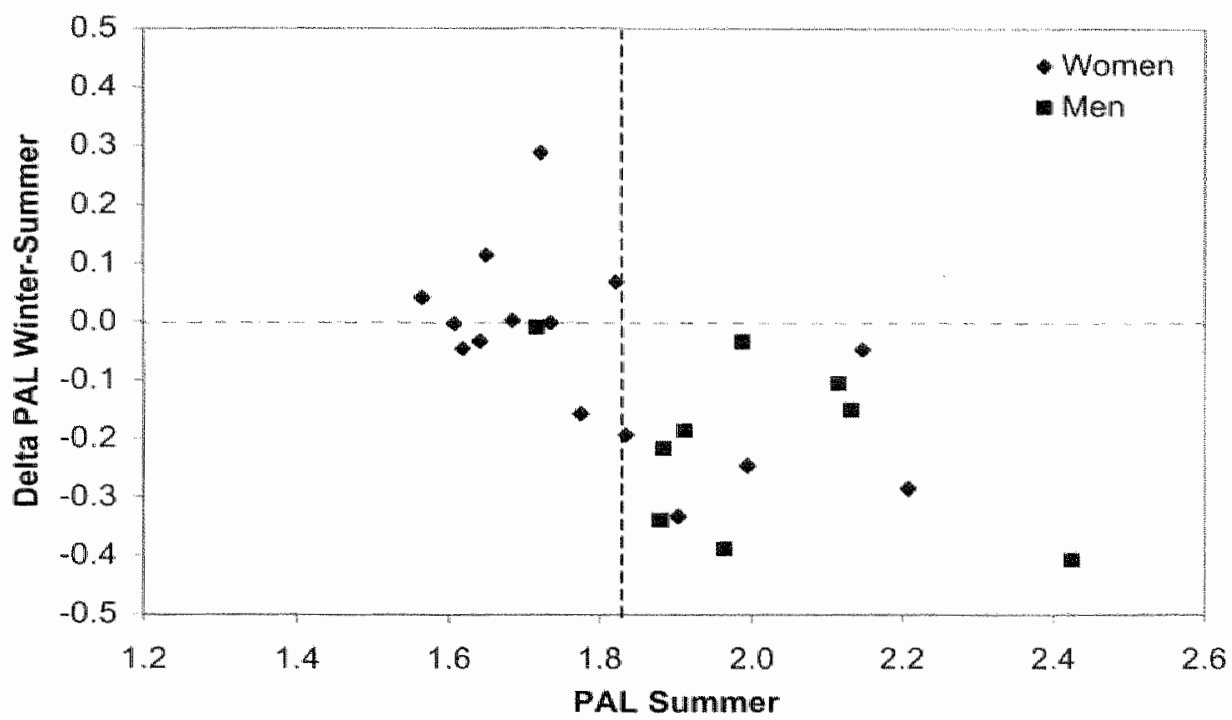

Figure 2: Difference in PAL between winter and summer season against the initial PAL (summer). The vertical dashed line represents the mean PAL of the whole group over both seasons. All subjects with a higher PAL in summer than the group mean, showed a decreased PAL in winter.

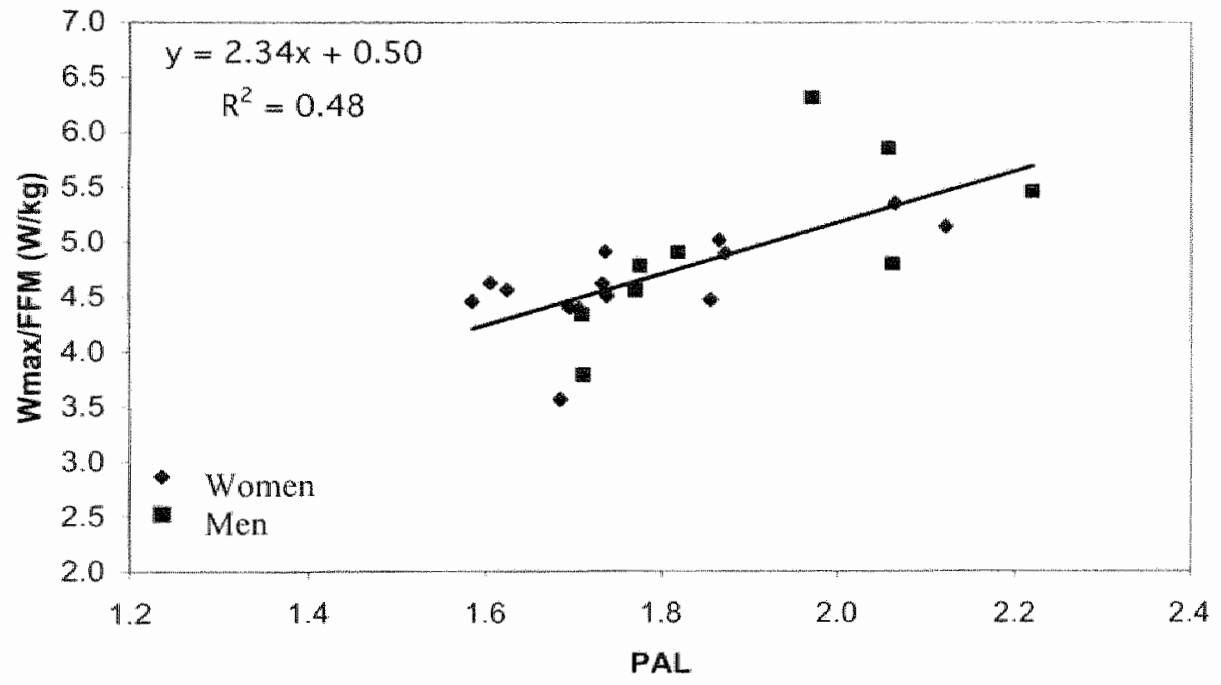

Figure 3: Linear regression of physical fitness ( $W_{\text {max }} / F F M$; mean values over both seasons) against the physical activity level (PAL; mean values over both seasons). Men and women (indicated with different symbols) were combined in the regression analysis. 


\section{Discussion}

TEE was not significantly different between seasons but PAL and AEE were. The drop in PAL towards the winter season was highest for those subjects with the highest activity level in summer. The change in physical activity did not result in a change in physicat uness.

TEE was not significantly different between seasons. This is in agreement with the study of Haggarly et all. (10) who found a difference in TEE of $0.98 \mathrm{MJ} / \mathrm{d}$ (not significant) between summer and winter in 9 adult males. However, we did find a significtntly lower PAL in winter than in summer season, which was more pronounced for men than for women. The average PAL over both seasons was 1.82 , which is higher than the population average of approximately $1.77(2,31)$. This is due to the high activity level in summer, while in winter the PAL dropped to the population average. Since we used SMR to calculate the PAL, values might be slightly higher compared to studies using RMR. Although there is no general consensus that RMR is in fact higher than ovemight SMR $(9,26)$. Even if so, given the longitudinal approach of our study, this would not affect any of the results.

These results indicate that the outcome of research about physical activity levels in relation to other variables may be highly dependent on the time of year the measurements took place. Seasomal differences were higher for men than for women, which is mainly attributable to the higher PAL (2.0) for men in summer season compared to women $(1.79)$ and the population average of 1.77 . In concurrence with the PAL, AEE was significantly different between seasons, even after correction for BM or FFM.

Haggary at al (10) found a PAL of 2.01 in summer versus 1.88 in winter. The fact that this difference was not significant might be due to the low number of subjects $(n=9)$, a problem inherent in the use of doubly labeled water. They stated however that the three subjects with the highest TEE exhibited the greatest reduction in expenditure in winter. In our study, the most active subjects in summer showed the greatest decrease in PAL in winter. When subjects were divided into a high activity' and a "low activity" group, by taking the average PAL of all subjects over both seasons, all subjects in the high activity group showed a drop in PAL in winter while in the low activity group subjects were equally distributed around the line of "zero change" (figure 2). In other words, the more active subjects are in the sumner season, the less likely it is they maintain their activity level in the wintel" season. This is perhaps not very surprising since the winter season includes substantial shorter day length and worse weather conditions. This would especially inthence the time spent in outdoor actrities. Most subjects in this study were working at the university, performing comparable activities that are independent of season. The difference in activity levels is therefore caused by leisure time activity, including sports as well as non-sports activities. Westeterp (32) showed that the PAL is positively related with time spent in moderate intensity activities, negatively related with rime spent in low intensity activities and not related with time spent in high intensity activities, implying that the PAL is not mainly determined by sports activities but by non-sports, moderate intensity activities such as walking or cycling. It might be these activities in particular that are decreased in the winter season resulting in a lower PAL. This is confirmed by a study of Matthews et al. (16) who measured 580 subjects by means of three different 24 h physical activity recalls administered five times over 12 months. He found peak values for total physical activity as well as moderate intensily 
activity in July, while low intensity activity peaked in January and high intensity activity peaked in January and May for men and women respectively. Therefore, it can be hypothesized that in winter, even though active people try to compensate for the drop in moderate intensity activities by sports activities, they are unable to maintain the same PAL as in summer.

We are aware that part of the observed decrease in PAL in winter is explained by an increased SMR. For both men and women SMR was significantly higher in winter than in summer $(6.51$ ws. 6.23 ; ANOVA, $p<0.0001)$, but the difference between seasons was not significantly different between sexes $(p=0.14)$. Possible reasons for the observed seasonal difference in SMR, including ambient temperature, are described elsewhere (22). Despite the increased SMR, TEE did not increase accordingly resulting in a lower amount of energy spent on activity (AEE) and a lower PAL.

The coeficient of variation (CV) of doubly labeled water measurements in free-living subjects is about $8 \%$, which is largely due to a $7 \%$ physiologic variation. The analytic variation is therefore, although variable between laboratories, about $1-2 \%(24)$. Given the small differences observed for women and the sensitivity of the DLW method, it is important to interpret these results with care. Although statistically significant for the entire group, the differences in $\mathrm{PAL}$ and $\mathrm{AEE}$ are mainly present for men, probably because of the high PAL obserwed for men in summer as also shown in figure 2.

Since there is no method available to accurately assess food intake or diet composition, no measure of energy intake was included. We assumed DIT to be $10 \%$ of TEE in both seasons. Even if DIT is higher in winter season due to an increased energy intake, this would result in an even lower $\mathrm{AEE}$ and therefore not affect our conclusion.

Regression analysis showed a strong linear relation between Wmas/FFM and PAL as well as AEE. This indicates that the overall physical activity level as well as the net amount of energy spent on activity is a strong predictor of physical fitness. However, despite the lower PAL in winter, $W_{\text {max }} /$ FFM stayed the same in both seasons. There is an ongoing discussion about whether physical activity or physical fitness is more important in relation to certain health outcomes such as cardiovascular disease and hence, whether physical fitness can be used as a measure of average daily activity 0,4 . 35). Physical activity is the main determinant of physical fitmess, although there is a large genetic component. Because physical activity is often measured by means of selfreport while physical fitness is usually measured more objectively, physical fitness often provides stronger associations with health outcomes (3). Furthermore, the fact wat PAL and AEE were significantly lower in winter than in summer season indicates that the time of the activity measurement can highly influence the outcome. Wustr F $\mathrm{M}$ on the other hand, did not change over seasons, despite the lower activity. Therefore, physical fitness is more resistant to "short" term environmental influences, in this casc season, than physical activity is and might provide a better measurement of "overall" activity in relation to health. The fact that physical fitness is unaffected by season, in contrast to physical activity, is also shown in the correlation between summer and winter which was 0.94 for $W_{\text {max }} / F F M$ and 0.63 for PAL. This suggests that physical fitness is a more long-term reflection of daily physical activity for nomally active, non-athletic subjects. It is also possible that the genetic component in physical fimess explains the mantained fitmess level or that subjects perform in high intensity, but less anergy consuming activities in winter. 
Several studies have demonstrated seasonality in blood pressure (18) and plasma lipids, with thigher levels of cholesterol $(5,36), \mathrm{LDL}$ (or apoB) $(7,36)$ and HDL (36) in winter than in summer. In addition, cardiovascular disease and mortality show a winter peak $(1,6,8)$. It is well known that regular physical activity can positively affect these cardiovascular risk factors and therefore lower the risk for cardiovascular mortality. The coincidence berween seasonality in cardiovasoular risk factors and physical activity suggests a causal relationship. Magnus et al. (15) reported a negative correlation bewcen acute coronary events and habitual light physical exercise when performed for mone than 8 months a year. The correlation disappeared when the activities were interrupted for several months ( $<8$ months/year) and thus seasonal in nature. Mundal et al. (18) stated that the seasonal variation in blood pressure, both during rest and excrcise, might be explained by a paralle seasonal variation in physical fitness. Douglas et al. (6) investigated seasonality amongst different death causes and found the highest anplitude for respiratory disease immediately followed by circulatory diseases including ischaemic heart disease and cerebrovascular disease. Changes in climatic features such as ambient temperature are very likely to be related with higher mortality rates in winter but can curtainly not be the only factor. Especially the higher blood pressure, lower cardiac output and stroke volume and higher heart rate in winter observed by $(z z o$ et al. (12), might be related with lower activity levels as observed in this study.

PAL was dependent on season while physical fimess did not change. On the other hand, seasonality in certain cardiovascular risk factors might be related with lower activity levels, implying that despite the same level of physical fitness, lower physical activity levels during certain months of the year could be an independent risk factor.

Some studies did find a seasonal variation in physical fitness $(11,18)$. The complexity in delining physical fimess might contribute to the contrary results found. We defined physical fitness as $W_{\text {max }}$ corrected for FFM. $W_{\text {unax }}$ is linearily correlated with $V O_{2 \text { max }}$, the most widely used fimess measure, with only a deviation in the extreme upper part of the curve. Therefore we believe that our fimess measure is sufficiently accurate. The correction for FFM was made because FFM is a major determinant of $W_{m a x}$ and also to correct for sex differences in body composition.

The use of doubly labeled water provided accurate information about total physical activily and energy expendiure over 14 days and revealed quite substantial seasonal difrerences, especially in men. The high costs related with this method make the data on this lopic very seatce, which emphasizes the uniqueness of this study. A disadvantage is the lack of information on activity patierns.

In conclusion, we found a significant seasonal variation in PAL with lower activity levels in winter. Especially the most active subjects in summer failed to maintain their activity level in winter. We believe that the extent of the changes in PAL is of physiological significance and that seasonality in physical activity should be taken into account when studying relationships between PA and health or when studying the seasonality in cardiovascular risk factors itself. 
1. Anderson, T. W. and W. H. Le Riche. Cold weather and myocardial infarction. Lancet. 1:291-296, 1970.

2. Black, A. E., W. A. Coward, T. J. Cole, and A. M. Prentice. Human energy expenditure in affluent societies: an analysis of 574 doubly-labelled water measurements. Eur J Clin Nutr. 50:72-92, 1996.

3. Blair, S. N., Y. Cheng, and J. S. Holder. Is physical activity or physical fitness more important in defining health benefits? Med Sci Sports Exerc. 33:S379-399; discussion $\$ 419-320 ., 2001$.

4. Blair, S. N. and A. S. Jackson. Physical fitness and activity as separate heart disease risk factors: a meta-analysis. Med Sci Sports Exere. 33:762-764, 2001.

5. Donahoo, W. T., D. R. Jensen, T. Y. Shepard, and R. H. Eckel. Seasonall variation in lipoprotein lipase and plasma lipids in physically active, normal weight humans. J Clin Endocrinol Metab. 85:3065-3068., 2000.

6. Douglas, A. S., T. M. Allan, and J. M. Rawles. Composition of seasonality of disease. Scott Med J. 36:76-82, 1991

7. Fager, G., O. Wiklund, S. O. Olofsson, and G. Bondjers. Seasonal variations in serum lipid and apolipoprotein levels evaluated by periodic regression analyses. J Chronic Dis. 35:643-648, 1982.

8. Fyle, T., M. G. Dumnigan, E. Hamilton, and R. J. Rae. Seasonal variation in serum lipids, and incidence and mortality of ischaemic heart disease. J Atheroscter Res. $8: 591-596,1968$.

9. Goldberg, G. R., A. M. Prentice, H. L. Davies, and P. R. Murgatroyd. Overnight and basal metabolic rates in men and women. Eur J Clin Nutr. 42:137-144, 1988.

10. Haggarty, P., G. McNeill, M. K. Manneh, L. Davidson, E. Milne, G. Duncan, and J. Ashton. The influence of exercise on the energy requirements of adult males in the UK. Br J Nutr. 72:799-813, 1994.

11. Ingemann-Hansen, $T$. and J. Halkjaer-Kristensen. Seasonal variation of maximal oxygen consumption rate in humans. Eur.J.Appl.Physiol. 49:151-157, 1982.

12. Izzo, J. L., Jr., P. S. Larrabee, E. Sander, and L. M. Lillis. Hemodynamics of Seasonal adaptation. Am J Hypertens. 3:405-407, 1990.

13. Kuipers, H., F. T. Verstappen, H. A. Keizer, P. Geurten, and G. van Kranenburg. Variability of aerobic performance in the laboratory and its physiologic correlates. Int J Sports Med. 6:197:201., 1985.

14. Lee, C. J., G. S. Lawler, M. Panemangalore, and D. Street. Nutritional status of middlewged and elderly females in Kentucky in two seasons: Part 1. Body weight and related factors. J Am Coll Nutr. 6:209-215, 1987.

15. Magnus, K.. A. Matroos, and J. Strackee. Walking, cycling, or gardening, with or without seasonal interruption, in relation to acute coronary events. Am J Epidemiol. 110:724-733, 1979 . 
16. Mathews, C. E., P. S. Freedson, J. R. Hebert, E. J. Stanek II. P. A. Merriam. M. C. Rosal, C. B. Ebbeling, and I. S. Ockene. Seasonal variation in household, occupational, and leisure time physical activity: longitudinal analyses from the seasonal variation of blood cholesterol study. Am. Epidemiol 153:172-183. 2001 .

17. Mobily, K. E., R. Nilson, L. J. Ostiguy, R. D. Mackeil, and R. B. Wallace. Seasonal variation in physical activity in older adults. Top Geriatr Rehabil. 10:11.22, 1995 .

18. Mundal, R., S. E. Kjeldsen, L. Sandvik, G. Erikssen, E. Thaulow, and J. Erikssen. Seasonal covariation in physical fitness and blood pressure at rest and during exercise in healthy middle-aged men. Blood Press. 6:269-273, 1997.

19. Murayama, N. and R. Ohtsuka. Seasonal fuctuation in energy balance among fammers in Northeast Thailand: the lack of response of energy intake to the change of energy expenditure. Eur J Clin Nutr. 53:39-49, 1999.

20. Panter-Brick, C. Inter-individual and seasonal weight variation in rural nepali women. Biosoc.sci. 27:215-233, 1995.

21. Pasquali, R., G. Baraldi, F. Casimini, L. Mattioli, M. Capelli, N. Melchionda, F. Capani, and $\mathrm{G}$. Labo. Seasonal variations of total and free thyroid hormones in healthy men: a chronobiological study. Acta Endocrinol Copenh. 107:42-48, 1984.

22. Plasqui, G. A. D. Kester, and K. R. Westerterp. Seasonal variation in sleeping metabolic rate, thyroid activity, and leptin. Am J Physiol Endocrinol Metab. $285: E 338-343,2003$.

23. Prentice, A. M. R. G. Whitehead, S. B. Roberts, and A. A. Paul. Long-term energy balance in child-bearing Gambian women. Am J Clin Nutr. 34:2790-2799, 1981.

24. Schoeller, D. A. and J. M. Hnilicka. Reliability of the doubly labeled water method for the measurement of total daly energy expenditure in freemiving subjects. J Nutr. 126:3485-354S, 1996.

25. Schoffelen, P.F.M., K. R. Westerterp, and W. H. M. Saris. A dual-respiration chamber system with automated calibration. J.Appl. Physiol. 83:2064-2072, 1997.

26. Seale, J. L. and J. M. Conway, Relationship between overnight energy expenditure and BMR measured in a room-sized calorimeter. Eur J Clin Nutt. 53:107-111, 1999 .

27. Scgal, K. R., A. Edano, and M. B. Tomas. Thermic effect of a meal over 3 and 6 hours in lean and obese men. Metabolism. 39:985-992, 1990.

28. Siri. W. E. Body composition from fluid spaces and density: analysis of methods. Washington, DC: Nati.Acad.Sci. Nat1.Res.Council, 1961, 223-224.

29. Van Staveren, W. A., P. Deurenberg, J. Burema, L. C. De Groot, and J. G. Hautvast. Seasonal variation in food intake, pattern of physical activity and change in body weight in a group of young adult Dutch women consuming selfselected diets. Int I Obes. 10:133-145, 1986. 
30. Weir, J. B. d. V. New methods for calculating metabolic rate with special reference to protein metabolism. J.Physiol. 109:1-9, 1949.

31. Westerterp, K. R. Obesity and physical activity. Int.J.Obes. 23:59-64, 1999.

32. Westerterp, K. R. Pattern and intensity of physical activity. Nature. $410 \cdot 539,2001$.

33. Westerterp, K. R. Seasonal variation in body weight: an experimental case study. J. Themal Biol. 26:525-527, 2001.

34. Westerterp, K. R., L. Wouters, and W. D. v. Marken-Lichtenbell. The Maastricht protocol for the measurement of body composition and energy expenditure with labeled water. Obes. Res. 3:49-57, 1995.

35. Williams, P. T. Physical fitness and activity as separate heart disease risk factors: a meta-analysis. Med Sci Sports Exerc. 33:754-761.,2001.

36. Woodhouse, P. R., K. T. Khaw, and M. Plummer. Seasonal variation of serum lipids in an elderly population. Age Ageing. 22:273-278, 1993. 

Chapter 4

Measuring free-living energy expenditure and physical activity with tri-axial accelerometry

Guy Plasqui, Annemiek M.C.P. Joosen, Arnold D. Kester, Annelies H.C. Goris and Klaas R. Westerterp 


\begin{abstract}
Objective To investigate the validily of a newly developed tri-axial accelerometer to predict total energy expenditure (TEE) and activity related energy expenditure (AEE) in free-living conditions.
\end{abstract}

Methods Subjects were 29 healthy subjects, between the age of 18 and 40 . The Triaxial Accelerometer for Movement Registration (Tracmor) was wom for 15 consecutive days. Tracmor output was defined as activity counts ${ }^{\text {day }} "$ (ACD) for the sum of all three axes or each axis separately ( $A C D-X, A C D-Y, A C D-Z$ ). TEE was measured with the doubly labelled water technique. Sleeping metabolic rate (SMR) was measured during an overnight stay in a respiration chamber. The physical activity level (PAL) was calculated as TEE.SMR and AEE was calculated as $[(0.9 \cdot \mathrm{TEE})$ - SMR]. Body composition was calculated from body weight, body volume and total body water using Siri's three-compartment model.

Results Age, height, body mass and ACD explained $83 \%$ of the variation in TEE (SEE $=1.00 \mathrm{MJ} / \mathrm{day}$ ) and $81 \%$ of the variation in $\mathrm{AEE}(\mathrm{SEE}=0.70 \mathrm{MJ} / \mathrm{day})$. The partial correlation for ACD was $0.73(p<0.001)$ and $0.79(p<0.001)$ with TEE and AEE respectively. When data on SMR or body composition was used with ACD, the explained variation in TEE was $90 \%$ (SEE $=0.74 \mathrm{MJ} / \mathrm{day}$ and $0.77 \mathrm{MJ} / \mathrm{day}$ respectively). The increase in the explained variation using three axes instead of one axis (vertical) was $5 \%$ (p<0.05).

Discussion The correlations between Tracmor output and energy expenditure measures are the highest reported so far. In daily life, the use of tri-axial accelerometry is superior to uni-axial. 


\section{Introduction}

Being sufficiently physically active is of major importance in the prevention and/or treatment of many diseases in affluent societies. Physical inactivity has been associated with health problems such as cardiovascular disease $(6,20)$, diabetes mellitus type $11(9$, $10,14,18)$, osteoporosis $(13,19)$ and obesity $(11,25,31)$. A problem in health related research is the difficulty in accurately defining physical activity (PA). Methods to assess free-living $\mathrm{PA}$ include direct observation, questionnaires, diaries, heart rate monitoring, pedometry, accelerometry and the doubly labelled water (DLW) method. To this point, DLW is the only technique available to accurately measure total energy expenditure (TEE) over prolonged periods in daily life. When this technique is combined with a measure of basal metabolic rate (BMR), activity related energy expenditure (AEE) or the physical activity level (PAL) can be calculated. The disadvantage is that this technique is expensive and that it does not provide any information about the frequency and intensity of physical activities. Accelerometers seem the most promising tools to overcome these problems. Body fixed accelerometers provide a measure of the total amount, as well as the duration, frequency and intensity of PA. By validating an accelerometer against DLW derived energy expenditure, prediction formulas can be developed to predict AEE, TEE or PAL from accelerometer counts and other physical characteristics, such as age, sex, height and body mass (BM). Correlations between accelerometer output and DLW derived energy expenditure measures, such as AEE or TEE are often very poor and mainly determined by subject's physical characteristics $(12,15,22)$. Significant correlations between activity counts and PAL, TEE and AEE were found for the CSA (Computer Science and Application's Inc., Shalimar, FL which is currently known as the MTI: Manufacturing Technology Ine., Fort Walton Beach, $\mathrm{FL}$ ) accelerometer $(4,16)$ and the various models of the Tri-axial Accelerometer for Movement Registration (Tracmor; Philips Research, Eindhoven, The Netherlands) (2, 7, $8,17,29)$. To our knowledge, the highest correlation between PAL and activity counts reported so far was in children with $\mathrm{R}=0.79$ (8).

Uni-axial accelerometers measure accelerations in one plane (usually vertical) whereas tri-axial accelerometers measure accelerations in the anterior-posterior, medio-lateral and vertical direction. Although uni-axial accelerometers are accurate to predict energy expenditure (EE) during walking, tri-axial accelerometers are more suitable when a variety of different activities is involved (3). This has been tested under laboratory conditions by using three different uni-axial accelerometers (1) and one tri-axial (3), but to our knowledge never in daily life.

Since EE is also dependent on BM and body composition, EE cannot be predicted from accelerometer counts alone. Very often, AEE is divided by BM, which is only correct when the intercept of the regression line of AEE on BM is zero. At this point there is still no consensus on how to correct TEE or AEE for body size $(21,28)$.

The purpose of this study was threefold: I) to test the validity of the Tracmor to assess free living physical activity, 2) to investigate the additional effect of a tri-axial over a uni-axial accelerometer to measure the wide variety of daily life activitics, and 3) to test which EE parameter correlates best with accelerometer counts. 


\section{Methods}

\section{Subjects}

Subjects were 30 healthy adults (10 males, 20 females), consisting of 6 monozygotic twin pairs, 8 dizygotic same-sex twin pairs and 1 same-sex sibling pair. Subjects were part of a study investigating genetic variation in physical activity. Detailed information about the objective and the protocol of the study was provided. Written informed consent was obtained and the study was approved by the Ethics Committee of Maastricht University. One subject had to be excluded from all analyses because of loss of the accelerometer, Subject characteristics $(n=29)$ are described in Table 1.

Table I: Subject characteristics

\begin{tabular}{|c|c|}
\hline & Mean $\pm \mathrm{SD}$ \\
\hline $\mathrm{n}(\mathrm{m} / \mathrm{f})$ & $29(10 / 19)$ \\
\hline age $(y)$ & $24 \pm 6$ \\
\hline Body mass $(\mathrm{kg})$ & $66.8 \pm 11.8$ \\
\hline Height $(\mathrm{m})$ & $1.71 \pm 0.10$ \\
\hline $\mathrm{BMI}\left(\mathrm{kg} / \mathrm{mm}^{2}\right)$ & $22.9 \pm 4.3$ \\
\hline $\mathrm{FM}(\mathrm{kg})$ & $17.3 \pm 9.1$ \\
\hline FFM (kg) & $49.5 \pm 9.2$ \\
\hline TEE (MJ/day) & $11.5 \pm 2.3$ \\
\hline SMR (MJ/day) & $6.3 \pm 0.7$ \\
\hline $\mathrm{AEE}(\mathrm{MN} / \mathrm{day})$ & $4.1 \pm 1.5$ \\
\hline PAL & $1.82 \pm 0.21$ \\
\hline $\mathrm{ACD}$ (kcounts/dlay) & $385 \pm 112$ \\
\hline
\end{tabular}

\section{Body Compasition}

Anthropometric measurements were taken in the moming after an overnight stay in a respitation chamber. Body mass was measured on an electronic scale (Mettler Toledo IDI Plus, Giessen, Germany) to the nearest $0.01 \mathrm{~kg}$. Height was measured to the nearest $0.1 \mathrm{~cm}$ (SECA Mod.220, Hamburg, Germany). Body volume was measured with underwater weighing. Residual lung volume was simultaneously measured using the helium ditution technique. Total body water (TBW) was measured with deuterium dilution acconding to the Mastricht protocoi $(30)$.

Body composition was calculated from body weight, body volume and TBW using Siri's threc-compartment model (24).

\section{Slexping metabolic rate}

SMR was measured during the second night of a $36 \mathrm{~h}$ stay in a respiration chamber. The chamber measured $14 \mathrm{~m}$ and was equipped with a bed, table, chair, freeze tollet, washing bowl, radio, television and computer (23). Energy expenditure was calculleted from $\mathrm{O}_{2}$-consumption and $\mathrm{CO}_{2}$-production according to Weir's formula (26). SMR was defined ats the lowest observed energy expenditure for three consecutive hours during 
the night, generally between 3:00 and 6:00 am. Room temperature was held constant at $20 \pm 1{ }^{\circ} \mathrm{C}$.

\section{Total energy expenditure}

TEE was measured with doubly labelled water acoording to the Maastrichl protocol (30). In short, after the collection of a baseline urine sample (day 0). subjects drank a weighed amount of ${ }^{2} \mathrm{H}_{2}{ }^{18} \mathrm{O}$ resulting in an initial excess body water enrichment of 150 ppm for deuterium and $300 \mathrm{ppm}$ for oxygen-18. Subsequent urine samples wera collected from the second voiding in the morning and a subsequent voiding in the evening on day 1 , day 8 and day 15 . Activity related energy expendiure $(A E F)$ was calculated as (0.9.TEE)-SMR and the physical activity level (PAL) was calculated as TEE.SMR ${ }^{-1}$.

\section{Accelerometry}

The tri-axial accelerometer for movement registration (Tracmor; Philips Research. Eindhoven, The Netherlands) is an improved version of the earlier validated Tracmor (7). The Tracmor contains three uni-axial piezo-electric accelerometers, measures $7.2 \%$ $2.6 \times 0.7 \mathrm{~cm}$ and weighs $22 \mathrm{~g}$ (battery included). It is attached to the lower back by means of an elastic belt, measuring accelerations in the antero-posterior, medio-lateral and longitudinal axis of the trunk. Subjects were instructed to wear the Tracmor for 15 consecutive days, during waking hours, except during water activities. The Tracmor was designed to enable data storage for at least three weeks and for optimal wearing comfort in order not to interfere with daily activities. The Tracmor provides minute by minute data for all three axes separately. For this study, Tracmor output was defined as activity counts per day (ACD for the sum of all three axes or ACD-X, ACD-Y and ACD-Z for each axis separately), which is the sum of all counts over 15 days divided by 15 .

\section{Statistics}

Linear multiple regression analysis was used to determine the best predictors of TEE and AEE. Single linear regression was used to test the correlation between PAL and $A C D$ and $A E E / k g$ and $A C D$. To determine the additional effect of tri-axial over uniaxial accelerometry, a model was developed with only the counts of the vertical axis ( $A C D-Y$ ) and the increase in $R^{2}$ by adding the other two axes (ACD-X and ACD-Z) was tested for significance. Univariate ANOVA was used to test whether the residuals of the prediction equations were related within twin pairs. The residuals of each model were entered as the dependent variable and 'pair' was entered as a fixed factor. All analyses were done with SPSS 10.0 for Macintosh (SPSS Inc., Chicago, Illinois). The statistical significance level was set at $\mathrm{p}<0.05$.

\section{Results}

\section{Determinants of TEE}

Three different models were used to correct TEE for differences in body size. The first model with SMR, the second with basic characteristics (age, height, sex, weight) and the third with data on body composition. For each model, ACD significantly contributed to the explained variation in TEE. 
With SMR and ACD as the independent variables, the total explaned variation of the model was $90 \%(\mathrm{R}=0.95)$ with a SEE of $0.74 \mathrm{MJ} /$ day or $6.4 \%$ of the mean TEE. When subject"s basic characteristics were used, age, height, BM and ACD significantly contributed to TEE, whereas gender was not significant. The total explained variation was $83 \%(\mathrm{R}=0.91)$ and the SEE was $1.00 \mathrm{MJ} / \mathrm{day}$ or $8.7 \%$. When data on body composition was added, ACD, age and both FFM and FM significantly contributed. The total explained variation was $90 \%(\mathrm{R}=0.95)$ and the $\mathrm{SEE}$ was $0.77 \mathrm{MJ}$ /day or $6.7 \%$. Coefficients with $\mathrm{SE}$, significance levels and partial correlations of all models are stummarized in Table 2.

Table 2: Multiple regression analysis with TEE as the dependent variable.

\begin{tabular}{|c|c|c|c|c|}
\hline independent & coefficients & $\mathrm{SE}$ & $\mathrm{p}$ & partial correlation \\
\hline Constant & -7.98 & 1.28 & & \\
\hline SMR (MV/day) & 2.58 & 0.20 & $<0.001$ & 0.93 \\
\hline ACD (kcounts/day) & $8.57 \cdot 10^{-3}$ & $1.24 \cdot 10^{-3}$ & $<0.001$ & 0.80 \\
\hline Model & & SEE 0.74 & $<0.001$ & $R=0.95$ \\
\hline Constant & -11.18 & 3.57 & & \\
\hline Age $(y)$ & -0.11 & 0.04 & 0.007 & -0.52 \\
\hline $\mathrm{BM}(\mathrm{kg})$ & 0.13 & 0.02 & $<0.001$ & 0.81 \\
\hline Height (m) & 7.69 & 2.06 & 0.001 & 0.61 \\
\hline ACD (kcounts/day) & $9.35 \cdot 10^{-3}$ & $1.77 \cdot 10^{-3}$ & $<0.001$ & 0.73 \\
\hline Model & & SEE 1.00 & $<0.001$ & $\mathrm{R}=0.91$ \\
\hline Constant & -0.63 & 1.10 & & \\
\hline $\operatorname{Agc}(y)$ & $-8.47 \cdot 10^{-2}$ & 0.03 & 0.005 & -0.53 \\
\hline $\mathrm{FFM}(\mathrm{kg})$ & 0.21 & 0.02 & $<0.001$ & 0.93 \\
\hline FM (kg) & $6.89 \cdot 10^{-2}$ & 0.02 & 0.001 & 0.61 \\
\hline ACD (kcounts/day) & $6.47 \cdot 10^{3}$ & $1.39 \cdot 10^{-.3}$ & $<0.001$ & 0.69 \\
\hline Model & & $\mathrm{SEE} \quad 0.77$ & $<0.001$ & $\mathrm{R}=0.95$ \\
\hline
\end{tabular}

Determinamts of $A E E$

When AEE was wsed as the dependent variable, the same independent variables significantly contributed to AEE. For the first model, age, height, BM and ACD $17.2 \%$ of the mean $(K=0.90)$ of the variation in $\mathrm{AEE}$ and the SEE was $0.70 \mathrm{MJ} / \mathrm{day}$ or $17.2 \%$ of the mean AEE. For the second model, data on body composition was used. 
Age FFM, FM and ACD explained $86 \%$ of the variation in $\mathrm{AEE}$ with $\mathrm{SEE}$ of 0.59 MJ/day or $14.5 \%$. Results for AEE are summarized in Table 3.

Table 3: Multiple regression analysis with AEE as the dependent variable.

\begin{tabular}{|c|c|c|c|c|}
\hline independent & coefficients & $\mathrm{SE}$ & $p$ & Partial correlation \\
\hline Constant & -8.11 & 2.50 & & \\
\hline Age $(y)$ & $-6.65 \cdot 10^{-2}$ & 0.03 & 0.013 & -0.48 \\
\hline $\mathrm{BM}(\mathrm{kg})$ & $7.14 \cdot 10^{-2}$ & 0.01 & $<0.001$ & 0.75 \\
\hline Height (m) & 3.46 & 1.44 & 0.025 & 0.44 \\
\hline ACD (kcounts/day) & $7.92 \cdot 10^{-3 .}$ & $1.24 \cdot 10^{-3}$ & $<0.001$ & 0.79 \\
\hline Model & & SEE 0.70 & $<0.001$ & $R=0.90$ \\
\hline Constant & -3.47 & 0.85 & & \\
\hline Age (y) & $-5.52 \cdot 10^{-2}$ & 0.02 & 0.016 & -0.47 \\
\hline FFM ( $(\mathrm{kg})$ & 0.11 & 0.01 & $<0.001$ & 0.87 \\
\hline FM (kg) & $4.13 \cdot 10^{-2}$ & 0.01 & 0.007 & 0.51 \\
\hline $\mathrm{ACD}($ kcounts/day $)$ & $6.48 \cdot 10^{-3}$ & $1.08 \cdot 10^{-3}$ & $<0.001$ & 0.78 \\
\hline Model & & SEE $\quad 0.59$ & $<0.001$ & $R=0.93$ \\
\hline
\end{tabular}

\section{PAL and AEE/kg}

Since both PAL and AEE/kg are commonly used measures to express physical activity. simple linear regression models are presented for these variables. ACD predicted PAL for $59 \%(R=0.77 ; p<0.001)$ with a SEE of 0.14 or $7.6 \%$. With AEE/kg as the dependent variable, the explained vartiation was $60 \%(R=0.78 ; \mathrm{p}<0.001)$ and the $\mathrm{SEE}$ was $0.012 \mathrm{MJ} / \mathrm{kg} / \mathrm{day}$ or $19.3 \%$.

\section{Uni-axial versus tri-axial accelerometry}

To test the additional effect of tri-axial accelerometry over uni-axial, we used the model with TEE as the dependent and subjects basic characteristics as the independent wariables. Age, height and BM alone explained $64 \%(R=0.80)$ of the variation in TEE. When $A C D-Y$ was added, $R^{2}$ significantly $(p<0.001$ ) increased to 0.80 . Adding the other two axes (ACD-X and $A C D-Z$ ) resulted in a significant $(p=0.04)$ increase in $R^{2}$ from 0.80 to 0.85 .

\section{Efect of wins}

To test whether our correlations were influenced by the fact that the subjects were related, we tested for each model whether the residuals were related within pairs. In none of the models tested, was there a significant "pair" effect. Not for TEE based on 
$S M R$ and $A C D(p=0.79)$ or based on age, BM, height and $A C D(p=0.09)$ or based on age, FM, FFM and $\mathrm{ACD}(p=0.23)$, not for $\mathrm{AEE}$ based on age, BM, height and ACD $(p=0.21)$ or based on age, FM, FFM and $A C D(p=0.40)$ not for PAL $(p=0.64)$ and not for AEE/kg $(p=0.07)$.

\section{Discussion}

The aim of this study was to validate a new tri-axial accelerometer (Tracmor) to measure free-living energy expenditure. $64 \%$ of the variation in TEE could be explained by subject's basic characteristics (age, BM, height) and the Tracmor added $19 \%$, resulting in a total $\mathrm{R}^{2}$ of 0.83 with a $\mathrm{SEE}$ of $8.7 \%$.

Of all the accelerometers available, only few llave been tested against DLW to provide an estimate of free-living physical activity. Those that were validated often show poor correlations with DLW derived energy expenditure measures, such as AEE or TEE or the correlations are mainly determined by subject"s physical characteristics. Activity counts from the Caltrac uni-axial accelerometer were not correlated with AEE in children (12). Rafamantanantsoa et al. (22) showed a correlation of 0.83 between the LifeCorder uni-axial accelerometer and DLW derived TEE, but the accelerometer provided a measure of TEE based on age, gender, height and body weight and no information was avalable on the contribution of activity counts to the explaned variation of TEE. Leenders et al. (15) found that the CSA uni-axial and the Tritrac-R3D tri-axial accelerometer underestimated free-living AEE with $59 \%$ and $35 \%$ respectively, but only 13 subjects were included in this study. In a study with 136 women (16), the CSA explained an additional $5 \%$ of the variation in TEE and AEE after correction for body mass. Ekelund at al. (4) tested the CSA in 26 children and found a correlation of 0.58 between CSA and PAL and a partial correlation of 0.66 with AEE after adjusting for body mass. The CSA seems to be the only commercially available accelerometer that correlates reasonably with DLW derived activity measures. The Tracmor is not commercially available yet, but so far, of all the accelerometers tested, the Tracmor seems to correlate best with DLW derived energy expenditure measures with correlations between PAL and activity counts of 0.73 in healthy young adults $(2), 0.78$ in elderly (17) and 0.79 in childen (8) and between TEE, corrected for BMR, and activity counts of $0.95(7)$. The current Tracmor is slightly smaller and lighter then the previous version. To our knowledge, the total explained variation in TEE $(83 \%)$ based only on subject's characteristics (age, BM, height) and Tracmor counts is the highest reported so far. Moreover, the Tracmor alone increased the $\mathbb{R}^{2}$ with $19 \%$, from 0.64 to 0.83. The correlation of 0.77 between ACD and PAL is comparable to those mentioned above. In the general population. PAL (TEE-RMR ${ }^{-1}$ ) ranges between 1.2 and $2.5(27)$, meaning that, ideally, the intercept of the regression line of PAL versus ACD should be close to 1.2. In our sample the intercept was 1.27, which is very close to the PAL value of 1.2 for an inactive person. The slightly higher value can be attributed to the fact that we used SMR instead of RMR.

In the regression analysis of PAL versus counts, there was one outlier with high activity counts for a relatively low PAL. Without this subject, the explained variation increased from $59 \%$ to $70 \%$. Although the high activity counts for a low PAL in this subject could be due to bad accelerometer functioning, it might also be related with the approach of correcting TEE for SMR by simply using the ratio. The issue of how to correct TEE for body size or resting metabolic rate (RMR) has recently gained new interest $(5,16,28)$. 
Theoretically, TEE should only be divided by RMR or SMR when the regression of TEE on SMR has a zero intercept. Since the impact of a non-zero intercept, as was the case in our sample, is always bigger at the lower range of energy expenditure, it is perhaps no coincidence that the outlier was the subject with the lowest SMR. When TEE was corrected (TEEadj) for SMR by adding the residual of the regression of TEE on SMR to the mean TEE, the $\mathrm{R}^{2}$ between TEEadj and ACD was 0.64 instead of 0.59 with PAl.

The same problem occurs trying to correct AEE for body mass or body composition. Many authors use $\mathrm{AEE} \cdot \mathrm{BM}^{-1}$ as a measure of physical activity. Prentice et al. (21) suggested using BM to the exponent of 0.5 rather than $\mathbb{V}$ as the denominator, since not all activities have the same weight-bearing impact on $\mathrm{AEE}$. But they also emplasize that it is not recommended to use this as a universal approach and that there is probably no generally applicable adjustment factor. According to our data, dividing $\mathrm{AEE}$ by BM would be an oversimplification, since not only $\mathrm{BM}$ but also height and age significanilly contributed to the explained variation in AEE. Furthermore, when data on body composition is available, a distinction should be made between FFM and FM given their different impact on AEE. FFM is directly related to AEE since it is the metabolic component of $\mathrm{BM}$ while $\mathbb{F M}$ is related to $\mathrm{AEE}$ due to its weight-bearing effect. As shown in Table 3 , both FFM and FM contribute to the explained variation in AEE to a different extent. In agreement to Prentice et al. (21), the relative contribution of FFM and FM to $A E E$ would be dependent on the activity performed. Therefore, dividing AEE by FEM only would again result in an oversimplification.

Many accelerometers are uni-axial, measuring only accelerations in the vertical plane. Ayen et all. (1) simulated the additional effect of tri-axial over uni-axial accelerometry by using three uni-axial accelerometers mounted in three different directions at the waist. They concluded that the output of three accelerometers correlated better with AEE than the output of any of the uni-axial separately. Bouten et al. (3) was the first to test the contribution of different directions to the estimation of AEE using a single triaxial accelerometer. The results were in agreement with Ayen et al. (1) that for a variety of activities, tri-axial assessment is better than uni-axial. To our knowledge, this is the first study comparing tri-axial with uni-axial acceleronetry using a single device, tunder daily life conditions, by comparison with doubly labelled water. After correcting for $B M$, height and age, the vertical axis ( $A C D-Y$ ) explained an additional $16 \%$ of the variation in TEE. Adding the other two axes caused a significant increase in $R^{2}$ with another $5 \%$, resulting in a total explained variation of $85 \%$. In comparison, when the sum of all three axes was used, the explained variation in TEE was 83\%. Therefore, to measure the wide variety of daily life activities, tri-axial accelerometers are more suitable than uni-axial.

We are aware that the current study population was somewhat unusual since it consisted of twins. Statistically there was no significant "twin" effect on the residuals of any of the variables tested. Therefore we believe that the reported correlations are not influenced by the fact that our subjects were related, although, the reported SEE might be some wat lower than in a more diverse study population.

A problem inherent to doubly labelled water studies is the low number of subjects. Larger study samples would allow more accurate prediction equations, with less 
susceptibility to ouliers. The advantage is that we included an accurate measure of SMR and body composition to study the impact of the different variables on energy expenditure.

In conclusion: 1) TEE can be explained for $90 \%(\mathrm{SEE}=6-7 \%)$ when either data on SMR or body composition, and Tracmor output is included and for $83 \%$ based on subject"s characteristics and Tracmor only (SEE $=8.7 \%$ ); 2 ) Using tri-axial accelerometers instead of uni-axial results in an increase of $\mathrm{R}^{2}$ up to $5 \%$ and 3) Since there's no general applicable coefficient to adjust TEE or AEE for body size and composition, the use of regression analys is is preferred over the use of simple ratios. 
1. Ayen, T. G. and H. J. Montoye. Estimation of energy expenditure with a simulated three-dimensional accelerometer. J. Ambulatory Monitoring. 1:293-301, 1988.

2. Bouten, C. V., W. P. Verboeket-van de Venne, K. R. Westerterp, M. Verduin, and J. D. Janssen. Daily physical activity assessment: comparison between movement registration and doubly labeled water. J Appl Physiol. 81:1019-1026, 1996.

3. Bouten, C. V., K. R. Westerterp, M. Verduin, and J. D. Janssen. Assessment of energy expenditure for physical actiwity using a triaxial accelerometer. Med Sei Sports Exerc. 26:1516-1523, 1994.

4. Ekelund, U., M. Sjostrom, A. Yngve, E. Poortvliet, A. Nilsson, K. Froberg, N. Wedderkopp, and K. Westerterp. Physical activity assessed by activity monitor and doubly labeled water in children. Medicine And Science In Sports And Exercise. Feb. 33:275-281, 2001.

5. Ekelund, U., A. Yngve, S. Brage, K. Westerterp, and M. Sjostrom. Body movement and physical activity energy expenditure in children and adoleseents: how to adjust for differences in body size and age. Am J Clin Nutr. 79:851-856, 2004.

6. Fang, J., J. Wylie-Rosett, H. W. Cohen, R. C. Kaplan, and M. H. Alderman. Exercise, body mass index, caloric intake, and cardiovascular mortality. Am J Prev Med. 25:283-289, 2003.

7. Goris, A. H., E. P. Meijer, A. Kester, and K. R. Westerterp. Use of a triaxial accelerometer to validate reported food intakes. Am J Clin Nutr. 73:549-553, 2001.

8. Hoos, M. B., G. Plasqui, W. J. Gerver, and K. R. Westerterp Physical activity level measured by doubly labeled water and accelerometry in children. Eur J Appl Physiol. 89:624-626, 2003.

9. Hu, F. B., T. Y. Li, G. A. Colditz, W. C. Willett, and J. E. Manson. Television watching and other sedentary behaviors in relation to risk of obesity and type 2 diabetes mellitus in women. Jama. 289:1785-1791, 2003.

10. Hu, G., Q. Qiao, K. Siventoinen, J. G. Eriksson, P. Jousilahti, J. Lindstrom, T. T. Valle. A. Nissinen, and J. Tuomilehto. Occupational, commuting, and leisure-time physical activity in relation to risk for Type 2 diabetes in middle-aged Finnish men and women. Diabetologia. 46:322-329, 2003.

11. Jebb, S. A. and M. S. Moore. Contribution of a sedentary lifestyle and inactivity to the etiology of overweight and obesity: current evidence and research issues. Med Sci Sports Exerc. 31:5534-541, 1999.

12. Johnson, R. K., J. Russ, and M. I. Goran. Physical activity related energy expenditure in children by doubly labeled water as compared with the Caltrac accelerometer. Int J Obes. 22:1046-1052, 1998,

13. Kai, M. C., M. Anderson, and E. M. Lau. Exercise interventions: defusing the world's osteoporosis time bomb. Bull World Health Organ. 81:827-830, 2003. 
14. Kriska, A. M. A. Saremi, R. L. Hanson, P. H. Bennett, S. Kobes, D. E. Williams, and W. C. Knowler. Physical activity, obesity, and the incidence of type 2 diabetes in a high-risk population. Am J Epidemiol, 158:669-675,2003.

15. Leenders, N. Y., W. M. Sherman, H. N. Nagaraja, and C. L. Kien. Evaluation of methods to assess physical activity in free-living conditions. Med Sci Sports Exerc. 33:1233-1240, 2001.

16. Masse, L. C., J. E. Fulton, K. L. Watson, M. T. Mahar, M. C. Meyers, and W. W. Wong. Influence of body composition on physical activity validation studies using doubly labeled water. J Appl Physiol. 96:1357-1364, 2004.

17. Meijer, E. P., A. H. Goris, L. Wouters, and K. R. Westerterp. Physical inactivity as a determinant of the physical activity level in the elderly. Int $J$ Obes Relat Melab Disord. 25:935-939, 2001.

18. Mensink, M, E. J. Feskens, W. H. Saris, T. W. De Brum, and E. E. Blaak. Sindy on Lifestyle Intervention and Impaired Glucose Tolerance Maastricht (SLIM): preliminary results after one year. Int J Obes Relat Metab Disord. 27:377-384, 2003.

19. Neville, C. E, L. J. Murray, C. A. Boreham, A. M. Gallagher, J. Twisk, P. J. Robson, J. M. Savage, H. C. Kemper, S. H. Ralston, and G. Davey Smith. Relationship between physical activity and bone mineral status in young adults: the Northern Ireland Young Hearts Project. Bone. 30:792-798, 2002.

20. Panagiotakos, D. B., C. Chrysohoou, C. Pitsavos, A. Menotti, A. Dontas, J. Skoumas, C. Stefanadis, and P. Toutouzas. Risk factors of stroke mortality: a 40 year follow-up of the Corfu cohort from the Seven-Countries Study. Neuroepidemiology, 22:332-338, 2003 .

21. Prentice, A. M., G. M. Goldberg, P. R. Murgatroyd, and T. J. Cole. Physical activity and obesity: problems in correcting expenditure for body size. Int J. Obes. 20:688-691, 1996.

22. Rafamantanantsoa, H. H., N. Ebine, M. Yoshioka, H. Higuchi, Y. Yoshitake, H. Tanaka, S. Saitoh, and P. J. Jones. Validation of three alternative methods to measure total energy expenditure against the doubly labeled water method for older Japanese men. IJ Nurr Sci Vitaminol (Tokyo). 48:5 17-523, 2002.

23. Schoffelen, P. F., K. R. Westerterp, W. H. Saris, and F. Ten Hoor. A dualrespiration chamber system with automated calibration. J Appl Physiol. 83:2064-
2072, 1997 .

24. Siri, W. E. Body composition from fluid spaces and density: analysis of methods. Washington, DC: Natl.Acad.Sci.Natl.Res Council, 1961, 223-224.

25. Weinsier, R. L., G. R. Hunter, R. A. Desmond, N. M. Byrne, P. A. Zuckerman, and B. E. Darnell. Free-living activity energy expenditure in women successful and unsuccessful at maintaining a nomal body weight. Am d Clin Nutr. 75:499-
$504 ., 2002$.

26. Weir, J. B. d. V. New methods for calculating metabolic rate with special reference to protein metabolism. J.Physiol. 109:1-9, 1949 . 
27. Westerterp, K. R. Alterations in energy balance with exercise. Am.J.Clin.Nutr. 68:970S-974S, 1998.

28. Westerterp, K. R. Energy metabolism and body composition: general principles. Eur Respir Mon. 24:1-10, 2003.

29. Westerterp, K. R. and C. V. C. Bouten. Physical activity assessment: Comparison between movement registration and doubly labeled water method. Z.Emahrungswiss. 36:263-267, 1997 .

30. Westerterp, K. R., L. Wouters, and W. D. v. Marken-Lichtenbelt. The Maastricht protocol for the measurement of body composition and energy expenditure with labeled water. Obes. Res. 3:49-57, 1995.

31. Williams, P. T. Vigorous exercise and the population distribution of body weight. Int J Obes Relat Metab Disord. 28:120-128, 2004. 

Chapter 5

Accelerometry and heart rate as a measure of physical fitness: proof of concept

Guy Plasqui and Klaas R. Westerterp

Accepted for publication 


\begin{abstract}
Objective This study focused on developing a new method to assess VO $\mathrm{P}_{\text {max }}$ outside laboratory conditions and without the need of maximal exertion. We hypothesized that the combined use of accelerometry and heart rate (HR) monitoring, under daily life conditions, could provide a good estimate of physical fitness.

Methods 26 healthy subjects ( 15 women, 11 men), aged $28 \pm 7$ years, performed a maximal incremental test on a bicycle ergometer to determine $\mathrm{VO}_{2 \max }$. Body composition was measured with underwater weighing and deuterium difution using a three-comparment model. A tri-axial accelerometer (Tracmor) and a HR monitor were worn for seven consecurive days under free-living conditions. The ratio of HR over activity counts per minute $(\mathrm{ACM})$ was used as a fitness-index $\left(\mathrm{HR} \cdot \mathrm{ACM} \mathrm{C}^{-1}\right)$.

Results As hypothesized. $H R \cdot A C M^{-1}$ was significantly correlated with $\mathrm{VO}_{\text {max. }}$ Using fat free mass (FFM) $(p<0.0001)$, age $(p=0.025)$ and $H R \cdot A C M^{-1}(p=0.021)$ as the independent variables, the explained variation in $\mathrm{VO}_{2 \text { max }}$ was $76 \%$ ( $\mathrm{p}<0.0001, \mathrm{SEE}=363$ $\mathrm{ml} / \mathrm{min}$ ). In order 10 generate a prediction formula that is applicable in the field when no data on body composition is avarlable, the same analysis was done with $B M$ and sex in the model instead of FFM. HR $A C M^{-1}$ was significantly $(p=0.023)$ correlated with $\mathrm{VO}_{2 \text { max }}$. The total explained variation of the model was $71 \%$ with a SEE of $409 \mathrm{ml} / \mathrm{min}$ or $13.7 \%$ of the average $\mathrm{VO}_{2 \max }$.

Discussion After correction for body composition, $\mathrm{VO}_{3 \text { nas }}$ was significantly related with $H R \cdot \mathrm{ACM}^{-1}$. It is to our knowledge the first tool that yields a measure of $\mathrm{VO}_{2 \max }$ by monitoring people in their daily life activities without the need of a specific protocol, without the need of maximal exertion and therefore applicable for a large variety of subjects.
\end{abstract}




\section{Introduction}

Maximal oxygen uptake $\left(\mathrm{VO}_{2 \max }\right)$ indicates the maximal capacity of the cardiovascular system to provide $\mathrm{O}_{2}$ to the muscle cell during sustained exercise and is the most widely used measure of physical fitness. Although there is a large genetic component, it is mainly determined by a person's activity level and inversely related with several health outcomes such as cardiovascular disease (2). $\mathrm{VO}_{2 \max }$ is usually measured by an incremental test on a motor driven treadmill or a bicycle ergometer. Because of the need of expensive equipment for the direct measurement of $\mathrm{VO}_{2 \mathrm{max}}$, several attempts have been made to estimate $\mathrm{VO}_{2 \max }$ outside laboratory settings. Various tests such as the 12-min performance test $(3)$ or the 20 -meter shuttle run test $(9,12)$ have been proven to correlate well with $\mathrm{VO}_{2 \text { max }}$. They require minimum equipment and can be easily performed with several subjects at the same time but require high levels of exertion. Other tests are based on sub-maximal, less-exerting exercise protocols but are still taxing and demand strict adherence to the protocol $(1,4,11)$. Ideally, an estimate of $\mathrm{VO}_{2 \max }$ should be obtained from sub-maximal, non-exerting activity, outside laboratory settings, that can be easily incorporated in daily life. Weyand et al. (17) used a combination of tood-ground contact monitoring and heart rate (HR) monitoring during treadmill running, to calculate an 'aerobic fitness index' as a measure of $\mathrm{VO}_{2 \max }$. The index was independent of treadmill running speed and correlated well with $\mathrm{VO}_{2 \max }$. Although the index was not yet tested in the field at volitional running speeds, they correctly stated it is a potentially powerful tool for the modification of sedentary behatvior and the improvement of aerobic fitness and health (17).

The lower HR observed in trained subjects is a consequence of an increased stroke volume, resulting from an increase in left ventricular size, myocardial contractility and end-diastolic volume, along with a decreased sensitivity to catecholamines (6). Many of the field tests used to estimate $\mathrm{VO}_{2 \text { inax }}$ are based on the inverse relation between $\mathrm{VO}_{\text {rmax }}$ and $\mathrm{HR}$ at a given exercise intensity. Meaning that, if one can measure the exercise intensity in the field and the corresponding heart rate, $\mathrm{VO}_{2 \max }$ can be predicted. Accelerometers can provide accurate information about intensity, frequency and duration of a variety of activities in daily life. They have been widely used as a measure of physical activity and activity patterns and proven to correlate well with energy expenditure during standard exerese protocols (10) but also in daily life $(5,15)$. We hypothesized that the combined use of accelerometry and heart rate monitoring could provide an accurate measure of $\mathrm{VO}_{2 \max }$ in daily living conditions, without the use of standardized protocols. Subjects with a high level of physical fitness should be able to generate higher activity counts (activity counts minute ${ }^{-1}$ or ACM) at a lower HR than their 'unfit' counterparts. More specifically, the aim was to use the ratio of HR.ACM' as a new fitness index and investigate its potential as a predictor of $\mathrm{VO}_{2 n \mathrm{na}}$.

\section{Methods}

\section{Subjects}

Subjects were 26 healthy volunteers ( 15 females and 11 males) between the age of 18 and 50 . Detailed information about the objective and the protocol of the study was provided. Written informed consent was obtained and the study was approwed by the Ethics Committee of Maastricht University. Subjects were selected in order to have a wide range in physical activity levels and physical fitness. Part of the subjects was 
recruited from a local fitness center $(n=12)$, where they were either a new member $(n=4)$, already an active member for several months $(n=5)$ or instructor $(n=3)$. The remaining subjects were recnifed at the university. One subject was excluded from all analyses due to missing data of the heart rate monitor. Subject characteristics $(n=25)$ are described in Table 1 .

Table I: Subject characteristics, values are mean \pm SD (range).

\begin{tabular}{lcc} 
& men & women \\
\hline N & 10 & 15 \\
Age $(\mathrm{y})$ & $28 \pm 7(19-42)$ & $28 \pm 7(22-46)$ \\
Body mass $(\mathrm{kg})$ & $73.6 \pm 16.6(51.4-106.0)$ & $64.7 \pm 7.8(52.1-78.1)$ \\
BMI $\left(\mathrm{kgem}{ }^{-2}\right)$ & $23.2 \pm 3.9(16.2-30.4)$ & $23.0 \pm 2.9(19-27.9)$ \\
\%FM & $17.3 \pm 5.6(9.3-24.9)$ & $27.7 \pm 7.4(14.9-37.1)^{*}$ \\
\hline
\end{tabular}

* Significantly different between men and women, $\mathrm{p}=0.001$

\section{Body compossition}

Anthropometric measurements were taken in the morning before the consumption of any foods or drinks. Body mass (BM) was measured on an electronic scale (Mettler Toledo IDI Plus, Germany) to the nearest $0.01 \mathrm{~kg}$. Height was measured to the nearest $0.1 \mathrm{~cm}$ (SECA Mod.220, Germany). Body volume was measured with underwater weighing. Residual lung volume was simultaneously measured using the helium dilution technique. Total body water (TBW) was measured with deuterium dilution according to the Maastricht protocol (16). Body composition was calculated from body density and TBW using Sir"s three-compartment model (113). Fat free mass (FFM) was used to correct $\mathrm{VO}_{2 \mathrm{max}}$ for body composition.

\section{Moxingal aerobic power}

VO $\mathrm{O}_{\text {riax }}$ was determined during an incremental test on a cycle ergometer according to the protocol of Kuppers of al. (8). After a warming up of 5 min at 100 Watt (W) for men and $75 \mathrm{~W}$ for women, workload was increased with $50 \mathrm{~W}$ every $2.5 \mathrm{~min}$. When HR reached a value of 35 beats per min (bpm) below the age predicted maximal HR (220 bpm-age) or the respiratory quotient (RQ) exceeded I, workload was increased with $25 \mathrm{~W}$ every 2.5 min until cxhaustion. Subjects were equipped with a mouthpiece and nose clip and expired air was continuously analyzed for $\mathrm{O}_{2}$-consumption and $\mathrm{CO}_{2}$-production (Oxycon-B, Bunnik. The Netherhands).

\section{Accelenomery}

The tri-axial accelerometer for movement registration (Tracmor; Philips Reseanch, Findhoven, The Netherlands) is an improved version of the earlier walidated Tracmor (5). The Tracmor contains thee uni-axial piezo-electric accelerometers, measures $7.2 \times$ $2.6 \times 0.7 \mathrm{~cm}$ and weighs $22 \mathrm{~g}$ (battery included). It is attached to the lower back by means of an elastic belt, measuring accelerations in the antero-posterior, mediomateral and longitudinal axis of the trunk. Subjects were instructed to wear the Tracmor for seven consecutive days, during waking hours, except during water activities. The Tracmor was designed to enable data storage for at least three weeks and for optimal 
wearing comfont in order not to interfere with daily activities. The Tracmor output is defined as activity counts min ${ }^{-1}$ (ACM) and is the sum of all absolute values in three axes.

\section{Heari rate monitoring}

Heart rate was continuonsly registered for seven consecutive days using a Polar (S610i) heart rate monitor (Polar Electro Oy, Kempele, Finland). Subjects were instructed on how to use the transmitter belt and the wristwatch and were asked to wear the monitor at the same time as the accelerometer (i.e. waking hours except during water activities). The HR monitor was programmed to store heartbeat every minute, allowing synchronization in time with the accelenometer. After 7 days the data was downloaded into the computer.

\section{Calculations}

The accelerometer and HR monitor, both programmed to provide one data point each minute, were synchronized in time. The data of all seven days were combined as one dataset. When the HR monitor generated inaccurate data (due to bad contact of the transmitter belt with the skin or telemetric interference from other electric devices) the corresponding accelerometer value was also removed. For each subject, one average walue (over the entire 7-day registration) was calculated for both ACM and HR (bpm). The ratio of $\mathrm{HR} \cdot \mathrm{ACM}^{-1}$ was then used as our fitness-index.

\section{Staristics}

Differences between men and women were tested with Student's t-test for unpaired samples. Multiple regression analysis was used to generate prediction formulas for $\mathrm{VO}_{2 \max }$. All analyses were done with SPSS 10.0 for Macintosh (SPSS Inc., Chicago, Illinois). The statistical significance level was set at $\mathrm{p}<0.05$.

\section{Results}

Results for $V O_{2 \text { max }}$ VO $O_{2 \max }$ corrected for $B M$ and FFM and the fitness index HR $A C M^{-1}$ are presented in table 2. As could be expected, there was a significant sex difference for $\mathrm{VO}_{2 \text { max }}$ except after correction fot FFM. There was no sex difference for the fitmess index $\mathrm{HR} \cdot \mathrm{ACM}^{-1}$.

Table 2: fitness parameters by gender, values are mean \pm SD.

\begin{tabular}{|c|c|c|}
\hline & Men & women \\
\hline $\mathrm{VO}_{2 \max }\left(\mathrm{m} / \cdot \mathrm{min}^{-1}\right)$ & $3556 \pm 657$ & $2587 \pm 388$ \\
\hline $\mathrm{VO}_{2 \max } \cdot \mathrm{BM}^{-1}\left(\mathrm{ml} \cdot \mathrm{kg}^{-1} \cdot \mathrm{min}^{-1}\right)$ & $49.56 \pm 10.18$ & $40.68 \pm 8.42^{(2)}$ \\
\hline $\mathrm{VO}_{2 \mathrm{~m}} \cdot \mathrm{FFM}^{-1}\left(\mathrm{ml} \cdot \mathrm{kg}^{-1} \cdot \mathrm{min}^{-1}\right)$ & $59.72 \pm 9.88$ & $55.88 \pm 7.19$ \\
\hline$H R \cdot A C M^{-1}\left(\right.$ beats $\left.\cdot A C^{-1}\right)$ & $0.17 \pm 0.06$ & $0.20 \pm 0.04$ \\
\hline
\end{tabular}

significant sex difference (l) $p=0.000$ t and $(2) p=0.03$

$\mathrm{BM}$, body mass; FEM, fat free mass; HR, heart rate; $\mathrm{ACM}$, activily counts per minute; AC, activity counts 
Based on the results in table 2, men and women will be combined in the regression analysis. When FFM is used as an independent variable, no correction for gender has to be made. When BM is used as an independent variable, gender is also included to correct for the difference in body composition. Since $V \mathrm{O}_{2 \mathrm{max}}$ is inversely related with age, this variable is always included in the model.

After correction of $V O_{2 m a x}$ for $F F M$ and age, $H R \cdot A C M^{-1}$ was negatively related with $\mathrm{VO}_{2 \text { max }}(\rho=0.02)$, resulting in a total explained variation of $76 \%$ ( $\left.p<0.0001\right)$. Regression coefficients with standard error, significance levels and correlations are presented in table 3. The standard error of estimate (SEE) of the model was $363 \mathrm{ml} / \mathrm{min}$ or $12.2 \%$ of the average $1 \mathrm{O}_{2 \max }$.

In order to generate a prediction formulat that is applicable in the field when no data on body composition is available, the same analysis was done with $B M$ and sex in the model instead of FFM. HR.ACM ${ }^{-1}$ was significantly $(p=0.02)$ correlated with $\mathrm{VO}_{2 \text { max }}$. The total explained variation of the model was $71 \%$ with a SEE of $409 \mathrm{ml} / \mathrm{min}$ or 13.7\%. Regression coefficients with standard error, significance levels and correlations are presented in table 4.

Table 3: Multiple regression analysis with $\mathrm{VO}_{2 \text { max }}$ as the dependent variable and FFM, age and $\mathrm{HR}-A \mathrm{CM}^{-1}$ as the independent variables.

\begin{tabular}{|c|c|c|c|c|c|c|}
\hline \multirow[b]{2}{*}{$\mathrm{VO}_{2 \max }$} & \multirow[b]{2}{*}{ coefficients } & \multirow[b]{2}{*}{ Std.error } & \multirow[b]{2}{*}{$\mathrm{P}$} & \multicolumn{3}{|c|}{ Comelations (R) } \\
\hline & & & & Zero-order" & Partial** & Part \\
\hline Constant & 1834 & 532 & 0.002 & & & \\
\hline FFM $(\mathrm{kg})$ & 50.61 & 7.49 & $<0.0001$ & 0.76 & 0.83 & 0.72 \\
\hline $\operatorname{Age}(y)$ & -27.16 & 11.29 & 0.025 & -0.18 & -0.47 & -0.26 \\
\hline $\begin{array}{l}\mathrm{HR} \cdot \mathrm{ACM} \\
\left(\text { beats } \cdot \mathrm{AC}^{-1}\right)\end{array}$ & -3844 & 1545 & 0.021 & -0.49 & -0.48 & -0.27 \\
\hline Model & & $\begin{array}{l}\mathrm{SEE} \\
363\end{array}$ & $<0.0001$ & & 0.87 & \\
\hline
\end{tabular}

FFM, fot free mass; HR, heart rate; $A C M$, activity counts per minute; $A C$, activity counts

* The zero order correlation is the simple (Pearson) correlation between the dependent and the independent variable.

* * The partial correlation is the correlation between the dependent and an independent variable when the linear effects of the other independent variables in the model have been removed from both.

* * The part (semipartiall) correlation is the correlation between the dependent and an independent variable when the linear effects of the other independent variables in the model have been removed from the independent variable only. 
Table 4: Multiple regression analysis with $\mathrm{VO}_{2 \mathrm{max}}$ as the dependent variable and age, sex, $\mathrm{BM}$ and $\mathrm{HR} \cdot \mathrm{ACM}^{-1}$ as the independent variables.

\begin{tabular}{|c|c|c|c|c|c|c|}
\hline \multirow[b]{2}{*}{$\mathrm{NO}_{\text {mmax }}$} & \multirow[b]{2}{*}{ coefficients } & \multirow[b]{2}{*}{ Std.error } & \multirow[b]{2}{*}{$\mathrm{P}$} & \multicolumn{3}{|c|}{ Correlations (R) } \\
\hline & & & & Zero-order & Partial & part \\
\hline Constant & 2714 & 541 & $<0.0001$ & & & \\
\hline Age $(y)$ & -31.48 & 14.06 & 0.037 & -0.18 & -0.45 & -0.27 \\
\hline Sex & 592 & 194 & 0.006 & 0.70 & 0.56 & 0.37 \\
\hline $\mathrm{BN}(\mathrm{kg})$ & 25.46 & 8.28 & 0.006 & 0.44 & 0.57 & 0.37 \\
\hline $\begin{array}{l}\mathrm{HR} \cdot \mathrm{ACM} \mathrm{C}^{-1} \\
\left(\text { beats } \cdot \mathrm{AC}^{-1}\right)\end{array}$ & -4401 & 1789 & 0.023 & -0.49 & -0.48 & -0.30 \\
\hline Model & & $\begin{array}{l}\text { SEE } \\
409\end{array}$ & $<0.0001$ & & 0.84 & \\
\hline
\end{tabular}

$\overline{B M}$, body mass; $\mathrm{HR}$, heart rate; $\overline{A C M}$, activity counts per minute; $A C$, activity counts

\section{Discussion}

This study aimed to develop a new fitness measure, based on the relation between HR and activity counts, which is applicable in daily life without the need of maximal exertion. As we hypothesized, our fitness index $\mathrm{HR} \cdot \mathrm{ACM}^{-1}$ was significantly related with $\mathrm{VO}_{2 \text { max }}$ corrected for differences in body composition and age.

It is clear that a substantial part of the variation in VO2mix was explained by our measure of FFM. Since measuring FFM with a three-compartment model is at least as expensive and labour-intensive as measuring $\mathrm{VO}_{2 m a x}$ in the lab, it wouldn't be fair to claim to have found a field test for the measurement of $\mathrm{VO}_{2 \mathrm{max}}$ using FFM in the model. For the discussion, we will therefore focus on the second model, with BM and sex instead of FFM in the regression equation.

Allhough physical fitness is a complex term that cannot be captured in one definition. $\mathrm{VO}_{2 \text { man }}$ is the most widely used measure of cardiorespiratory himess and has been shown to be strongly related with several health outcomes (18). Even though direet measurement of $\mathrm{VO}_{2 \text { max }}$ in a laboratory setting, using a graded exercise test, is the most accurate assessment, these tests are limited by the need of expensive equipment, trained technicians, the low number of subjects that can be measured simultanoously and the maximal exertion required. Many attempts have been made to develop a field test for the measurement of $\mathrm{VO}_{2 \text { max }}$ resulting in good to very good prediction equations. Cooper (3) reported a correlation of 0.897 between the distance covered in a 12 -min field test and laboratory determined oxygen consumption. Léger and Lambert (9) reported a correlation of 0.84 between $V O_{2 m a x}$ and maximal speed achieved in the 20 m shutle nun. The SEE in his study was $11.4 \%$ of the average $\mathrm{VO}_{2 m a x}$ (men and wonen combined). These results are comparable with the present study that showed a correlation of 0.84 with a SEE of $13.7 \%$. Both tests, the 12-min field test and 20 -m shutle rum, prowide though very good estimates of $\mathrm{VO}_{2 \max }$ but are limited by the maximal exertion needed. The use of sub-maximal exercise tests to estimate $\mathrm{VO}_{2 m a x}$ are generally based on the inverse relation between heart rate at a given exercise intensity and $V O_{2 m a x}(1,11)$. Kline et a. (7) developed a fitness-measure based on a one-mile track walk. The best 
prediction of $\mathrm{VO}_{2 \text { max }}$ was achieved when weight, age, sex, elapsed time and HR during the fourth quarter of the walk were used as the independent variables, resulting in correlation of 0.93 and a SEE of $0.325 \mathrm{Im} \mathrm{min}^{-1}\left(12.4 \%\right.$ of the mean $\mathrm{VO}_{2 \mathrm{max}}$ ). They also reviewed the accuracy of various maximal as well as sub-maximal tests (7).

Various tests should be evaluated not only on their accuracy and validity but also on Wheir applicability in a varied study population, on costs and on ease and convenience of the protocol. It is obvious that protocols requiring maximal exertion as well as submaximal running protocols are too strenuous or even unsafe for individuals with low functional capacities. Weyand et al (17) developed a fitness index that predicted $\mathrm{VO}_{2 \text { max }}$ independent of running speed. However, the lowest speed tested was $2.4 \mathrm{~m} / \mathrm{s}$, which may already be difficult for some subjects, for example the obese, which is a study population of great interest regarding physical activity and fitness. Furthermore, tests were performed with a controlled treadmill protocol and not in the field.

We aimed at developing fitness measure that does not require adherence to a strict protocol, that is applicable for a wide variety of subjects and can be used in daily life. Accelerometers have been proven to correlate well with activity related energy expenditure, during standard running tests as well as in daily life $(5,10,14,15)$. They provide information about the amount, frequency and intensity of activity performed. The total amount of physical activity performed is best reflected by the sum of all counts or counts day whereas counts min $^{-1}$, the output variable used in this study, is more a reflection of exercise intensity and thus represents a measure of the mechanical work rate performed. By combining this with a neasure of $H R$, the physiological basis of our fitness index is comparable to that of many other sub-maximal tests based on the inverse relation between physical fitness and $H R$ at a given exercise intensity.

Daily life consists of a huge variety of different activities all resulting in different accelerometer output as well as heart rate readings. Both methods have their shortcomings with regard to the measurement of different activities. Accelerometers for example don't measure static activities, such as carrying loads, whereas heart rate is influenced by other factors but activity such as emotions or environmental temperature. Despite these shortcomings, we demonstrated that "Gitter" subjects are able to generate higher activity counts at a lower heart rate than their "unfit" counterparts. The wide vartety in activities ass observed in daily life make measurements susceptible to errors but might also be advantageous. The long observation period (1 week) we used, allows an enomous variety in activity intensities and therefore a large range in tracmor output as well as heart rate.

The primary goal of this kind of fitness measure is not only for research purposes but also for public use. Motivating people to engage in sufficient physical activity is a major problem. An instrument that provides feedback on their personal physical fitness without having to enroll in a fitness club might be very useful to stimulate people to engage in physical activity.

We are aware that the major shorteoning of this study is the lack of a crosswalidation group. The number of subjects was to small to divide the subjects into an experimental and a cross-validation group. Our further research will aim at testing the prediction formula in a different group as well as testing our fitness-index for the ability to detect changes in fitmess over time. Other issues, such as the monitoring time needed to 
prowide a good estimate of $\mathrm{VO}_{2 \text { max }}$ and validity in other study populations, such as the obese or elderly should be addressed. However, it is to our knowledge the first tool that yields a measure of $\mathrm{VO}_{2 \max }$ by monitoring people in their daily life activities without the need of a specific protocol, without the need of maximal exertion and therefore applicable for a large variety of subjects. We conclude that this fimess-index is a promising tool for the measurement of $\mathrm{VO}_{2 \max }$ for both research purposes as well as the improvement of public health by stimulating people into physical activity. 
1. Astrand, P. O. and I. Ryhming. A nomogram for calculation of aerobic capacity (physical fitmess) from pulse rate during sub-maximal work. J Appl Physiol. $7: 218-221,1954$

2. Blair, S. N., Y. Cheng, and J. S. Holder. Is physical activity or physical fitness more important in defining health benefits? Med Sci Sports Exerc. 33:5379-399; discussion $\$ 419-320,2001$.

3. Cooper, K. H. A means of assessing maximal oxygen intake. Correlation between ficld and treadmill testing. Jana. 203:201-204, 1968.

4. George, J. D., P. R. Vehrs, P. E. Allsen, G. W. Fellingham, and A. G. Fisher. $\mathrm{VO}_{2 m}$ estimation from a submaximal 1 -mile track jog for fit college-age individuals. Med Sci Sports Exerc. 25:401-406, 1993.

5. Goris, A. H. E. P. Meijer, A. Kester, and K. R. Westerterp. Use of a triaxial accelerometer to validate reported food intakes. Am J Clin Nutr. 73:549-553, 2001 .

6. Jones, A. M. and H. Carter. The effect of endurance training on parameters of aerobic finess. Sports Med. 29:373-386, 2000 .

7. Kline, G. M., J. P. Porcari, R. Hintermeister, P. S. Freedson, A. Ward, R. F. McCarron, J. Ross, and J. M. Rippe. Estimation of $\mathrm{VO}_{2 \max }$ from a one-mile track walk, gender, age, and body weight. Med Sci Sports Exerc. 19:253-259, 1987.

8. Kuipers, H., F. T. Verstappen, H. A. Keizer, P. Geurten, and G. van Kranenburg. Variability of aerobic performance in the labotatory and its physiologic correlates. Int J Sports Med. 6:197-201, 1985.

9. Leger, L. A. and J. Lambert. A maximal multistage 20-m shuttle run test to predict $\mathrm{VO}_{2 \mathrm{max}}$. Eur J Appl Physiol Occup Physiol. 49:1-12, 1982.

10. Levine, J. A., P. A. Baukol, and K. R. Westerterp. Validation of the Tracmor triaxial accelerometer system for walking. Med Sci Sports Exerc. 33:1593-1597, 2001 .

11. Margaria, R., P. Aghemo, and E. Rovelli. Indirect determination of maximal $\mathrm{O}_{2}$ consumption in man. J Appl Physiol. 20:1070-1073, 1965.

12. Paliczka, V. J., A. K. Nichols, and C. A. Boreham. A multi-stage shuttle run as a predictor: of runing performance and maximal oxygen uptake in adults. Br $\mathrm{J}$ Sports Med. 2]:163-165, 1987

13. Siri, W. E. Body composition from fuid spaces and density: analysis of methods. Washington, DC: Natl.Acad.Sci. Natl.Res.Council, 1961, 223-224.

14. Westerterp, K. R. Physical activity assessment with accelerometers. Int.J.Obes. $23: \mathrm{S} 45-\mathrm{S} 49,1999$

15. Westerterp, K. R. and C. V.C. Bouten. Physical activity assessment: Comparison between movement registration and doubly labeled water method. Z.Ernahungswiss. 36:263-267, 1997 . 
16. Westerterp, K. R., L. Wouters, and W. D. W. Marken Licltenbelt. The Maastricht protocol for the measurement of body composition and energy expenditure with labeled water. Obes. Res. 3:49-57, 1995.

17. Weyand, P. G., M. Kelly, T. Blackadar, J. C. Darley, S. R. Oliver, N. E. Ohlenbusch, $S$. W. Joffe, and R. W. Hoyt. Ambulatory estimates of maximal aerobic power from foot-ground contact times and heart rates in running humans. J Appl Physiol. $91: 451-458,2001$.

18. Williams, P. T. Physical fitness and activity as separate hear disease risk factors: a meta-analysis. Med Sci Sports Exerc. 33:754-761., 2001. 

Chapter 6

Accelerometry and heart rate monitoring as a measure of physical fitness: cross-validation

Guy Plasqui and Klaas R. Westerterp 


\begin{abstract}
Objective We recently reported on a new method to assess physical fitness, based on the combined use of accelerometry and heart rate registration. This study aimed to test de validity of the prediction formula in a second group of healthy young adults.

Methods 26 healthy subjects (12 women, 14 men) performed a maximal incremental test on a bicycle ergometer to determine $\mathrm{VO}_{2 \text { max }}$. A tri-axial accelerometer (Tracmor) and a HR monitor were worn for seven consecutive days under free-living conditions. The formula developed in a previous experimental group (EXP), based on body mass, age, sex and the ratio of HR over activity counts (HR.ACM ${ }^{\prime}$ ) per minute, was applied of the cross-validation group (CV).

Results There was no difference in age, sex, body mass or $V \mathrm{O}_{2 \max }$ between the experimental and cross-validation group except for activity counts. Although measured $\mathrm{VO}_{2 \mathrm{max}}$ could be predicted for $80 \%(\mathrm{p}<0.0001)$ a paired t-test showed a significant difference between measured and predicted $V O_{2 \max }(1.78 \mathrm{ml} / \mathrm{min} ; \mathrm{p}=0.015)$. Bland Alman plotting revealed a significant positive $(p=0.007)$ relation between the mean of predicted and measured $V_{2 \max }$ and the difference between measured and predicted. Because of the difference in activity between the EXP and the CV group, all data were combined, sorted according to activity counts and two new groups were formed by coding all odd numbers 0 and even numbers 1 . This way an EXP and CV group were created that did not significantly differ in activity or any of the other parameters. The formula developed in the new experimental group $\left(R^{2}=0.74 ; p<0.0001\right)$ predicted $\mathrm{VO}_{2 \text { max }}$ in the cross-validation group for $72 \%(\mathrm{p}<0.0001)$, a paired tutest showed no difference between measured and predicted $\mathrm{VO}_{2 \text { max }}$ and Bland Altman plotting no longer showed a significant correlation.
\end{abstract}

Discussion Although there was a very good correlation between measured and predicted $\mathrm{VO}_{2 \max }$ in both cross-validation groups, care should be taken in applying the prediction formula on groups that differ in physical activity from the current study population. 


\section{Introduction}

Maximal oxygen uptake ( $\mathrm{VO}_{2 \mathrm{max}}$ ) is the most widely used measure of physical fitness and is inversely related with several health outcomes such as cardiovascular disease and coronary heart disease (25). Because physical fitness is strongly related to physical activity (2), $\mathrm{VO}_{2 \mathrm{nnx}}$ is also often used as a measure of physical activity. $\mathrm{VO}_{2 \text { max }}$ can be accurately measured in a laboratory sefing, during standardized protocols that require sophisticated equipment and maximal exertion of the subject. The physiological importance of $\mathrm{VO}_{2 \text { mix }}$ as a measure of aerobic fitness, as an indication of physical activity and as a health parameter has led to the development of various maximal and sub-maximal field tests to estimate $V_{2 m a x}(1,5,9,12,15,19,22)$. Although useful for research purposes, exertion and the requirements for specific procedures limit the applicability of these tests for personal assessment.

Weyand et al. (24) developed a fitness index by the combined use of foot-ground contact times and heart rate monitoring during running on a treadmill. The fitness index correlated well $(\mathrm{R}=0.90)$ with $\mathrm{VO}_{\text {2max }}$ and the predictive power was independent of running speed. Although this fitness index is a promising tool to assess physical fitness, its usefulness is limited to a laboratory test on a treadmill and is yet to be tested in the field at volitional running, and preferably walking, speeds.

Most sub-maximal protocols are based on the inverse relationship between heart rate at a given exercise intensity and physical fitness, i.e. when the intensity of a certain activity is known and heart rate is registered, $\mathrm{VO}_{2 \text { max }}$ can be predicted. Developing at fitness index for application in daily life therefore requires a tool that provides an estimate of the intensity of different activities.

We recently reported on a new fitness index, based on the combined use of accelerometry and heart rate registration, that could be used in daily life without the need of a specific protocol (23). When the output of the accelerometer (activity counts min ${ }^{-1}$ ) is used to define the intensity of the activity performed, then the corresponding heart rate (HR) would be inversely related with physical fitness. Multiple regression analysis showed that this fitness index, defined as heart rate over activity counts per minute $\left(\mathrm{HR} \cdot \mathrm{ACM} \mathrm{M}^{-1}\right)$, significantly contributed to the explained variation in $\mathrm{VO}_{2 \text { max }}$. This study was designed to validate the prediction equation in a second group of healthy subjects, with a warying degree of physical fitness.

\section{Methods}

\section{Subjects}

Subjects were 26 healthy adults between the age of 18 and 50 , most of them recruited from the university. Information about the protocol of the study was provided and the study was approved by the Ethics Committee of Maastricht University. This group will be referred to as the cross-validation (CV1) group. The experimental (EXPI) group, used to develop the prediction formula, was already described in a previous study (23). Physical characteristics of the CVI group and the EXPI group are presented in Table 1. 


\section{Maximal aerobic power}

VO $\mathrm{x}_{\text {max }}$ was determined during an incremental test on a cycle ergometer according to the protocol of Kuipers et al (13). After a warming up of 5 min at 100 Watt (W) for men and $75 \mathrm{~W}$ for women, workload was increased with $50 \mathrm{~W}$ every $2.5 \mathrm{~min}$. When HR reached a value of 35 beats per min (bpm) below the age predicted maximal HR (220 bpm - age) or the respiratory quotient (RQ) exceeded 1, workload was increased with 25 W every $2.5 \mathrm{~min}$ until exhaustion. Subjects were equipped with a mouthpiece and nose clip and expired air was continuously analyzed for $\mathrm{O}_{2}$-consumption and $\mathrm{CO}_{2}$-production (Oxycon-B, Bunik, The Netherlands).

Table 1: Subject characteristics of the experimental group (23) and the validation group. Values are mean $\pm \mathrm{SD}$.

\begin{tabular}{|c|c|c|}
\hline & Experimental & Validation \\
\hline$N(M / F)$ & $25(10 / 15)$ & $26(14 / 12)$ \\
\hline $\operatorname{Age}(y)$ & $28 \pm 7$ & $29 \pm 6$ \\
\hline Bodly Mass (kg) & $68.3 \pm 12.6$ & $71.2 \pm 12.0$ \\
\hline $\mathrm{BMI}\left(\mathrm{kg}^{2} \mathrm{~m}^{2}\right)$ & $23.1 \pm 3.2$ & $22.7 \pm 2.7$ \\
\hline Activity counts (counts/min) & $478 \pm 117$ & $394 \pm 89 *$ \\
\hline $\mathrm{HR} \cdot \mathrm{ACM} \mathrm{C}^{-1}$ (beats/count) & $0.19 \pm 0.05$ & $0.21 \pm 0.05$ \\
\hline $\mathrm{VO}_{2 \mathrm{max}}(\mathrm{ml} / \mathrm{min})$ & $2975 \pm 696$ & $3177 \pm 752$ \\
\hline
\end{tabular}

* significant difference between groups $(p=0.006)$

HR, heart rate; $A C M$, activity counts per minute

\section{Anthropometrics}

Body mass (BM) was determined, to the nearest $0.1 \mathrm{~kg}$ (SECA, model 707, Hamburg, Germany, prior to the bicycle ergometer test, in light sports wearing and without shoes.

\section{Accetsonetry}

The triaxial accelerometer for movement registration (Tracmor; Philips research, Eindhoven. The Netherlands) was used to register daily life activity. The accelerometer was wom for seven consecutive days, during waking hours, except during water activitios. The accelerometer is worn at the lower back by means of an elastic belt. It registers accelerations in the antero-posterior, medio-lateral and longitudinal axis of the trunk. Data were collected and stored minute by minute, downloaded to the computer and the sum of all three axes was used a the activity measure. Tracmor output is defined as activity connts per minute (ACM).

\section{Heart rate moniroring}

Heart rate (HR) was contimously registered for seven consecutive days using a Polar (S610i) heart rate monitor (Polar Electro Oy, Kempele, Finland). Subjects were instructed on how to use the transmitter bett and the wristwatch and were asked to wear the monitor at the same time as the accelerometer (i.e. waking hours except during water activitics). The HR monitor was programmed to store heartbeat every minute, 
allowing synchronization in time with the accelerometer. After 7 days the data was downloaded into the computer.

\section{Fimess index}

By dividing heart rate (bpm) by activitiy counts per minute (ACM), the fitness index $\left(\mathrm{HR} \cdot \mathrm{ACM}^{-\mathrm{T}}\right.$ ) was calculated (23).

\section{Comparison of EXP and CV group}

Sudent's t-test for umpaired data was used to compare the EXP1 with the CV1 group. A significant difference for activity counts $(p=0.006)$ was found, i.e. the EXPl group was significantly more active than the CVI group (Table 1). Therefore, subjects of both the EXPI and the CV1 group were combined $(n=51)$ and sorted for activity counts. "Two new groups were formed by coding all odd numbers 0 and even numbers 1 , creating a new EXP group and CV group that did not differ in physical activity. These groups will be referred to as EXP2 and CV2. Characteristics of EXP2 and CV2 group are presented in Table 2. Student's t-test for umpaired data showed no significant differences in any of the parameters between both groups (Table 2).

Table 2: Subject characteristics of the experimental group and the validation group after stratification for physical activity. Values are mean $\pm \mathrm{SD}$.

\begin{tabular}{lcc}
\hline & Experimental 2 & Validation 2 \\
\hline $\mathrm{N}(\mathrm{M} / \mathrm{F})$ & $26(10 / 6)$ & $25(14 / 1)$ \\
Age (y) & $28 \pm 6$ & $30 \pm 7$ \\
Body Mass $(\mathrm{kg})$ & $69.6 \pm 11.2$ & $70.0 \pm 13.5$ \\
$\mathrm{BMI}\left(\mathrm{kg} \mathrm{m}^{2}\right)$ & $22.7 \pm 2.7$ & $23.6 \pm 4.2$ \\
Activity counts (counts/min) & $439 \pm 125$ & $432 \pm 97$ \\
$\mathrm{HR} \cdot \mathrm{ACM}{ }^{-1}$ (beats/count) & $0.20 \pm 0.06$ & $0.20 \pm 0.05$ \\
$\mathrm{VO}_{2 \text { max }}(\mathrm{m} / \mathrm{min})$ & $3054 \pm 643$ & $3103 \pm 814$ \\
\hline
\end{tabular}

$H R$, heart rate; ACM, activity counts per minte

\section{Statistics}

EXP' and CV groups were compared using Student's t-test for unpaired data Multiple linear regression was used to develop the prediction formula in EXP2. In the CV groups, Student's t-test for paired data was used to test differences between predicted (equations developed in EXP groups) and measured $\mathrm{VO}_{2 m a x}$. Linear regression wats used to test agreement between predicted and measured $V O_{2 m i x}$ Bland Alman plotting (3) and linear regression was used to detect systematic differences between measured and predicted $V O_{2 \text { max }}$. All analyses were done with Statview 5.0 for Macintostr (SAS Institute Inc., North Carolina) and SPSS 10.0 for Macintosh (SPSS Inc., Chicago, Ilinois). The level for statistical significance was set at $p<0.05$. 


\section{Results}

\section{EXPl and CVI}

Predicted $\mathrm{VO}_{2 \text { max }}$ (equation 1) correlated very well with measured $\mathrm{VO}_{2 \max }(\mathrm{R}=0.90, \mathrm{P}<$ 0.0001 ) and the standard error of estimate (SEE) was $341 \mathrm{ml} / \mathrm{min}$ or $10.7 \%$ of the average $\mathrm{VO}_{2 \max }$. Predicted $\mathrm{VO}_{2 \max }$ was $178 \mathrm{ml} / \mathrm{min}$ or $5.6 \%$ lower than measured ( $\mathrm{p}=$ 0.015 ). Bland Altman plotting and linear regression showed a significant positive relation $(p=0.007)$ between the average of predicted and measured $\mathrm{VO}_{2 \max }$ and the difference between both (Figure 1).

Equation 1: $\mathrm{VO}_{2 \mathrm{max}}=2714-31.48 \cdot \mathrm{age}+592 \cdot \mathrm{sex}+25.46 \cdot \mathrm{BM}-4401 \cdot \mathrm{HR} \cdot \mathrm{ACM}^{-1}$ (sex, 0 for women and I for men; $B M$, body mass; $H R \cdot A C M^{-1}$, fitness index)

\section{EXP2 and $C V_{2}$}

The same independent variables as for equationl were used to predict $\mathrm{VO}_{2 \max }$ in the EXP2 group. BM, age, sex and $\mathrm{HR} \cdot \mathrm{ACM}^{-1}$ significantly contributed to the prediction of $V_{2 m a x}$ and resulted in a total explained variation of $74 \%$ with a SEE of $358 \mathrm{ml} / \mathrm{min}$ or $11.7 \%$. Regression coefficients with standard error, significance levels and correlations are presented in Table 3. When this prediction equation (equation2) was used on CV2, the correlation with measured $\mathrm{VO}_{2 \max }$ was $0.85(\mathrm{p}<0.0001)$ and the SEE was 437 $\mathrm{ml} / \mathrm{min}$ or $14.1 \%$. There was no significant difference between measured and predicted $\mathrm{VO}_{2 \max }(32 \mathrm{ml} / \mathrm{min})$ and Bland Altman plotting and linear regression no longer showed a significant relation between the average of predicted and measured $\mathrm{VO}_{2 \max }$ and the difference between both (Figure 2). 


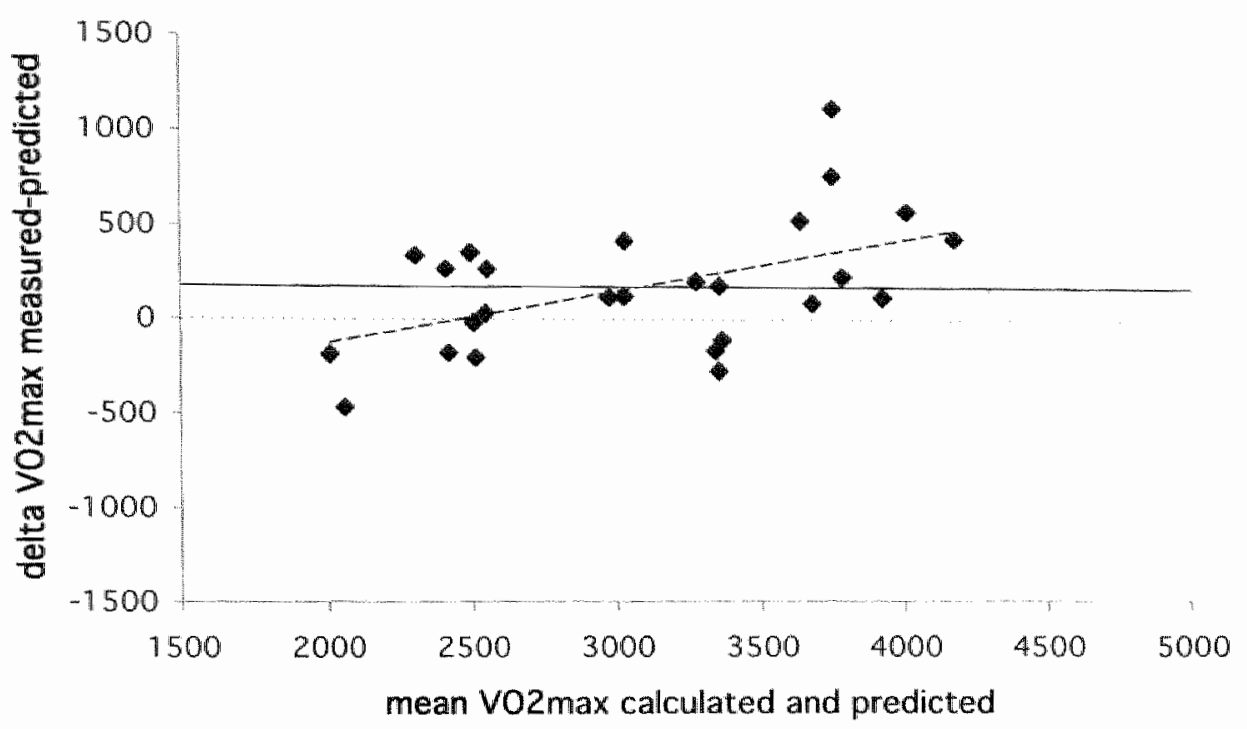

Figure 1: Bland Altman plot for validation group 1: mean VO $\mathrm{O}_{2 \mathrm{~m} x}$ (measured and predicted) plotted against the difference (measured-predicted) in $\mathrm{VO}_{2 \text { mas. }}$. The dashed line shows the significant positive relation $(p=0.007)$. The full line represents the underestimation $(5.6 \%)$ of the predicted versus the measured $\mathrm{VO}_{2 \max }$.

Table 3: Multiple regression analysis with $\mathrm{VO}_{2 \text { naik }}$ as the dependent variable and age, sex, $B M$ and $H R \cdot A C M^{-1}$ as the independent variables. Data from experinental group 2.

Correlations (R)

\begin{tabular}{|c|c|c|c|c|c|c|}
\hline $\mathrm{VO}_{\text {2max }}$ & coefficients & Std.error & $\mathrm{P}$ & Zero-order & Partial & part \\
\hline Constant & 2938 & 596 & 80,0001 & & & \\
\hline Age $(y)$ & -38.46 & 13.92 & 0.01 & 0.07 & -0.50 & -0.30 \\
\hline Siex & 563 & 185 & 0.006 & 0.67 & 0.55 & 0.35 \\
\hline Body mass (kg) & 27.66 & 7.75 & 0.002 & 0.54 & 0.58 & 0.38 \\
\hline $\mathrm{HR} \cdot \mathrm{ACM}^{-1}$ (beats $\left.\mathrm{AC}^{-1}\right)$ & -4842 & 1417 & 0.003 & -0.49 & -0.60 & -0.39 \\
\hline Model & & $\begin{array}{l}\text { SEE } \\
358\end{array}$ & $<0,0001$ & & 0.86 & \\
\hline
\end{tabular}

Sex: women, 0 ; men, 1; HR, heart rate; $\mathrm{ACM}$, activity counts per minute 


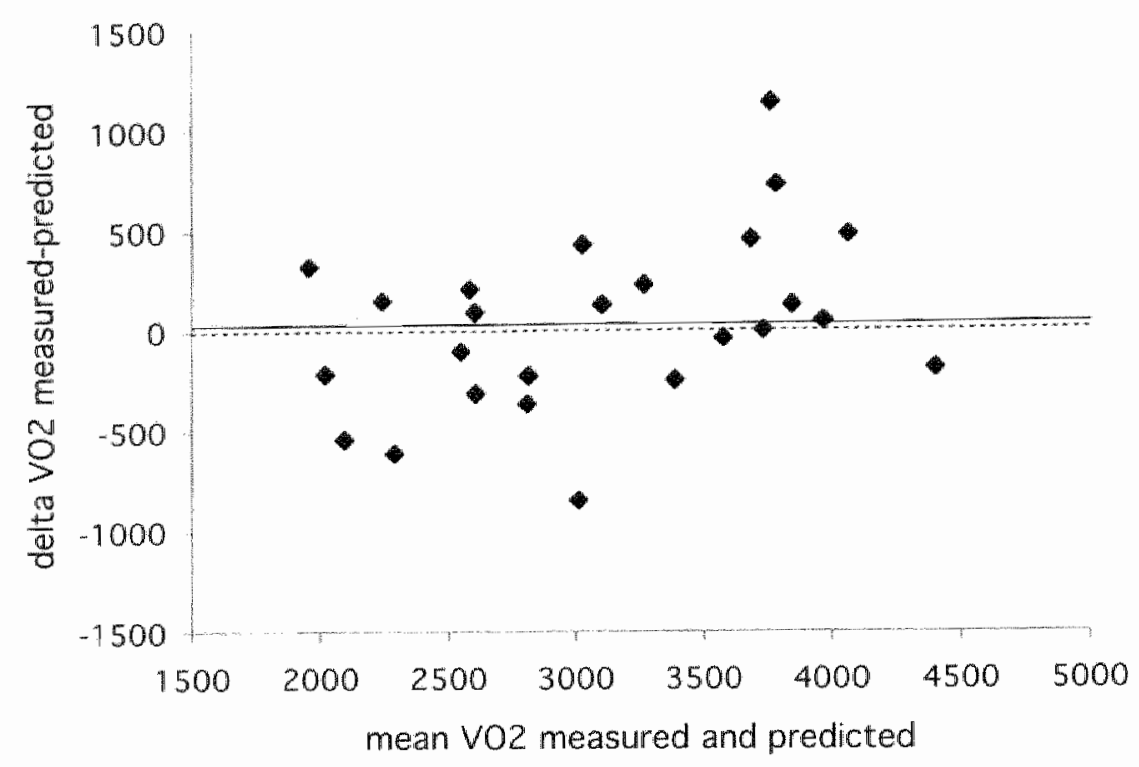

Figure 2: Bland Altman plot for validation group 2: mean $\mathrm{VO}_{2 \max }$ (measured and predicted) plotted against the difference (measured-predicted) in $\mathrm{VO}_{2 \max }$. The full line represents the mean difference $(1 \%)$.

\section{Discussion}

The purpose of this study was to test the validity of our fitness index to predict $\mathrm{VO}_{2 \text { max }}$ in a sample of healthy subjects with a wide range in physical activity and fitness. In CVI, Equation l resulted in a total explained variation in $\mathrm{VO}_{2 \max }$ of $81 \%$ with a SEE of $10.7 \%$. In CV2, equation 2 predicted $\mathrm{VO}_{2 \text { max }}$ for $72 \%$ with a SEE of $14.1 \%$.

In our previous study (23) an equation was developed to predict $\mathrm{VO}_{2 m a x}$ from $\mathrm{BM}$, age, sex and the fitness index $H R \cdot A C M^{-1}$. The number of subjects however was too small to create an EXP and a CV group. In this study we attempted to create a CV group with comparable characteristics as the EXP group. However, there was a significant difference in physical activity beiween groups. Regression analysis showed very good correlation between predicted and measured $\mathrm{VO}_{2 \text { nax }}$ but there was a systematic difference between predicted and measured of 5.6\%. Furthermore, Bland Altman plotting showed an over-prediction of $\mathrm{VO}_{2 \text { max }}$ at the lower fitmess levels and an underprediction at the higher levels. To test whether this was due to the difference in physical activity, all subjects were combined, sorted for physical activity and a new EXP and CV group was created. This technique has been applied by other authors (24). Although equation2 resulted in a slighily lower correlation $(R=0.85)$ and larger SEE $(14.1 \%)$ in the $\mathrm{CV}$ group, there was no longer a systematic difference between measured and predicted $\mathrm{VO}_{2 \text { nia }}$ and $\mathrm{Bland}$ A itman plotting showed no correlation. 
The practical utility of various protocols to predict $\mathrm{VO}_{2}$ max can be questioned based on the basis of three main considerations: accuracy and validity of the prediction; ease and convenience of the protocol; generalized application to a broad population. Accuracy and valicity of a prediction equation should be evaluated by the correlation coefficient and the SEE in both the EXP and CV group and by investigating systematic differences between predicted and measured $\mathrm{VO}_{2 \max }$. Fiteld tests requiring maximal exertion resulted in good to very good correlations $(5,15)$. Cooper (5) reported a correlation of 0.90 between the 12-min performance test and measured $V_{\text {max, }}$ but he didn't provide information about the SEE and no cross-validation was included. Attempts of other authors to validate this field test resulted in correlations ranging from $R=0.13$ to $R=$ 0.90 (12). Various sub-maximal tests have yielded correlations ranging from $R=0.46$ to $R=0.95$ (12). Many of these tests do not present cross-validation results $(7,11,20)$, require sophisticated laboratory equipment $(4,7,20)$ and many do not provide a measure of the SEE $(6,10,18,21)$. When cross-validating a prediction equation, the use of SEE is preferred over correlation coefficients and mean values of measured and predicted should be comparable (17). George et al. found a SEE of $6.5 \%$ and $7.5 \%$ for at submaximal treadmill jogging test (8) and a 1 -mile track jog (9) respectively, both in fit college-age individuals. Kline et al. (12) reported an SEE of $12.6 \%$ in the CV group for a one-mile track walk. McNaughton et al. (21) validated the Canadian (14) and the European (16) version of the $20 \mathrm{-m}$ shuttle run test in schoolchildren and found an underestimation of $\mathrm{VO}_{2 \text { max }}$ of $7.7 \%$ for the European and an overestimation of $11.4 \%$ for the Canadian version. No estimate of the SEE was provided. Weyand et al. (24) developed a fitness index based on footuground contact times and heart rate during treadmill rumning. The theoretical model of their fitness index is probably the most closely related to our fitness index, although they did not use a field setting. They found a correlation of $\mathrm{R}=0.84$ between predicted and measured $\mathrm{VO}_{2 \text { max }}$ in the $\mathrm{CV}$ group but no SEE was provided. They did find a systematic difference between measured and predicted of $8.3 \%(24)$. Our equation 1 resulted in a SEE of $10.7 \%$ but there was a systematic difference between measured and predicted $\mathrm{VO}_{2 \mathrm{max}}$, whereas equation2 resulted in a slightly higher SEE $(14,1 \%)$ but no difference between measured and predicted. In addition, a Bland Alman plot showed a positive correlation in CVI but not in CV2. The higher SEE in CV2 was mainly explained by two outliers, one whose $\mathrm{VO}_{2 \mathrm{max}}$ was highly underestimated with the prediction equation and one whose $\mathrm{VO}_{2 \text { max }}$ was highly overestimated. Without these outliers, the SEE in CV2 was $338 \mathrm{ml} \cdot \mathrm{min}^{\prime}$ or $10.9 \%$. The overestimation was in a subject using 12 -agonists, but only as acrosols to treat chronic aspecific respiratory affection (CARA), which was unlikely to affect heart rate. The underestimation was in a subject very fit $\left(53.1 \mathrm{~m} / \cdot \mathrm{kg}^{-1} \cdot \mathrm{min}^{-1}\right)$ and able to generate a very high maximal heart rate $(193 \mathrm{bpm})$ for his age (4! y).

Regarding ease and convenience of the protocol, our finess measure is very attractive for personal use as well as for research purposes. Since the monitors are worn during dally life, no specific protocol is required. The accelerometer was developed to be unobtrusive, in order not to interfere with the nomal daily life activity patien. Given its small size and weight, it was not experienced as bothering by any of the subjects. The heart rate monitor is sometimes more obtrusive when worn for longer periods but most subjects enjoyed being able to monitor their own heart rate during different activities and considered it rather interesting and pleasant. Combining both the accelerometer and the heart rate monitor into one device would further improve wearing comfort. 
Application for a broad population has to be evaluated on different considerations. Validity in different study populations than used in this study has yet to be investigated. The major advantage however is the lack of need for a specific protocol and that no maximal exertion is needed, which makes it useful for subjects with low functional capacity. Total cost of a combined accelerometer heart rate monitor should also be considered.

It is to our knowledge the first study attempting to develop a finess index without a specific protocol needed, that can be used in daily life, is unobtrusive and that is sufficiently accurate. Care should be taken when applying the formula on subjects with a different activity pattern or activity level than used in the current study. Further research should focus on testing the fitness index in larger and different study populations and on the ability to track changes in fitness over time. Further technical improvement, such as conbining both monitors into one device could improve wearing comfort and might result in even higher accuracy. 
1. Astrand, P. O and I. Ryhming. A nomogram for calculation of aerobic capacity (physical fitness) from pulse rate during sub-maximal work. I Appl Physiol. $7: 218-221,1954$.

2. Blair, S. N., Y. Cheng, and J. S. Holder. Is physical activity or physical fitmess more important in defining health benefits? Med Sci Sports Exerc. 33:5379.399; discussion $5419-320,2001$.

3. Bland, J. M. and D. G. Altman. Statistical methods for assessing agreement between two methods of clinical measurement. Lancet. 1:307-310., 1986.

4. Bonen, A., V. H. Heyward, K. J. Cureton, R. A. Boileau, and B. H. Massey. Prediction of maximal oxygen uptake in boys, ages 7.15 years. Med Sei Sports. 11:24-29, 1979.

5. Cooper, K. H. A means of assessing maximal oxygen intake. Correlation between field and treadmill testing. Jama. 203:201-204, 1,968.

6. Doolittle, T. L. and R. Bigbee. The twelve-minute runwalk: a test of cardiorespiratory fitness of adolescent boys. Res Q. 39:491-495, 1968.

7. Fox, E. L. A simple, accurate technique for predicting maximal aerobic power. $\mathrm{J}$ Appl Physiol. 35:914-916, 1973.

8. George, J. D., P. R. Vehrs, P. E. Allsen, G. W. Fellingham, and A. G. Fisher. Development of a submaximal treadmill jogging test for fit college-aged individuals. Med Sci Sports Exerc. 25:643-647, 1993.

9. George, J. D., P. R. Vehrs, P. E. Allsen, G. W. Fellingham, and A. G. Fisher. $\mathrm{VO}_{2 \max }$ estimation from a submaximal 1 -mile track jog for fit college-age individuals. Med Sci Sports Exerc. 25:401-406, 1993.

10. Getchell, L. H., D. Kirkendall, and G. Robbins. Prediction of maximal oxygen uptake in young adult women joggers. Res Q. 48:61-67, 1977.

11. Jette, M., J. Campbell, J. Mongeon, and R. Routhier. The Canadian Hone Finess Test as a predictor for aerobic capacity. Can Med Assoc J. 1 14:680 682, 1976.

12. Kline, G. M., J. P. Porcari, R. Hintemeister, P. S. Freedson, A. Ward, R. F. McCarron, J. Ross, and J. M. Rippe. Estimation of VO ras from a one-mile track walk, gender, age, and body weight. Med Sei Sports Exerc. 19:253-259, 1987.

13. Kuipers, H., F. T. Verstappen, H. A. Keizer, P. Geurten, and G. van Kranenburg. Variability of aerobic perfomance in the laboratory and its physiologic correlates. Int J Sports Med. 6:197-201., 1985.

14. Leger, L, and R. Boucher. An indirect continuous ruming multistage licald test: the Universite de Montreal track test. Can J Appl Sport Sci. 5:77-84, 1980.

15. Leger, L. A. and J. Lambert. A maximal multistage $20 \mathrm{~m}$ shutte run test to predict VOn max. Eur I Appl Physiol Occup Physiol. 49:1-12, 1982.

16. Leger, L. A., D. Mercier, C. Gadotry, and J. Lambert. The multistage 20 metre shuttle run test for aerobic fitness. J Sports Sci. 6:93-101, 1988. 
17. Lohman, T. G. Skinfolds and body density and their relation to body fatness: a review. Hum Biol. 53:181-225, 1981.

18. Maksud, M. G. and K. D. Couts. Application of the Cooper twelve-minute rumwalk tegt to young males. Res Q. 42:54-59, 1971.

19. Margaria, $\mathbb{R}$, P. Aghemo, and $\mathrm{E}$. Rovell. Indirect determination of maximal $\mathrm{O}_{2}$ consumption in man. J Appl Physiol. 20:1070-1073, 1965.

20. Mastropaolo, J. A. Prediction of maximal O 2 consumption in middle-aged men by multiple regression. Med Sci Sports. 2:124-127, 1970.

21. Naughton, L. M., D. Cooley, V. Kearney, and S. Smith. A comparison of two different shuttle run tests for the estimation of $\mathrm{VO}_{2 \text { max. }} J$ Sports Med Phys fitmess. $36: 85-89,1996$.

22. Paliczka, V. J., A. K. Nichols, and C. A. Boreham. A multi-stage shuttle run as a predictor of running performance and maximal oxygen uptake in adults. Br Sports Med. 21:163 165, 1987.

23. Pasqui, G. and K. R. Westerterp. Accelerometry and heart rate monitoring as a neasure of physical limes: proof of concept., submitted.

24. Weyand, P. G., M. Kelly, T. Blackadar, J. C. Darley, S. R. Oliver, N. E. Ohlenbusch, S. W. Joffe, and R. W. Hoyt. Ambulatory estimates of maximal aerobic power from foot -ground contact times and heart rates in running humans. IAppl Physiol. 91:451-458, 2001.

25. Williams, P. T. Physical fitness and activity as separate heart disease risk factors: a meta-analysis. Med Sci Sports Exerc. 33:754-761., 2001. 
Chapter 7

\section{Daily physical activity in patients with heart failure before and after cardiac resynchronisation therapy}

Guy Plasqui, Corstiaan J. Storm and Klaas R. Westerterp

Submitted for publication 


\begin{abstract}
Objective Reduced physical activity or exercise capacity is related to a poor prognosis in patients with heart failure. This study investigated the effect of cardac resynchronisation therapy (CRT) on submaximal exercise capacity and daily physical actiwity.

Methods Subjects were 11 patients with heart failure, all categorized according to the NYHA (New York Heart Association) as class III and JV. 6 patients were measured before and after implantation of a pacing device. The other 5 patients already had a pacing device and were measured when the device was switched on and when it was switched off. Sub-maximal exercise capacity was measured with the 6-min walk test. Daily physical activity was measured with the Tri-axial accelerometer for movement registration (Tracmor), which was won for one week.

Results The distance covered in the 6-min walk test was significantly higher with the pacing device switched on than with the pacing device switched off (434 vs $383 \mathrm{~m}$; p 00.0001 ) whereas total daily physical activity was not different between the two conditions (225 vs $195 \mathrm{kcounts} / \mathrm{day} ; \mathrm{p}=0.13$ ). Daily physical activity was positively related with the 6 min walk test with the pacing device switched off $(R=0.78 ; p<0.01)$ but not with the device switched on $(R=0.26 ; p=0.47)$. On average, patients spent $97.6 \%$ of their time in low intensity, $2.1 \%$ in moderate intensity and $0.3 \%$ in high intensity activities.
\end{abstract}

Conclusion Although sub-maximal exercise capacity improved, daily physical activity remained unchanged. 


\section{Introduction}

Heart failure is a serious condition with a poor prognosis and high mortality rate. The prevalence in a random population sample of men was $0.6 \%, 2.8 \%$ and $6.2 \%$ in the age groups 55-64, 65-74 and 75-79 respectively (23). Patients suffering from heart failure have reduced functional capacities and are restricted in the performance of every day acrivities $(11,14,20)$. Reduced functional capacity in this population has been shown to be associated with a poor prognosis $(2,15,22)$. Functional exercise capacity is often assessed during laboratory exercise tests or sub-maximal exercise tests such as the 6min walk test $(3,11,12,14,17)$. The advantage of a simple walking test, such as the 6walk test, is that it is sub-maximal, safe and ease to administer. Especially in patients of high age and underlying disease, such as heart failure patients, the 6-min walk test can be a good alternative for bicycle or treadmill testing (8). The question remains however whether such a test also reflects the ability to perform daily activities or the daily activity level. It can be assumed that a measure of the daily activity level is a better reflection of daily functionality and quality of life. Furthermore, Walsh et al. showed that symptom-limited treadmill exercise capacity using 2 different protocols did not predict survival, whereas reduced weekly pedometer scores were strong predictors of death (22).

Accelerometers are able to provide a measure of the total anount as well as the frequency, intensity and duration of physical activity and are therefore suitable to provide an estimate of the daily activity level. To our knowledge, onlly few studies used

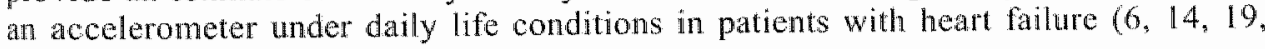
21)].

The aim of this study was to test whether cardiac resynchronisation therapy (CRT) in patients with heart failure improves exercise capacity, and if so, whether these changes also result in changes in total daily activity, and thus to which extent the 6-min walk test reflects daily activity. Furthermore, accelerometry was used to describe the amount of time patients spent in different activity intensities.

\section{Methods}

\section{Subjects and protocol}

Subjects were 11 patients with heart failure, all classified according to the New York Heart Association (NYHA) as class III or IV. They were recuiled from the 'Zuiderziekenhuis' in Rotterdam. The Netherlands. Patients were diagnosed as having heart failure with complete left bundle branch block. Subject characteristics are summarized in Table 1.

Daily physical activity as measured with accelerometry and sub-maximal exercise capacity as measured with the 6 -min walk test was assessed twice in all patients. Six patients were measured before and after CRT. There were at least four weeks between implantation of the pacing device and the second measurement. The other 5 subjects already had a pacing device and were measured once with the device switched on and once with the device switched off. All patients will be combined for the analyses. 
Table 1: Subject characteristics

\begin{tabular}{lcc}
\hline & Patients & Elderly \\
\hline N(male/female) & $11(10 / 1)$ & $28(14 / 14)$ \\
Age $(y)$ & $77 \pm 8$ & $60 \pm 4$ \\
Body mass $(\mathrm{kg})$ & $77 \pm 7$ & $76 \pm 11$ \\
Height $(\mathrm{m})$ & $1.76 \pm 0.04$ & $1.70 \pm 0.09$ \\
BMI $\left(\mathrm{kg} / \mathrm{m}^{2}\right)$ & $24.8 \pm 1.7$ & $26.5 \pm 3.4$ \\
\hline
\end{tabular}

* Data adopted from Mejer et al. (9).

\section{Daily physical activity}

The tri-axial accelcrometer for movement registration (Tracmor; Philips Research, Eindhoven, The Netherlands) was worn for seven consecutive days, during waking hours, except during water activities. The Tracmor contains three uni-axial piezoelectric accelerometers, measures $7.2 \times 2.6 \times 0.7 \mathrm{~cm}$ and weighs $22 \mathrm{~g}$ (battery included). It is attached to the lower back by means of an elastic belt, measuring accelerations in the antero-posterior, medio-lateral and longitudinal axis of the trunk. The Tracmor has been proven valid for the measurement of total daily physical activity by comparison with doubly labeled water (16).

Different activity intensity categories were defined by dividing the range of Tracmor output into three equal sections. Low intensity activity was defined as tracmor output < 878 counts $\mathrm{min}^{-1}$, moderate intensity was defined as Tracmor output between 878 and 1731 countsmin and high intensily was defined as Tracmor output $>1731$ counts mun I. The percentage of time spent in each intensity category (\%time low, \%time moderate and \%time high) was calculated as the time spent on a certain intensity divided by the total activity time multiplied by 100 .

The percentage of time spent in different categories was compared with a group of healthy elderly (table 1), described in another study (9).

\section{6-min walk tes:}

The 6-min walk test was used as a measure of sub-maximal exercise capacity (5). The patients were instructed to walk up and down a hallway of $60 \mathrm{~m}$ and to cover as much distance as possible within 6 min. There was an instructor providing oral chcouragement. Patients were dressed in normal indoor clothing

\section{Siatisticis}

All variables were lested for normal distribution by the Shapiro-Wilk test. When variables were normally distributed, the paired student's t-test was used to compare both conditions, when variables were not normally distributed, the Wilcoxon Signed Rank test was used. The relation between total daily activity and the 6 -min walk test was tested by simple linear regression analysis. All analyses were done with SPSS 10.0 for Macintosh (SPSS Ino. Chicago, Illinois). The statistical significance level was set at $\mathrm{p}<0.05$.

\section{Results}

All variables were normally distributed, except for the percentage of time spent in high 
With the pacing device switched on, patients significantly $(\mathrm{p}<0.0001)$ improved in the distance covered in the 6 -min walk test (table 2). Total daily activity counts were not different with the pacing device switched on of off $(p=0.13$ ), not was there any change in the percentage of time spent in low $(p=0.08)$, moderate $(p=0.12)$ and high $(p=0.12)$ intensity activity (table 2 ).

There was a significant relation between total activity counts and the distance covered in the 6-min walk test with the pacing device switched off $(p<0.01)$ but not with the device switched on $(p=0.47)$ (Figure 1$)$.

Table 2: Distance walked in the 6-min walk test, total daily activity and \%time spent in different intensity activities with the pacemaker switched off and on. Results are presented as mean $\mathbb{S} \mathrm{SD}$.

\begin{tabular}{lcc}
\hline & pacemaker switched off & pacemaker switched on \\
\hline 6-min walk distance $(\mathrm{m})$ & $383 \pm 78$ & $434 \pm 87$ * \\
Daily activity (kcounts/day) & $195 \pm 50$ & $225 \pm 64$ \\
\%time low & $98.3 \pm 1.2$ & $96.9 \pm 3.0$ \\
$\%$ time moderate & $1.5 \pm 1.0$ & $2.6 \pm 2.5$ \\
$\%$ time high & $0.2 \pm 0.2$ & $0.5 \pm 0.7$
\end{tabular}

$* \mathrm{p}<0.0001$

$\%$ time low: the percentage of time spent in low intensity activity

$\%$ time mod: the percentage of time spent in moderate intensity activity

$\%$ time high: the percentage of time spent in high intensity activity

Figure 2 shows the percentage of time spent in different activity intensity categories. For comparison, data adopted from another study with healthy adults (9), are displayed as well. Patients spend almost all their time in low intensity activities $(97.6 \%)$ and only $2.1 \%$ in moderate and $0.3 \%$ in high intensity activities, while healthy elderly spend $82 \%$ in low, $15 \%$ in moderate and $4 \%$ in high intensity activities. 
A)

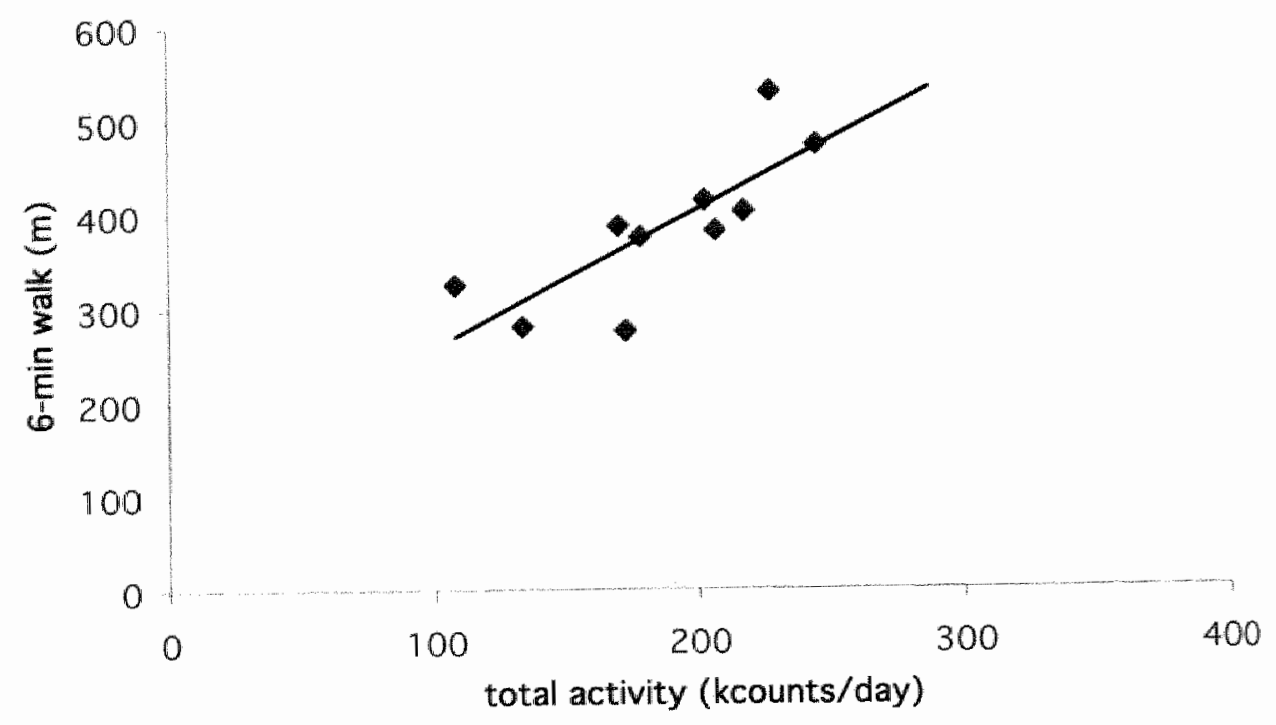

B)

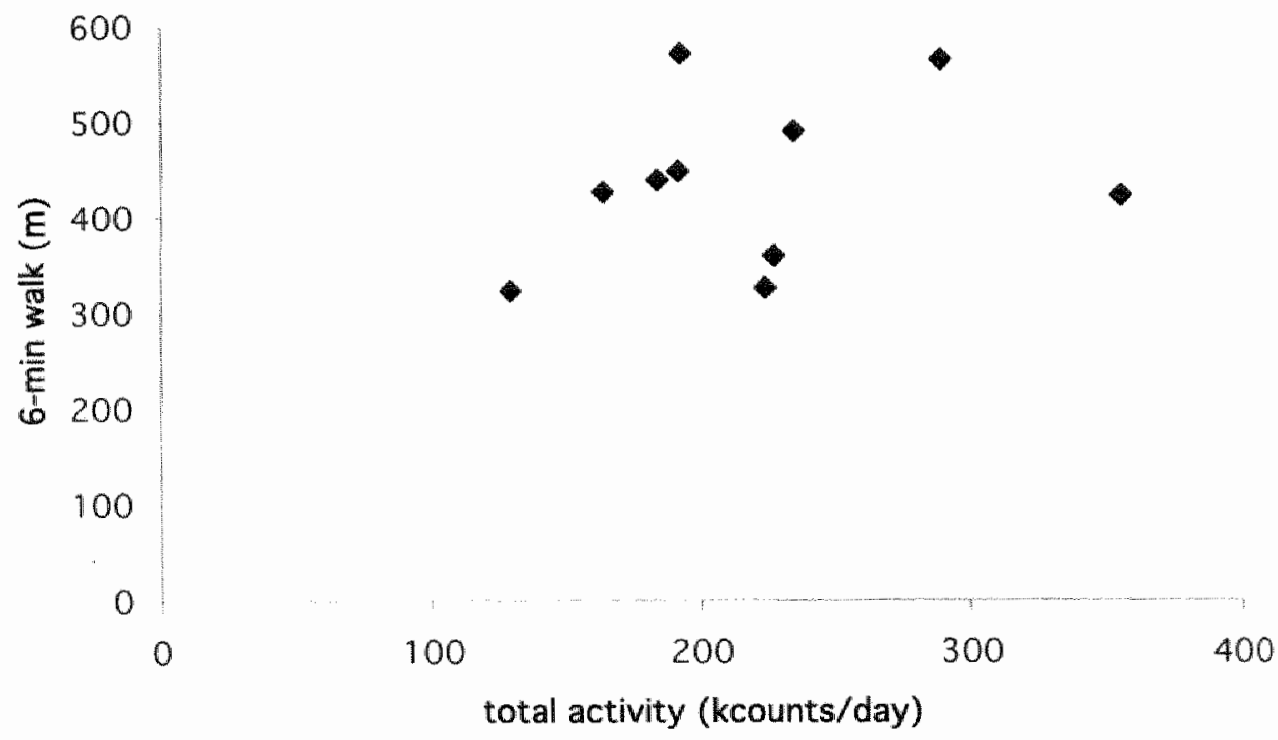

Figure 1: Relation between tolal activity counts as measured with the tri-axial accelerometer and distance walked in the 6-min walk test $)$ with the pacing device switched off and $\mathbf{B}$ ) with the pacing device switched on. 


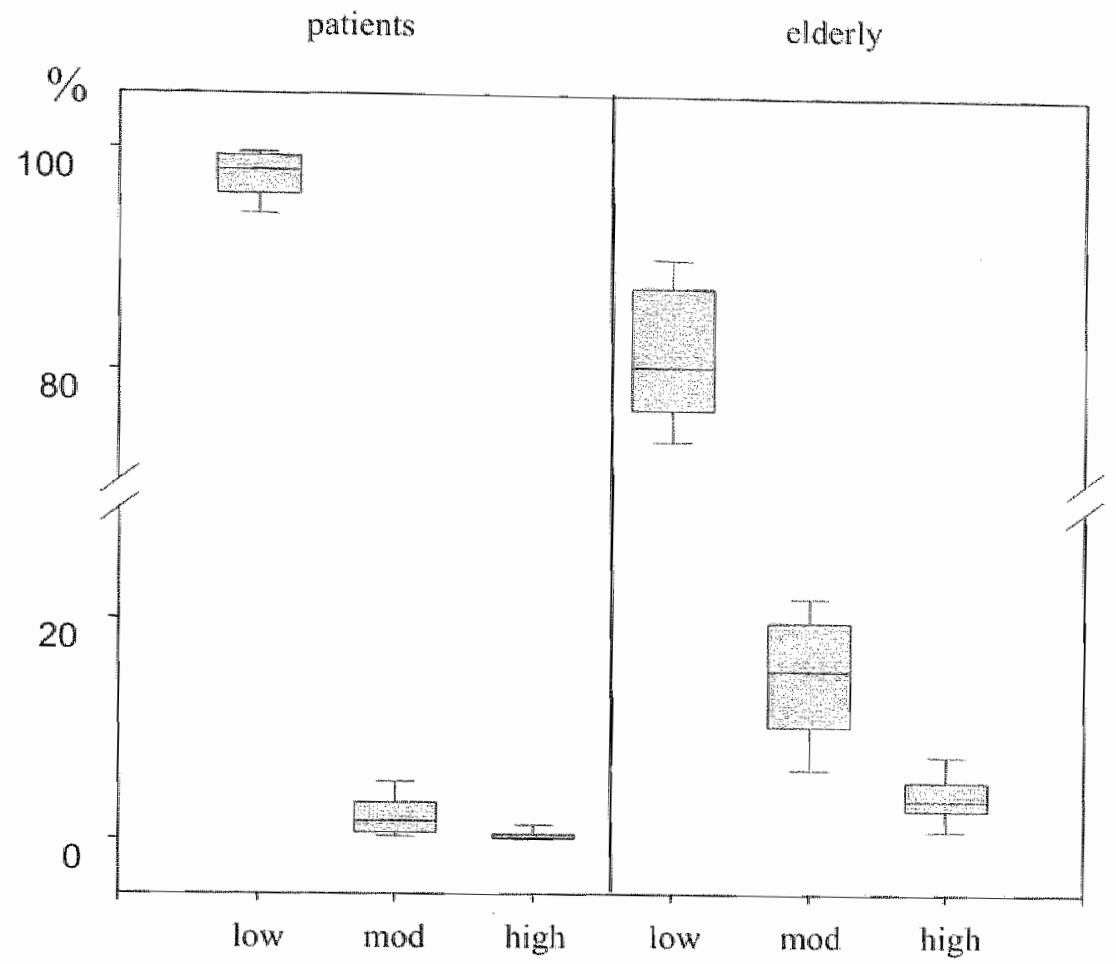

Figure 2: Percentage of time spent in different intensity categories. Left: patients from this study, values are the mean values of both measurements (with and without pacemaker); right: healthy elderly, adopted from Meijer et al, (9). Low: \% tine spent in low intensity activity; mod: \% time spent in moderate intensity activity, high: \% time spent in high intensity activity.

\section{Discussion}

Although patients improved significanty in sub-maximal exercise capacity with the pacing device switched on, no increase in dally physical activity was found. Daily physical activity was correlated with exercise capacity with the pacing device switched on but not with the device switched off.

Laboratory based bicycle or ergometer exercise tests are often used to investigate the effect of an intervention on functional capacity in patients with heari failure $(1,3,13$, 14). Because of the artificial nature, high costs and required exertion of these tests, other simple walking tests, such as the 6 -min walk test $(5,8,18)$ or self-paced 100 -m corridor walk $(1,4,7)$, have been developed to estimate a patient's functional capacily. These tests are sub-maximal and are more likely to reflect a subject's normal daily activity than ergometer tests. However, these tests are sill perfomed under controlled conditions and do not necessarily relate to nomal dally activity. To address this 
question, some studies included pedometers as a measure of dally physical activity. Cowley at. (4) found an improvement in treadmill exercise tests and the $100 \mathrm{~m}$ corridor walk after 5 weeks with hosequinan treament but total pedometer score remained unchanged. Houghton et al. (7) found no correlation between a treadmill exercise test and a quality of life questionnaire score, whereas the pedometer score was related with quality of life. Neither of these two studies found a correlation between the pedometer score and the treadmill exercise or $100-\mathrm{m}$ walk test. These results largely agree with the findings of this study, where an increase in covered distance in the 6-min walk test was not accompanied by an increased daily physical activity. However, we did find a correlation between total activity counts and the 6 -min walk test, but only with the pacing device switched off. This means that habitual physical activity relates to submaximal exercise performance but that an increase in this exercise capacity, due to an intervention such als CRT, does not necessarily result in increased physical activity. These findings are relevant since Walsh et al. (22) showed that symptom-limited treadmill exercise capacity did not predict survival whereas reduced weekly pedometer scores were strong predictors of death.

Only few studies used accelerometers under daily life conditions in patients with heart failure $(6,14,19,21)$. Accelerometers are electronic devices and in contrast with mechanical pedometers, they do not only provide a measure of total physical activity (in case of pedometers total steps), but also give information about the frequency, intensity and duration of physical activity. Gottleb et al. (6) measured peak oxygen consumption, distance covered during a 6min walk, doubly labelled water measured total energy expenditure, physical activity wh the Caltrac accelerometer and quality of life before and after exercise training in patients with heart failure. Athough peak oxygen and distance covered in the 6-min walk increased, none of the other variables changed. This is in agreement with a study of Mejier et al. (10) who found no influence on total daily activity by an exercise program of moderate intensity in healthy elderly subjects. These results suppont the use of accelerometers instead of or in addition to laboratory tests to evaluate the ffect of a certain intervention. To gain more insight in the activity pattern of patients, we used the Tracmor to differentiate between time spent in different activity levels. Figure 2 shows that $97.6 \%$ of the total activity time is spent in low intensity activities and that there was no positive effect of the CRT on activity behavior. In comparison, healthy elderly spent $82 \%$ of their time in low intensity activity. The Tracmor used for these henthy elderly was an earlier version of the one used in this study, which complicates direct comparison of total activity. Therefore, the cut-off points used to divide the Tracmor counts in different intensity categories were also different. Althougl the cut-off points were determined in a similar way, care should be laken in comparing these results. The data on healthy elderly were merely shown to have some idea of the activity patten of elderly subjects and statistical analyses to compare both groups were therefore deliberately not done. Furthermore, the elderly were on average 16 years younger than the patients in this study, so it is probably a combination of both the age difference and the heart failure that caused the difference in time spent in different categories.

The 6-min walk test is a commonly used test to measure functional capacity in heart failure patients $(3,12,17)$. Wu et al. (24) investigated the learning effect that occurs with multiple administration and found an increase in walking distance between the 
second and first walk of $4.07 \%$. Since the increase in walking distance in our patient group was on average $14 \%$, it is unlikely that this could be totally atributed to a leaning effect.

Due to the low number of subjects, this study has low statistical power. To have a more valid idea of the activity pattern in patients with heart falure, and possible changes in activity due to CRT, a larger study population would be appropriate as well as the inclusion of a control group of comparable age. Still we believe to have shown that accelerometers could be useful tools to assess daily physical activity in patients with heart failure since they provide a measure of habitual activity and might therefore be better predictors of prognosis than single exercise tests. They are also superior to pedometers since they are able to store minute by minute data over periods of several weeks thereby providing a measuire of total as well as frequency, duration and intensity of physical activity. Detailed information about activity behavior is essential to develop intervention strategies as well as to evaluate the effect of certain interventions. Future research should focus on how accelerometer output relates to quality of life and longterm prognosis. 
1. Andrews, R., A. Charlesworth, A. Evans, and A. J. Cowley. A double-blind, cross-over comparison of the effects of a loop diuretic and a dopamine receptor agonist as first line therapy in patients with mild congestive heart failure. Eur Heart J. 18:852-857, 1997.

2. Cohn, J. N. and T. S. Rector. Prognosis of congestive heart failure and predictors of mortality. Am a Cardiol. 62:25A-30A, 1988.

3. Corwera-Tindel, T., L. V. Doering, M. A. Woo, S. Khan, and K. Dracup. Effects of a lome waking exercise program on functional status and symptoms in heart failure. Am Heart J. 147:339-346, 2004.

4. Cowley, A. J., L. Fullwood, K. Stainer, and J. R. Hampton. Exercise tolerance in patients with heart failure--how should it be measured? Eur Heart J. 12:50-54, 1991.

5. Enright, P. L. The six-minute walk test. Respir Care. 48:783-785, 2003.

6. Gottieb, S. S., M. L. Fisher, R. Freudenberger, S. Robinson, G. Zietowski, L. Alves, C. Krichten, $\mathrm{P}$. Vaikevicus, and R. McCarter. Effects of exercise training on peak performance and quality of life in congestive heart failure patients. J Card Fail. 5:188-194, 1999.

7. Houghton, A. R., M. Harrison, A. J. Cowley, and J. R. Hampton. Assessing exercise capacity, quality of life and haemodynamics in theart failure: do the tests tell us the same thing? Eur I Heart Fail. 4:289-295, 2002.

8. Langenfeld, H., B. Schneider, W. Grimm, M. Beer, M. Knoche, G. Riegger, and $\mathbb{K}$. Kochsiek. The six-minute walk-an adequate exercise test for pacemaker patients? Pacing Clin Electrophysiol. 13:1761-1765, 1990.

9. Mejjer, E. P., A. H. Goris, L. Wouters, and K. R. Westerterp. Plyysical inactivity as a determinant of the physical activity level in the elderly. Int $J$ Obes Relat Metab Disord 25:935-939, 2001.

10. Mcijer, E. P. K. R. Westerterp, and F. T. J. Verstappen Effect of exercise training on total daily physical activity in elderly humans. Eur.J.Appl.physiol. 80:16-21, 1999.

11. Mezzani, A., U. Corra, C. Baroffio, F. Bosimini, and P. Giannzzi. Habitual activines and peak aerobic capacily in patients with asymptomatic and symplomatic left ventriculat dysfunction. Chest. 117:1291-1299, 2000.

12. Morales, F. J., T. Montemayor, and A. Martinez. Shuttle versus six-minute walk test in the prediction of outcome in chronic heart fallure. Int $\mathbb{J}$ Cardiol. 76:101105,2000 .

13. Oka, R. K., T. De Marco, W. L. Haskell, E. Botvinick, M. W. Dae, K. Bollen, and K. Chatterjee. Impact of a home-based walking and resistance training program on quality of tife in patients with heart failure. Am J Cardiol. $85: 365-369,2000$. 
14. Oka, R. K., N. A. Stotts, M. W. Dae, W. L. Haskell, and S. R. Gortner. Daily physical activity levels in congestive heart failure. Am I Cardiol. 71:921-925, 1993.

15. Pillote, L., J. Silberberg, R. Lisbona, and A. Snideman. Prognosis in patients with low left ventricular ejection fraction after myocardial infarction. Importance of exercise capacity. Circulation. 80:1636-1641, 1989.

16. Plasqui, G., A. M. C. P. Joosen, A. D. Kester, A. H. C. Goris, and K. R. Westerterp. Measuring free-living energy expenditure and physical activity with tri-axial accelerometry..submitted.

17. Rostagno, C., G. Olivo, M. Comeglio, V. Boddi, M. Banchelli, G. Calanti, and G. F. Gensini. Prognostic value of 6-minute walk corridor test in patients with mild to moderate heart failure: comparison with other methods of functional evaluation. Eur I Heart Fail. 5:247-252, 2003.

18. Rozkovec, A., M. Papouchado, M. A. James, A. H. Kendrick, L. M. Clarke, and J. $R$. Rees. The relationship of symptoms to performance in paced patients with breathlessness. Eur Heart J. 10:63-69, 1989.

19. Skotzko, C. E., C. Krichten, G. Zietowski, L. Alves, R. Freudenberger, S. Robinson, M. Fisher, and S. S. Gottlieb. Depression is common and precludes accurate assessment of functional status in elderly patients with congestive heart failure. J Card Fail. 6:300-305, 2000.

20. Toth, M. J., S. S. Gottlieb, M. I. Goran, M. L. Fisher, and E. T. Poehlman. Daily energy expenditure in free-liwing heart fallure patients. Am I Physiol. 272:E469$475,1997$.

21. van den Berg-Emons, R., A. Balk, H. Bussmann, and H. Stam. Does aerobic training lead to a more active lifestyle and improved quality of life in patients with chronic heart failure? Eur J Heart Fail. 6:95-100, 2004.

22. Walsh, J. T., A. Charlesworth, R. Andrews, M. Hawkins, and A. I. Cowley. Relation of daily activity levels in patients with chronic heart fallute lo long-tem prognosis. Am J Cardiol. 79:1364-1369, 1997.

23. Wilhelmsen, L., A. Rosengren, H. Eriksson, and $G$. Lappas. Heart failure in the general population of men--morbidity, risk factors and prognosis. IIntern Med. $249: 253-261,2001$.

24. Wu, G., B. Sanderson, and V. Bitner. The 6-minute walk test: how important is the leaming effect? Am Heart J. 146:129-133, 2003. 
Chapter 8 


\section{Discussion}

The main emphasis of this thesis was on how physical activity, energy expenditure and physical finess relate to each other, on how they can be assessed under daily life conditions and on how season can affect one or more of these variables. Given the importance of physical activity (PA) and other components of total energy expenditure (TEE) in the maintenance of energy balance, and other health parameters, factors influencing these components should be addressed. First the impact of season on sleeping metabolic rate (SMR), activity related energy expenditure (AEE) and TEE was investigated. If these components change with the time of year, this could influence many research outcomes regarding $P A$ and health. Accurate and validated techniques are needed to quantify and qualify $\mathrm{PA}$ in daily life. A new version of the Tri-axial accelerometer for movement registration (Tracmor) was validated against doubly labelled water (DLW) to determine its ability to predict free-wiving energy expenditure. Another frequently used measure in health and sports related research is physical fitness, usually defined as $V O_{2 m i x}$ or maximal oxygen uptake. The am was to develop a new fitness index, based on the combined use of accelerometry and heart rate monitoring as a measure of physical fitness. Finally, these techniques were used in a clinical setting to test the benefit of pacemaker implantation on the activity level of patients with heart failure.

\section{Seasonal variation in energy expenditure}

Energy balance is only achieved when on the longer term, i.e. weeks to months, energy intake (EI) matches energy expenditure (EE). When there is an imbalance between EI and $E \mathbb{E}$ the result will be a change in body energy stores and thus body mass. In. developing countries, seasonal variations in body mass were observed in both men and women (17). These were the consequence of the lack of response of EI, because of food shortage, to the change in EE due to high physical activity during harvest season. Interestingly, seasonal changes in body mass were also observed in industrialized countries, where a varied food supply is guaranteed over the year and for most people work related activity is independent of season (23). Since there is no accurate method avatuble to assess daily life EI, this research focused on the different components of EE. As described in chapter 2, SMR showed a significant sinusoidal pattern over the year with a pealk in winter season and a minumum in summer season. This within subject variation was present for both men and women and could partly be explained by ambient temperature. Although the measurement of SMR was performed each time in a temperature controlled room at $20 \pm 1^{\circ} \mathrm{C}$, there seemed to be a long-term effect of ambient temperature on SMR. As it was suggested before, that seasonal changes in BMR might be due to chunges in thyroid activity (18), measurements of thyroid hormones were included as well. Although there was a seasonal variation in free $\mathrm{T} 4 \mathrm{in}$ men, and total T4 explained $8 \%$ of the within-subject variation in SMR, these changes were unrelated with the seasonal variation in SMR. The significant increase in SMR in winter season did not result in an increase in TEE, and as a consequence. AEE was significantly lower in winter (chapter 3). The drop in AEE was confirmed by a drop in the pliysical activity level (PAL). As it is especially moderate intensity physical activity that is positively related with the PAL (28), it was hypothesized that it is especially this type of activity that is decreased in winter. A study of Mathews et al. (14) supports this 
hypothesis but since in the current study, no data on accelerometry was available, there was no evidence for changes in time spent in different intensity categories.

More research is needed on how season can influence EE components and what the consequences are for health. Hormonal changes, possibly triggered by changes in environmental temperature or day length, could directy or indireetly affect SMR. With regard to $\mathrm{PA}$, more insight is needed in how climate changes activity patterns. The outcome of PA and health related research might be highly dependant on the time of year the measurements are performed. Furthermore, the higher incidence of cardiovascular disease and mortality as observed in winter season (4) might be partly attributable to decreased $P A$ levels. If so, intervention could aim at keeping a moderate activity level throughout the year to prevent adverse health effects.

\section{Assessing free-living energy expenditure}

The studies described above (chapter 2 and 3) dealt with the impact of season as an environmental factor on energy expenditure components. If data on activity patterns, as can be measured with accelerometry, had been available, it would have provided more insight in how climatic features can influence behaviour. The advantage of accelerometry is that it provides information about the total amount, the frequency, the intensity and the duration of physical activity in daily life. The advantage of DLW is that it is the only technique available to accurately measure energy expenditure in daily life over longer periods of time. Ideally, the combination of both methods should be used to gain further insight in the level of physical activity. Ekelund et al. (5) observed that, after adjusting for differences in body composition (FM, FFM or body weighi). there was no significant difference in TEE or AEE beween obese and lean adolescents. However, the total activity counts, measured with accelerometry, as well as the amount of time spent in moderate and high intensity activity was significantly lower in the obese subjects. The implication is that, even though the DLW derived EE measures were corrected for differences in body size in a statistically correct way, data from DLW alone would have led to the wrong conclusion that obese and lean subjects were equally active. In fact, the conclusion was that body movement is reduced in the obese and that physical activity is not identical with the energy costs of activity (5). However, given the high cost of DLW, the combination of DLW with accelerometry is not always possible and is not applicable for large study populations. The study described in chapter 4 therefore aimed at developing prediction equations, based on accelerometry and subject characteristics to predict DLW derived $\mathbb{E E}$ measures. In a multiple regression analysis with data on SMR or body composition, and accelerometer counts, the explained variation in TEE was $90 \%$ with a SEE of $6.4 \%$ when SMR was used and $6.7 \%$ when body composition was used. When no data on SMR or body composition is available. TEE can be predicted for $83 \%$ (SEE $=8.7 \%$ ) from body mass, theight, age and activity counts. Table 1 summarizes some of the observed correlations between DL.W derived energy expenditure measures and various field techniques to assess physical activity. One has to keep in mind however, that comparison between technicues, based on correlations only, is complicated. Firstly, when multiple regression is used with subject's characteristics and activity counts, many studies don't mention partial correlations for activity counts or the increase in $R^{2}$ caused by the activity counts. For example, in the study of Rafamantanantsoa et al. (19) the accelerometer predicted TEE for $69 \%(\mathrm{R}=0.83$, Table 1$)$ while the calculation of TEE from the accelcrometer was 
based on age, sex, height, body mass and activity counts and no data on the contribution of the activity counts was available. In comparison, in the current study (chapter 4), age, body mass and height alone already explained $64 \%$ of the variation in TEE. Secondly, studies based on heart rate monitoring require individual calibration with an incremental exercise protocol, to determine the relation between heart rate and $\mathrm{O}_{2}$-consumption. Then, inter-individual differences in $O_{2}-$ consumption for a given heart rate are already accounted for. Only 2 out of many studies based on heart rate are presented in Table :, since most studies do not present a correlation coefficient but only mean differences (tSD) between both techniques. These differences range from $-5 \%( \pm 11 \%)$ to $+17 \%$ $( \pm 13 \%)(27)$. Thirdly, methods based on questionnaires often use subjects' body mass and MET-equivalents for different activities to convert the activities into energy expenditure. Indeed, in order to compare EE between subjects, a correction for body size has to be made, but this also means that the reported correlations are party atributable to body mass as a common factor in both, the dependent and independent variable. All these factors complicate the comparison between methods. It is more appropriate to provide as much information as possible, i.e. correlations, SEE, mean differences, Bland Altman plotting. For example, in the study of Washburn et al. (26) (Table 1), there was no significant difference in $\mathrm{AEE}$ as measured with the Stanford Seven-Day Physical Activity Recall (7D-PAR) or DLW. However, the 7D-PAR underestimated AEE with $-8 \pm 56 \%$, the two measures were not significantly correlated $(\mathrm{R}=0.12)$ and the Bland-Altman plot showed that the magnitude of underestimation increased with increasing levels of PA. AEE was calculated by removing measured RMR from DLW measured TEE (TEEDLW) and estimated RMR from TEE7D-PAR. For TEE the correlation between the 7D-PAR and DLW was 0.36 (NS) for men and 0.32 (NS) for women and after subtracting RMR the correlations were 0.07 (NS) and -0.07 (NS) for men and women, respectively (26). This means that the correlation between the two measures, that was already low and non-significant, completely disappeared when the effect of RMR was removed. Slinde et al. (22) reported a correlation of 0.73 between TEE predicted by an extended version of the Minnesota Leisure Time Physical Activity questionnaire (eMNLTP) and TEEDLW. However, the questionnaine underestimated TEEDLW with $25 \%$ (95\% limits of agreement $-1 \%$ to 49\%). Questionmaires have the advantage that they are cheap and can be applied for large populations, however, a major shortcoming is the subjectivily, resulting in low correlations and poor predictions on the individual level. Heart rate monitoring generally has better accuracy then questionmaires but is limited by the need of individual calibration to establish the relationship between $\mathrm{O}_{2}$-consumption and heart rate. Furthermore, heart rate is influenced by other factors than activity such as stress or environmental temperature. Heart rate monitoring provides a reasonable estimate of EE on a group but not on an individual level. Accelerometry seems to be the best field method to assess daily PA since it provides an objective measure of total PA as well as the activity pattern over periods long enough to be representative for daily life (days to weeks) and no individual calibration is required. Unfortunately, not many validated accelerometers are available. Of those validated against DLW, the Tracnor so far shows the best accutacy. Of those commercially available, only the CSA (or MTI) has been proven to correlate reasonably with DLW derived $\mathrm{EE}$. 


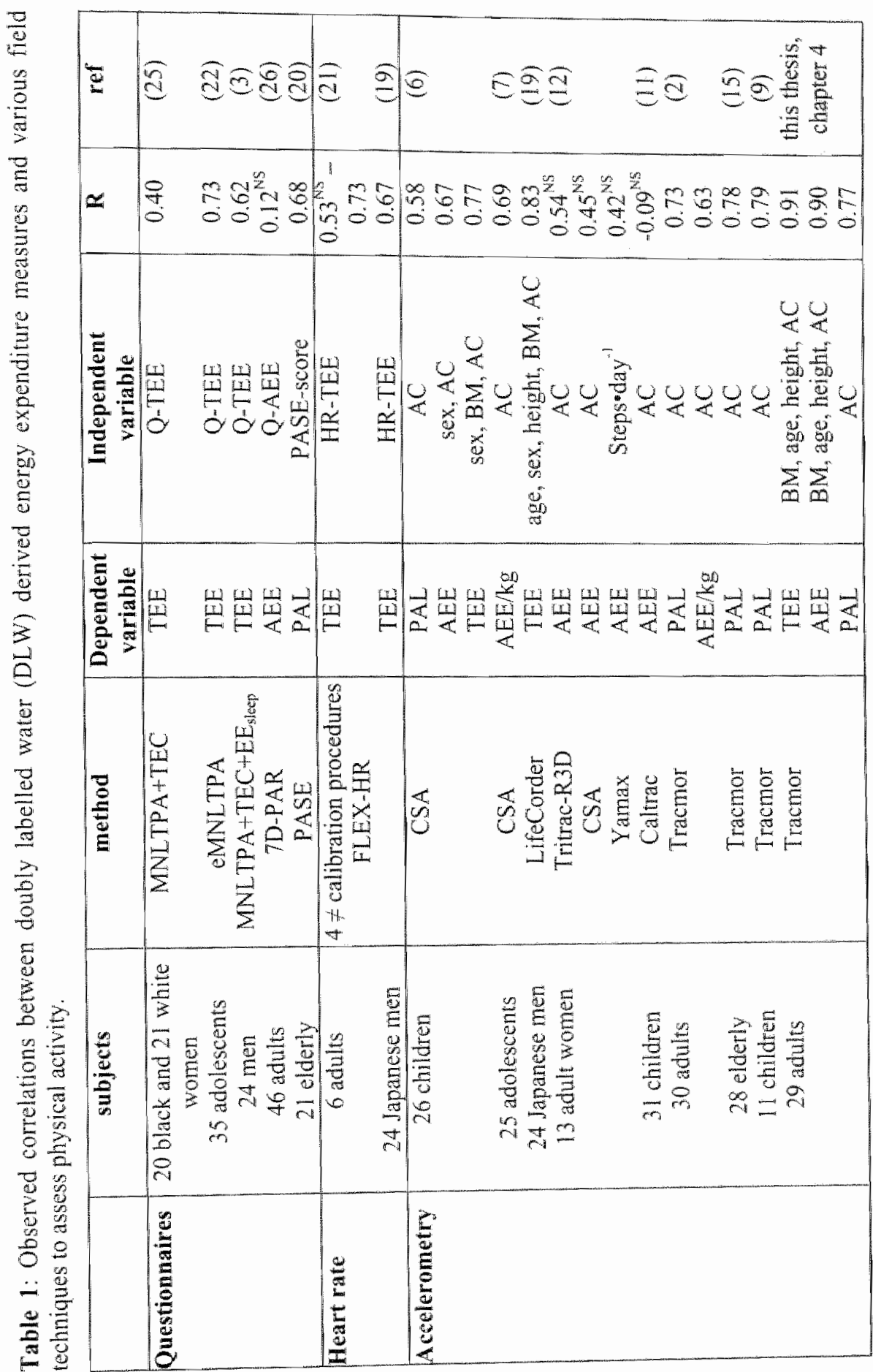




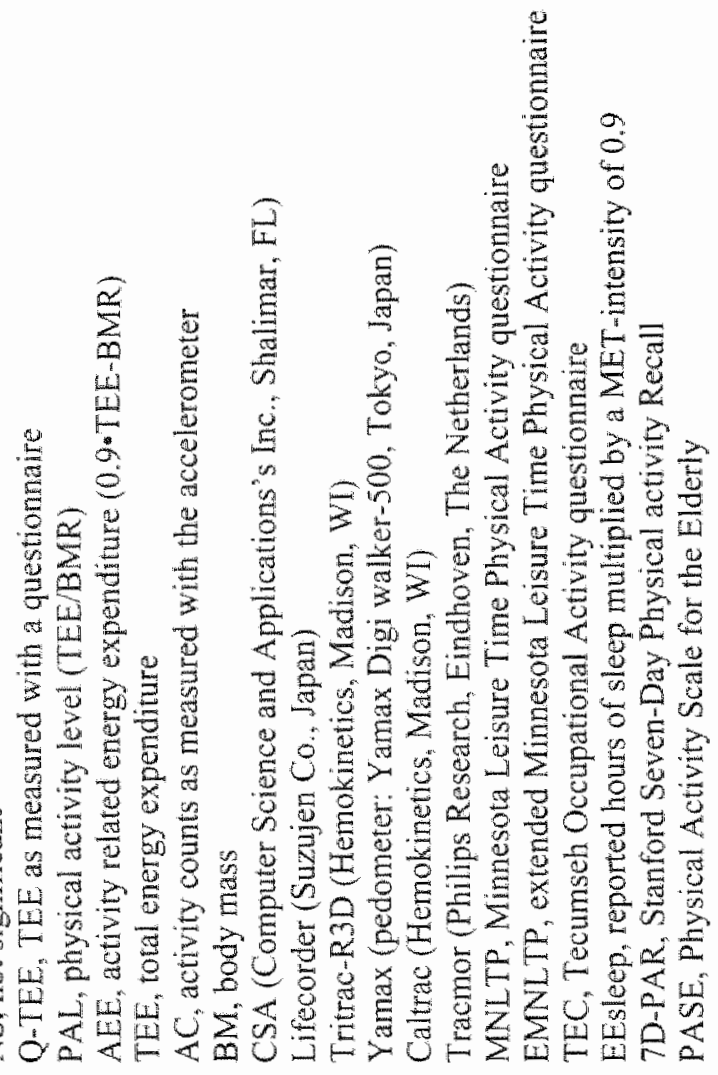




\section{Physical activity and physical fitness}

Just as physical activity can be divided into different categories, such as occuparional, leisure time, household and exercise, physical fithess as well consists of different aspects (chapter 1, Figure 1.3). PA and physical fitness are interrelated. The overall PAL is positively correlated with maximal mechanical power ( $W_{\max }$ ) (chapter 3 ), which in tum is linearly related to maximal aerobic capacity $\left(\mathrm{VO}_{2 \text { wax }}\right)$, both common measures to quantify physical fitmess. Furthermore, aerobic exercise is usually perfomed to maintain or improwe physical fitness. Athough there is a strong relation, a change in PA does not necessarily imply a change in plnysical fitness, or the other way around. For example, Meijer et al. showed that, in elderly subjects, an exercise induced increase in physical fitmess did not result in an increase in total daily activity (16). The training exercise was compensated by a decrease in non training activity, already on the same day, and there was no change in habitual PA on non-training days. The patients with heart failure described in chapter 7 increased in sub-maximal performance when the pacemaker was switched on, whereas total daily activity did not change. On the other hand, a change in the PAL, as observed between seasons, does not necessarily imply a change in physical fitness (chapter 3 ).

Both physical activity and physical fitness are inversely related with several health outcomes, and although they are strongly related, they are each considered as a separate risk factor for heart disease $(1,29)$. This is illustrated in figure 1 , which shows an inverse relation between physical finess and all cause mottality and between the activity level and all cause mortality within each fitness category. The highest death rates for both men and women were in the unfit-sedentary group and the lowest death rates were in the high fit-highly active group (1). Furthemore, quality of life and prognosis in patients with heart failure seems to relate better with daily physical activity than with physical fitness or sub-maximal performance $(10,24)$. The givesion then arises: how much and what type of activity is needed to become physically fit and to live a healthy life.

To address this problem, more research is needed to determine the dose-response relationship between $P A$ and ploysical fitness, between PA and health outcomes and between physical fitness and health outcomes. Therefore, objective methods are needed to measure both PA and physical hiness. The ability of accelerometers to measure the amount, frequency, duration and intensity of physical activily has alrcady been discussed above. Physical fitness can be measured under laboratory conditions using an incremental ergometer or treadmill protocol or with a variety of maximal and submaximal field tests. Accuracy, advantages and disadvantages of various field-lests have been discussed in chapters 5 and 6 . The objective was to develop a new finess-index, based on accelerometry and heart rate monitoring, which is sufficiently accurate, which does not require maximal exertion and is applicable under daily life conditions without the need of a specific protocol. The sudies described in chapters 5 and 6 show that a fitness-index, based on accelerometry and heart rate monitoring, predicted $V O_{2 m a x}$ for $72 \%$ with a SEE of $\mathbb{4} \%$. Furthermore, the Bland Alman plot showed no mean difference and no systematic error for the predicted $\mathrm{VO}_{2 \text { max. }}$. It should be noted, however, that the best results were obtained, after the experimental group and the cross-validation group were created by stratifying subjects according to their activity level. Therefore, the prediction formula needs further testing in study populations will an 


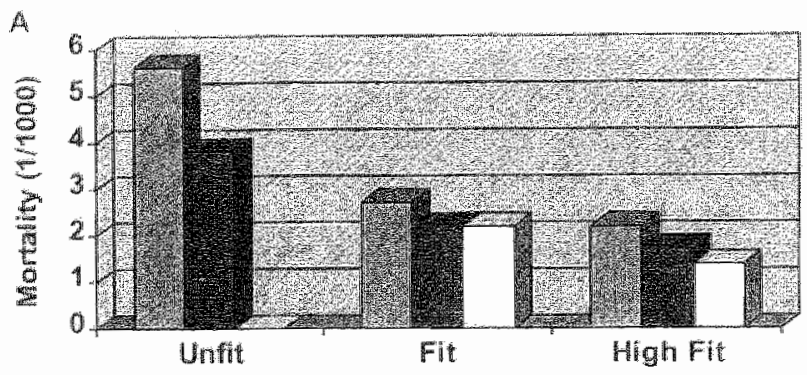

Sedentary Active a High Active

Sis

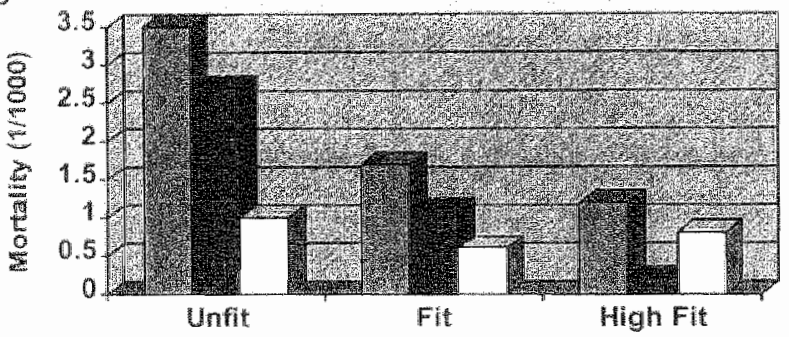

Sedentary Active 0 High Actue

Figure 1: All-cause mortality rates by cardiorespiratory fitness and physical activity categories in 26764 men (A) and 8755 women (B). Height of the bars represents the death rate per 1000 person-years of observation. Adopted from Blair et al. (1).

activity level different from the subjects in the current studies. Especially populations who would benefit most of a litness measure without the requirement of maximat exertion, stch as the obese or elderly, should be addressed.

\section{Intervention strategies to increase physical activity and fitness}

Know/ledge about quantitative and qualitative aspects of physical activity, nequired to improve or maintain health, las to be translated into recommendations and guidelines for the general population. An intervention strategy, focussed on informing subjects about the gans and benefits of being physically active, is a necessary but usually insulficient approach to change behaviour. Other aspects to induce behavioural change. such as goal setting and self-monitoring are common used tools to modify behaviour (13). For example, Guare ef all. (8) showed that, in patients with diabetes type II, participating in behavioural weight-control programs, after 1 year of follow up, those participants who frequently monitored their food intake, lost $18 \mathrm{~kg}$ of body mass compared with $5 \mathrm{~kg}$ by those that monitored their intake less often. The same strategy could be used to maintain a certain activity level. An accelerometer that provides information on the amount of PA performed over a certain period as well as a target 
amount of PA would be a useful tool for both self-monitoring and goal setting. Subjects would gain more insight in their own activity pattems, be able to compare their results with population averages or activity guidelines and could change their activity level accordingly. This also applies for our fitness index based on accelerometry and heart rate. Since no specific protocol is needed, this could easily be implemented as a selfmonitoring and goal setting tool in daily life activities.

\section{Future research}

The emphasis of this thesis was on how physical activity, energy expenditure and physical fitness relate to each other, on low they can be assessed under daily life conditions and on how season can affect one or more of these variables.

Although it was shown that season could cause changes in EE components, the mechanisms remained largely unrevealed (chapter 2 and 3). There were indications that ambient temperature could have a llong-term effect on SMR. Whether or not the thyroid gland is partly responsible for these changes could not be proven. Other methods to measure thyroid activity as well as measuring other homones such as melatonin would be relevant. With regard to the decrease in AEE and PAL in winter season, more information is needed abont changes in the qualitative aspects of physical activity and whether or not this is related to any adverse health effects. Accelerometers seem the most appropriate tools to address this issue. The Tracmor has been proven to contelate well with doubly labelled water derived EE. The SEE for estimating TEE with the Tracmor was only $1.00 \mathrm{MJ} / \mathrm{day}$ or $8.7 \%$ of the average TEE in the current study population (chapter 4). Future research should focus on validating the Tracmor in different study populations, with different activity levels, such as the edderly or the obese. This also applies for the validation of the fitness-index described in chapter 5 and 6. The fitness-index should be tested for the ability to detect changes in fitness over time. Furthermore, another mathematical approach to calculate the fitness-index might improve the accuracy. Combining both the accelerometer and the heart rate monitor into a single device might improve the wearing comfort and one small instrument would provide feedback on both, a subject's activity and fitness level. Such a device could be useful in sports applications (Lifestyle) as well as weight management (Hoalthoute).

In order to define healthy guidelines for physical activity and physical finess, future research should focus on further clarification of the dose response relationship between physical activity, physical fitness and several health aspects. 
1. Blair, S. N., Y. Cheng, and $\mathbb{J}$. S. Holder. Is physical activity or physical finess more important in defining health benefits? Med Sci Sports Exerc. 33:5379-399; discussion $5419-320,2001$.

2. Bouten, C. V., W. P. Verboeket-yan de Venne, K. R. Westerterp, M. Verduin, and J. D. Janssen. Daily physical activity assessment: comparison between movement registration and doubly labeled water. J Appl Physiol. 81:1019-1026, 1996.

3. Conway, J. M. M. L. Irwin, and B. E. Ainsworth. Estimating energy expendinure from the Minnesota Leisure Time Physical Activity and Tecumseh Occupational Activily questionnaires - a doubly labeled water validation. J Clin Epidemiol. $55: 392-399,2002$.

4. Douglas, A. S., T. M. Allan, and J. M. Rawles. Composition of seasonality of disease. Scoth Med J. 36:76-82, 1991.

5. Ekelund, U., J. Aman, A. Yngve, C. Renman, K. Westerterp, and M. Sjostrom. Physical activity but not energy expenditure is reduced in obese adolescents: a case-control study. Am J Clin Nutr. 76:935-941, 2002.

6. Ekelund, U., M. Sjostrom, A. Yngve, F, Poortvliet, A. Nilsson, K. Froberg, N. Wedderkopp, and $K$. Westerterp. Physical activity assessed by activity monitor and doubly labeled water in children. Medicine And Science In Sports And Exercise. Feb. 33:275-281,2001.

7. Ekelund, U., A. Yngve, S. Brage, K. Westerterp, and M. Sjostrom. Body movement and physical activity energy expenditure in children and adolescents: how to adjust for differences in body size and age. Am J Clin Nutr. 79:851-856, 2004.

8. Guare, J. C., R. R. Wing, M. D. Marcus, L. H. Epstein, L. R. Burton, and W. E. Gooding. Analysis of changes in eating behavior and weight loss in type II diabetic patients. Which behaviors to change. Diabetes Care. 12:500-503, 1989.

9. Hoos, M. B., G. Plasqui, W. J. Gerver, and K. R. Westerterp. Physical activity level measured by doubly labeled water and accelerometry in children. Eur I Appl Physiol. 89:624-626, 2003.

10. Houghton, A. R., M. Harrison, A. J. Cowley, and J. R. Hampton. Assessing exercise capacity, quality of life and haemodynamics in heart failure: do the tests tell us the same thing? Eur 』 Heart Fail. 4:289-295, 2002.

11. Johnson, R. K., J. Russ, and M. I. Goran. Physical activity related energy expenditure in children by doubly labeled water as compared with the Caltrac accelerometer. Int.J. Obes. 22:1046-1052, 1998.

12. Leenders, N. Y., W. M. Sherman, H. N. Nagaraja, and C. L. Kien. Evaluation of methods to assess physical activity in tree-living conditions. Med Sci Sports Exerc 33:1233-1240,2001.

13. Leemakers, E. A., A. L. Dunn, and S. N. Blair. Exercise management of obesity. Med Clin North Am. 84:419.440, 2000. 
14. Matthews, C. E.. P. S. Freedson, J. R. Hebert, E, J. Stanek IH, P. A. Merriam, M. C. Rosal, C. B. Ebbeling, and 1. S. Ockene. Seasonal variation in household. occupational, and leisure time physical activity: longitudinal analyses from the seasonal variation of blood cholesterol study. An.J. Epidemiol 153:172-183, 2001 .

15. Meijer, E. P., A. H. Goris, L. Wouters, and K. R. Westerterp. Physical inactivity as a determinant of the physical activity level in the elderly. Int $J$ Obes Relat Metab Disord. 25:935-939, 2001.

16. Meijer, E. P., K. R. Westemterp, and F. T. J. Verstappen. Effect of cxercise traming on total daily physical activity in elderly humans. Eur.J.Appl.Physiol. 80:16-21, 1999.

17. Murayama, N. and R. Ohtsuka. Seasonal fluctuation in energy balance among farmers in Northeast Thailand: the lack of response of energy intake to the change of energy expenditure. Eur J Clin Nutr. 53:39-49, 1999.

18. Osiba, $\mathrm{S}$. The seasonal variation of basal metabolism and activity of thyroid gland in man. Jap.J. Physiol. 7:355-365, 1957.

19. Rafamantanantsoa, H. H., N. Ebine, M. Yoshoka, H. Higuchi, Y. Yoshitake, H. Tanaka, S. Saitoh, and P. J. Jones. Validation of three allernative methods to measure total energy expenditure against the doubly labeled water method for older Japamese men. J Nutr Sci Vitaminol (Tokyo). 48:517-523, 2002.

20. Schuit, A. I., E. G. Schouten, K. R. Westerterp, and W. H. Saris. Validity of the Physical Activity Scale for the Elderly (PASE): according to energy expenditure assessed by the doubly labeled water method. J Clin Epidemiol. 50:541-546, 1997.

21. Schulz, S., K. R. Westerterp, and K. Brick. Comparison of energy expenditure by the doubly labeled water technique with energy intake, heart rate, and activily recording in man. An.J.Clin.Nutr. 49:1146-1154, 1989.

22. Slinde, F, D. Arvidsson, A. Sjoberg, and L. Rossander-Hulthen. Minnesota leisure time activity questionnaire and doubly labeled water in adolescents. Med Sci Sports Exerc. 35:1923-1928, 2003.

23. Van Staveren, W. A., P. Deurenberg, J. Burema, L. C. De Groot, and J. G. Hautvast. Seasonal variation in food intake, pattern of physical activity and change in body weight in a group of young adult Dutch women consuming selfselected diets. Int J Obes. 10:133-145, 1986.

24. Walsh, J. T., A. Charlesworth, R. Andrews, M. Hawkins, and A. J. Cowley. Relation of daily activity levels in patients with chronic heart failure to long-term prognosis. Am J Cardiol. 79:1364-1369. 1997.

25. Walsh, M. C., G. R. Hunter, B. Sirikul, and B. A. Gower. Comparison of selfreported with objectively assessed energy expenditure in black and white women before and after weight loss. Am J Chin Nutr. 79:1013-1019, 2004

26. Washburn, R. A., D. J. Jacobsen, B. J. Sonko, I. O. Hill, and I. E. Donnelly. The validicy of the Stanford Seven-Day Physical Activity Recall in young adulls. Med Sci. Sports Exerc. 35:1374-1380, 2003. 
27. Westerterp, K. R. Assessment of physical activity level in relation to obesity: current evidence and research issues. Med.Sci.Sports Exerc. 31:S522-\$525, 1999.

28. Westerterp, K. R. Pattern and intensity of physical activity. Nature $410 \cdot 539,2001$.

29. Willams, P. T. Physical fitness and activity as separate heart disease risk factors: a meta-analysis. Med Sci Sports Exerc. 33:754-761., 2001. 
Appendix 1 


\section{Energy expenditure: general principles}

The metabolism of an organism is a process of energy production by the combustion of fuel in the form of carbohydrate, protein, fat or alcohol. In this process oxygen $\left(\mathrm{O}_{2}\right)$ is consumed and carbon dioxide $\left(\mathrm{CO}_{2}\right)$ produced. Energy expenditure can be measured by measuring the heat production, which is called direct calorimetry or by measuring the $\mathrm{O}_{2}$-consumption and $\mathrm{CO}_{2}$-production, which is called indirect calorimetry. When a subject is at rest, all energy is lost as heat. The heat production is a consequence of both the heat directly lost during chemical processes as well as the energy stored in ATP (adenosine triphosphate). ATP is a chemical component used by the cells for essential processes such as biosynthesis of molecules, mechanical contractions and active transport. The energy used for these processes will eventually also be converted into heat and external work. Since no external work is performed during rest, all energy will be converted into heat and both direct and indirect calorimetry will measure the same amount of energy expenditure. When a subject is physically active, part of the energy production is used for external work. In that case, only indirect calorimetry will measure the total energy expenditure.

With indirect calorimetry, heat production is calculated from chemical processes. Knowing for example that 1 mol glucose oxidizes with 6 mols $\mathrm{O}_{2}$ to 6 mols water and 6 mols $\mathrm{CO}_{2}$ and produces $2.8 \mathrm{MJ}$ heat, energy expenditure or heat production can be calculated from $\mathrm{O}_{2}$-consumption and $\mathrm{CO}_{2}$-production. The energy equivalent of $\mathrm{O}_{2}$ and $\mathrm{CO}_{2}$ varies with the nutrient oxidized. Formulae for calculating the energy expenditure and the quantities of carbohydrate $(\mathrm{C})$, protein $(\mathrm{P})$ and fat $(\mathrm{F})$ oxodized are based on $\mathrm{O}_{2}$ consumption, $\mathrm{CO}_{2}$-production and urine-nitrogen loss (1). The principle of the calculation consists of three equations with the mentioned three variables:

$$
\begin{aligned}
& \mathrm{O}_{2} \text {-consumption }=0.829 \mathrm{C}+0.967 \mathrm{P}+2.019 \mathrm{~F} \\
& \mathrm{CO}_{2} \text {-production }=0.829 \mathrm{C}+0.775 \mathrm{P}+1.427 \mathrm{~F} \\
& \text { Heat production }=21.1 \mathrm{C}+18.7 \mathrm{P}+19.6 \mathrm{~F}
\end{aligned}
$$

Protein oxidation $(\mathrm{g})$ is calculated as $6.25 \mathrm{x}$ urine-nitrogen $(\mathrm{g})$, and subsequently $\mathrm{O}_{2}-$ consumption and $\mathrm{CO}_{2}$-production can be corrected for protein oxidation to allow calculation of carbohydrate- and fat oxidation. The general formula for the calculation of energy production (E) derived from these figures is:

$$
E=16.20 \mathrm{O}_{2} \text {-consumption }+5.00 \mathrm{CO}_{2} \text {-production }-0.95 \mathrm{P}
$$

In this fomula, the contribution of $\mathrm{P}$ to $\mathrm{E}$, the so-called protein correction, is small. In the case of a nomal protein oxidation of $10-15 \%$ of the daily energy production, the protein correction for the calculation of $\mathbb{E}$ is about $1 \%$. Usually, one only measures urine nitrogen when information on the contribution of $\mathrm{C}, \mathrm{P}$ and $\mathrm{F}$ to energy production is needed. For calculation of energy production, the protein correction is often meglected.

1. Westerterp, K. R. Energy expenditure. In. Food intake and energy expenditure. M. S. Westerterp-Plantenga, E. W. H. M. Fredrix, and A. B. Steffens (Eds.): CRC Press, 1994, pp. 235-257. 
Summary 


\section{Summary}

A large proportion of the Western population is physically inactive. A sedentary lifestyle is a major concem for public health since it is associated with several diseases such as cardiovascular disease, diabetes mellitus type 11 , osteoporosis and obesity. The dramatic increase in the prevalence of owerweight and obesity over the past decades is related with, and possibly caused by lower levels of physical activity.

Physical activity can be defined as body movement, produced by skeletal muscles, resulting in energy expenditure. It is a complex behaviour including sports as well as non-sponts activities. Physical activity has an impact on energy expenditure and physical fitness. The extent to which body movement leads to energy expenditure is dependent on body size and body composition. The extent to which physical activity improves physical finess is dependent on the amount and type of activity performed. Physical activity is a behaviour that can be influenced by the environment. Season is an envirommental factor that modulates climatic features such as ambient temperature and day length. These changes in climatic conditions can affect one or more aspects of physical activity and energy expenditure.

The main emphasis of this thesis was on how physical activity, energy expenditure and physical fitness relate to each other, on how they can be assessed under daily life conditions and on how season can affect one or more of these variables.

Total energy expenditure (TEE) was measured with the doubly labelled water technique and sleeping metabolic rate (SMR) by an overnight stay in a respiration chamber. Physical activity was expressed in terms of activity related energy expenditure (AEE), as physical activity level (PAL) and as body movement. $\mathrm{AEE}$ ( $\mathrm{AEE}=0.9 \cdot \mathrm{TEE}-\mathrm{SMR}$ ) was calculated by substracting. SMR from TEE assuming diet induced energy expenditure (DIT) to be $10 \%$ of TEE. PAL was calculated as TEE $\mathrm{SMR}^{-1}$. Body movement was assessed with a tri-axial accelerometer for movement registration (Tracmor), providing information about total physical activity as well as activity patterns in terms of duration, frequency and intensity. Physical fitness was defined as maximal mechanical power ( $\left.\mathrm{W}_{\max }\right)$ or maximal aerobic capacity $\left(\mathrm{VO}_{2 \max }\right)$, assessed with an incremental test on a bicycle ergometer.

II was shown that there is a significant seasonal variation in SMR ower the year with a minimum in summer season (July, August) and a maximum in winter season (January, February). AEE and PAI were significantly lower in winter season whereas physical finess did not change. It was concluded that information on activity patterns was needed to gain more insight in the effect of season on physical activity. For this purpose, accelerometers are more appropriate than the use of doubly labelled water alone.

The Tracmor was validated against doubly labelled water to assess energy expenditure under daily life conditions. Age, height, body mass and activity counts (Tracmor outpult) explained $83 \%$ of the variation in TEE with a standard error of estimate of $1.00 \mathrm{MJ} / \mathrm{day}$ or $8.7 \%$ of the average TEE. The Tracmor is therefore a suitable instument to provide information about activity pattems as well as an estimate of energy expenditure.

As for physical activity, there is a need for accurate field techniques to assess physical finess. Measuring physical fitmess under laboratory conditions using an incremental exercise test, requires a specific protocol, expensive equipment and maximal exertion of the subject. A new fitnessundex was developed, based on the combined use of 
accelerometry and heant rate registration. The fitness-index predicted $\mathrm{VO}_{2 \mathrm{max}}$ for $72 \%$ with a SEE of 14\%. Furthermore, the Bland Altman plot showed no mean difference and no systematic error for the predicted $\mathrm{VO}_{2 \mathrm{max}}$. The fitness-index is therefore a promising tool for the assessment of physical fitness outside laboratory conditions and without the need of a specific protocol.

As a clinical application, the Tracmor was used to measure daily physical activity in patients with heart failure, i.e. a population with low physical activity levels due to cardiac impairment. The objective was to investigate whether the implantation of a pacing device positively affected physical activity. It was shown that although patients improved in exercise capacity, defined as the distance covered in a 6 -min-walk test. there was no change in daily physical activity as neasured with the Tracmor.

In conclusion, the importance of physical activity and physical fitness in relation to several diseases, such as cardiovascular disease and obesity, highlights the need for accurate assessment tools that are relatively inexpensive and applicable under daily life conditions. The impact of season on physical activity, and TEE and its components should be considered when studying relationships between physical activity and health or when studying the seasonality in health parameters, such as cardiovascular risk factors. In order to define healthy guidelines for physical activity and physical fitness, more research is needed to clarify the dose response relationship between physical activity, physical fitness and several health aspects. The devices described in this thesis could be useful for health related research as well as sports applications and weight management. 



\section{Samenvatting}

Een groot deel van de Westerse bevolking is onvoldoende Jichamelijk actief. Fen inactieve levensstijl verhoogt het risico op tal van aandoeningen zoals hart- en vaatziekten, diabetes mellitus type III, osteoporose en obesitas. De enorme toename in de prevalentic van overgewicht en obesitas in de laatste decennia is gerelateerd aan en mogelijk veroorzakik door een afname in lichamelijke actiwiteit.

Cichamelijke activiteit kan men definieren als lichammbeweging, veroorzaakt door de skeletspieren en resulterend in energiegebruik. Het is een complex gedrag dat zowel sport als niet-sport gerelateerde activiteit omvat. Lichamelijke activiteit beinvloedt zowel het energiegebruik als de lichamelijke fitheid. Het energiegebruik als gevolg van activiteit is afhankelijk van het lichaamsgewicht en de lichaamssamenstelling. In hoeverre lichamelijke activiteit leidt tot een toename in fitheid is athankelijk van de hoeveelheid en het type activiteit. Tal van omgevingsfactoren, zoals het seizoen, dat de klumatologische omstandigheden zoals de omgevingstemperatuur en de daglengte bepaalt, kunnen een invloed hebben op de lichamelijke activiteit en het energiegebruik.

Dit proefschift handelt over de relatie tussen lichamelijke actiwiteit, energiegebruik en fitheid, over hoe deze grootheden kunnen worden gemeten in het dagelijks leven en over hoe de seizoenen een of meerdere van deze factoren kunnen beïnvloeden.

Het totale energiegebruik werd gemeten met behulp van tweevoudig gemerkt water. De slapstolwisseling werd gemeten tijdens een overnachting in een respiratiekamer. Lichamelijke activiteit kan men uitdrukken als energiegebruik of als lichaamsbeweging. Het energiegebruik als gevolg wan activiteit werd berekend als $90 \%$ van het totale energiegebruik vermindert met de slaapstofwisseling. Hierbij werd aangenomen dat $10 \%$ van het totale energiegebruik bestaat uit het dieet geinduceerde energiegebruik. Het lichamelijke activiteitenniveau werd berekend als het totale energiegebruik gedeeld door de slaapstofwisseling. Lichaamsbeweging werd gedetecteerd met behulp van een drie-assige bewegingsmeter (tri-axial accelerometer for movement registration, Tracmor) die informatie geeft of de totale hoeveelheid maar ook over de dur, frequentie en intensiteit van lichamsbeweging. Lichamelijke fitheid werd bepaald met een maximaltest op een fietsergometer en gedefinieerd als maximate trapweerstand of maximale zurstofopname.

Er was een significante seizoensvariatie in de slapstofwisseling, met en minimum in de zomor (juli, augustus) en een maximum in de winter (januari., februari). Het activiteit gerelated energiegebruik en het activiteitenniweau was significant lager in de winter dan in de zomer. Lichamelijke fitheid bleef onveranderd. Om meer inzicht te verwerven in het effect van de serzoenen op lichamelijke activiteit is er meer informatie nodig over het bewegingspatroon (duur, frequentie en intensileit van bewegen). Bewegingsmeters zijn hiervoor beter geschikt dan het gebruik van tweevoudig gemerkt water alleen. De Tracmor werd gevalideerd, met tweevoudig gemerkt water als de gouden standaard, voor het meten van energiegebruik in het dageliks leven. $83 \%$ van de variatie in her total energiegebruik kon verklatard worden door leeftij, gewicht, lengte en de hoeveelheid beweging geregistreerd met de Tracmor. De standaardfout was 1.00 MJ of $8.7 \%$ van het gemiddelde energiegebruik. De Tracmor is darom en geschikt instrument om her bewegingspatroon te meten en een goede schatting van het energiegebruik te geven in het dagellijks leven. 
Net als voor lichamelijke activiteit is er ook behoefte an nauwkeurige technieken on. buiten het laboratorium, lichamelijke fitheid te meten. Een maximal test in het laboratorium vraagt immers een specifiek protocol, duur materiaal en volledige uitputting van de proefpersoon. Het doel was een nieuwe fitheidsmat te ontwikkelen, gebaseerd op de combinatie van bewegingsregistratie met de Tracmor en hartslagregistratie. Deze fitheidsmaat voorspelde de maximale zumrstofopmame voor $72 \%$ met een standaardfout van $14 \%$. Er bleek ook geen systematisch verschil te zijn tussen de voorspelde en gemeten maximale zuustofopname. De nieuwe fitheidsmat is darom een veelbelovende methode om lichamelijke fitheid te meten, zonder de behoefte aan een specifick protocol of maximale uitputing.

Tenslotte werd de Tracnor ook gebruikt om lichamelijke activiteit te meten bij patiënten met hartalen en als gevolg daarvan een laag activiteitemiveau. Het doel was na te gaan of de implantatie van een pacemaker een positief effect had op het activiteitenniveau. Patiènten bleken wel een toename te vertonen in fitheid, geneten als de maximaal afgelegde wandelafstand bimen 6 min tijd, maar er was geen verandering. in dagelijkse activiteit.

Het belang wan lichamelijke activiteit en fitheid in de etiologie van tal van aandoeningen zoals hart- en vaatziekten en obesitas, benadrukt de behoefte aan nauwkeurige meettechnieken die toepasbaar zijn in het dagelijks leven. Bij de siudie van de relatie tussen lichamelijke activiteit en gezondheid is het belangrijk rekening te houden met de invloed van de seizoenen op de lichamelike activiteit en en op het energiegebruik. Om duidelijke richtlijnen te kumnen opstellen in verband met lichamelijke activiteit en fitheid, is meer onderzoek nodig naar de dosisrespons relatie tussen lichamelijke activiteit, fitheid en gezondheidsparameters. De meetmethoden, beschreven in deze thesis zijn toepasbaar in gezondheidsonderzoek, voor sportgerelateerde doeleinden en gewichtsregulatie. 

In Nedertand gaan werken on te doctoreren, mijn "Vlaamse" wrienden en familie verklatden mij voor $20 t$, maar, ze hadden ongelijk. Ik heb 4 geweldige jaren. doorgebracht in Maastricht, heb mij de enige echte Nederlandse tal eigen gemaakt, inclusief de accenten, wonder boven wonder heb ik ook een proefschrift geschreven binnen de daar voorzene tijd. En daarvoor zijn er toch een heleboel mensen die ik even will bedanken. Laat ik daarom beginnen met een eenvoudig DANK U WEL aan IEDEREEN. Bij deze (volgens de spellingcontrole moet het 'bij dezeN" zijn, maar kritsch en eigenwijs als ik ben, geloof ik dat niet) ben ik alwast niemand vergeten.

Allerecrst wil ik mijn promotor en tevens co-promotor Klaas Westerterp bedanken voor de dagelijkse begeleiding bij mijn werk, het mede bedenken en opzetten van het onderzoek, het verbeteren van de artikels en het tijdig stellen van deadlines, wat af en toe wel nodig was. Iij behicld altijd een goed overzicht, bracht altijd weer structuur als er chaos dreigde en was altijd bereikbaar als dat nodig was. Als er iemand moet bedankt worden voor het tijdig afwerken wan dit proefschrift, dan ben jij het wel. Bedankt dus!!!

Dan wil ik nu diegenen bedanken die eerder een bedreiging vormden voor het tijdig tot stand komen van mijn doctoraat, maar tevens op hun eigen manier hebben bijgedragen door voor de nodige ontspanning te zorgen. Laat ons zeggen dat ik af en toe de werkweek nodig had om uit te rusten van het weekend. On te beginnen, het comité der festiviteiten, en daarmee bedoel ik zowel, om voor een keer de goede wrede te bewaren, de raad van bestuur als de raad wan beheer en alle leden. Met name Jeroen (alias Juinkes), Andy (alias Willy), Wim (alias Manske), Peter (alias Coupe Janet of ook wel Haarsnitnicht), Sara (alias helaas gecensureerd), Nele (alias Feestwlierbes), Astrid (alias De Rolfabriek), Luc (alias Jul), Jul (alias Stinn), Marnix (alias Het Oog), Sophie (alias Sophiscus Naivus, naar eigen zeggen). Jullie zorgden allemaal voor, op zijn zachtst uitgedrukt, de nodige ontspanning, maar zeker en vast ook voor hééél veel vriendschap. Eigenlijk verdient elk van jullie nog een aparte paragraaf, maar nu is de ruimte in zo 'n proefschrift toch wel beperkt zeker. Jammer!

Wie ik zeker niet mag vergeten zijn twee goede vrienden, die misschien geen lid waren van hef festcomite maar daarom niet minder mijn nachtrust bedreigd hebben en zeker ook niet minder vriendschap hebben gegeven, zoals daar zijn Bert (alias Bijre) en Matke (alins Knuffelmaike). Maaike, jou verwacht ik alvast in Australie.

Verder zijn er nog een heleboel gelegenheidsfeesters zoals Elisabeth (Elisabeast), Eveline, Kristel, de Bende van Friedel, de Bende van Tramalant, nieuwe mensen die ik elk restje leer kennen,...

Tenslotte, maar nict minder belangrijk. An. dij was jarenlang mijn waste vriendin en hebt dus een belangrijke rol gespeeld in mijn leven. Het woord 'vaste' is misschien niet meer van loepassing, mar die vriendin, dat blijft.

En hoe had ik Mastricht kumen ovetleven zonder mijn dierbare collega's of noet ik zeggen zootje ongeregeld, warvan het wetenschappelijk onderzoek zich grotendeels loespitst op de dag tot dag of zells uur tot uur varuatie in de koffiesmaak. Joost en Freddy, bedankt voor de suikerklont-werp-wedstrijden waarin mijn van nature aanwezige heer- en meesterschap, steeds meer wordt bedreigd door jullie intensieve training. Andere fanatieke koffe- en/of thee drinkers mag ik ook niet vergeten, zoals Marieke, Manuela, Lydia, Neeltje, Mirjam, Nathalie, Roy en vaste klets-partner Marje, bedankt voor het artikel. En niet te vergeten, Kristel en Kristof, jullie zijn dan wel geen 
koffie- en/of thee drinkers maar toch bedankt voor het luisteren naar mijn af en toe bizarre levenservaringen. Ook andere Belgjes die samen met mij de Nederlande heerschappij hebben getrotseerd of nog steeds trotseren, zoals Mandy, Elke, Petra en in het bijzonder, Kaatje, de beste fietspartmer die er is en zeker ook een goede vriendin.

Natuurlijk is er ook nog meine liebe Tanja (alias helaas ook gecensureerd), mijn vaste psychologe, koffiedrinkster en hartsvriendin. Ik reis de halve wereld rond, juj een kwant van de wereld, waardoor de afstand tussen ons slechts een kwart-wereld wordt. Ik zie dus geen enkele reden om niet af en toe bij elkar op de koffie te komen.

En zoals beloofd, een aparte paragraaf voor Claudia, wel geen halve pagina maar toch, jij bent de beste secretaresse oont?

Laat mij ook even om wat medeleven wagen voor Annemiek. Zij heeft tenslotte 4 jaar lang, 8 uur per dag met mij op een kamer moeten doorbrengen. Ik hoor het jullie allemaal luidop denken: man, man, man, wat een miserie, wat een miserie! Maar Miekje Piekje heeft het overleefd en heeft mij helpen overleven. Bedankt Miekje.

Paul en Loek, de techneuten van de vakgroep, jullie hulp was onontbeorlijk. En natuurlijk zijn er nog zovele andere collega's het vermelden ward, waarvan velen ook altijd bereid waren proefpersoon te spelen voor miju onderzoek, Marco, Marja, Eefje, Gijs, Joris, René, Astrid, Antoine, Jos, Luc, Patrick, Johan, Reinout,..., en ook mijn stagiaires door de jaren heen, Mirjam, Maria Dolores, Indith en Diane, iedereen eigenlijk!

A special paragraph for both a collegue and a dear friend. Dear Tanja (alias Psycho German), I know you did your very best for keeping me from writing ny own thesis by having me write yours, but 1 made it after all, and so did you. We started off as collegues (only $22000 \mathrm{~km}$ a part), became E-mail friends and ended up as very close friends. Ironically, now that you're back from Australia and we live only $50 \mathrm{~km}$ away from each other, it's me who's going to Ozzie-land. One thing l'm sure of, we will meet again!

Tot slot wil ik mijn ouders bedanken. Zij hebben de zware taak gehad mij op te voeden, wat, zoals jullie je kunnen voorstellen. niet makkelijk geweest kan zijn. Zij hebben ervoor gezorgd dat ik kon studeren en dus doctoreren. En wat doet zoonlief dan. hij is nooit meer thuis en vertrekt naar de andere kant van de werehd. Ik weed warr ik voor sta als ik ooit kinderen heb. Héééééééééééd veeceeeeceel dank dus! En mijn twee zusjes, Ann en Kristel, die zijn waarschijnlijk blij dat ik hun niet langer kan pesten, maar pas op, ik kom terug!

Uiteraard is er maan een enkel woord dat dergelijk relaas als een dankwoord waardig kan afsluiten,

Kleir! 



\section{Full papers}

1. Hoos, M. B., G. Plasqui, W. J. Gerver, and K. R. Westerterp. Physical activity level measured by doubly labeled water and accelerometry in children. Eur $J$ Appl Physiol 89:624-626, 2003.

2. Plasqui, G., A. D. Kester, and K. R. Westerterp. Seasonal variation in sleeping metabolic rate, thyroid activity, and leptin. Am I Physiol Endocrinol Metab. $285: E 338-343,2003$.

3. Plasqui, G. and K. R. Westerterp. Seasonal wariation in total energy expenditure and physical activity in Dutch young adults. Obes Res, 12:688$694,2004$.

4. Vogels, N. G. Egger, G. Plasqui and K.R. Westerterp. Estimating Changes in Daily Physical Activity Levels over Time: Implication for Health Interventions from a Novel Approach.. Int J Sports Med. 2004 Nov;25(8):607-10.

5. Westerterp, K.R. and G. Plasqui. Physical activity and human energy expenditure. Curr Opin Clin Nutr Metab Care. 2004 Nov;7(6):607-613.

6. Westerterp, K.R., G. Plasqui and A.H.C. Goris. Water loss as a function of energy intake, physical activity and season. Br I Nutr. In press.

7. Plasqui, G., A. M. C. P. Joosen, A. D. Kester, A. H. C. Goris, and K. R. Westerterp. Measuring free-living energy expenditure and physical activity with tri-axial accelerometry. Accepted for publication.

8. Plasqui, G. and K. R. Westerterp. Accelerometry and heart rate monitoring as a measure of physical fitness: proof of concept. Accepted for publication.

9. Plasqui, G. and K.R. Westerterp. Accelerometry and heart rate monitoring as a measure of physical fitness: cross-validation. Submitted.

10. Plasqui, G., C. J. Storm and K. R. Westerterp. Daily physical activity in patients with heart failure before and after cardiac resynchronisation therapy. Submitted.

11. Hechler, T., G. Plasqui, P. Beumont, R. Laessle, S. Touyz and K. R. Westerterp. Seasonal variation in physical activity in anorexia nervosa patients. Submitted. 


\section{Abstracts}

1. Plasqui, G. and $\mathbb{K}$. R. Westerterp. Seasonal variation in sleeping metabolic rate and body composition, Int J Obes. Vol 26 (Suppl 1): S71, 2002.

2. Plasqui, G. and K. R. Westerterp. Seasonal variation in energy metabolism and body composition in Dutch men and women. Proceedings of the nutrition society. Vol $61,2002$.

3. Plasqui, G. and K. R. Westerterp. Seasonal variation in total energy expenditure and physical activity, Int J Obes, Vol27 (SupplI): S139, 2003.

4. Plasqui, G. and K. R. Westerterp. Accelerometry and heart rate monitoring as a measure of physical fitness: proof of concept. Int J Obes. Vol28 (Suppll): S211, 2004.

5. Westerterp, K. R. and G. Plasqui. Water loss as a function of energy intake, physical activity and season. Int J Obes. Vol28 (Suppl 1): S212, 2004.

6. Plasqui, G., A. M. C. P. Joosen, A. D. Kester, A. H. C. Goris, and K. R. Westerterp. Measuring Free-Living Energy Expenditure and Physical Activity with Tri-Axial Accelerometry. Obes Res. In press.

7. Hechler, T., G. Plasqui, P. Beumont, R. Laessle, S. Touyz and K. R. Westerterp. Is there a "high-risk season" for physical activity in patients with anorexia nervosa? Int I Behav Med. In press. 

Guy Plasqui werd geboren op 2 juni 1976 te Bonheiden en groeide op in Hombeek (Mechelen). In 1995 behalde hij zijn middelbaar diploma in wiskunde-wetenschappen aan het Sint-Theresia college te Kapelle-op-den-Bos. Datzelfde jaar startie hij de opleiding voedings-en dieetleer aan de KU Leuven waar hij 4 jaar later afstudeerde. Aangezien cen licentiaat in de voeding zich nog geen diëtist mag noemen behaalde hij daarna nog een graduaat diploma in de voedings-en dieetleer. Na 5 jaar in Leuven gewoond te hebben, werd het tijd voor iets nieuws en in oktober 2000 startte hij alls AlO aan de Universiteit Maastricht, op het project 'Lichamelijke activiteit en energiegebruik in het dageli.jks leven: meting en interventie, onder begeleiding van Prof. Klaas Westerterp. Nu, 4 jaar later, is het proefschrift klaar en dus de hoogste fijd om weer een nieuwe uitdaging aan te gaan. Vanaf 1 oktober 2004 zal hij werken als "associate lecturer" aan de Universiteit van Wollongong, Australie. Wat daarna volgt... zal blijken.

Guy Plasqui was born the 2 nd of June 1976 in Bonheiden and was raised in Hombeek (Mechelen). In 1995, he got his highschool degree in nuths and sciences at the SintTheresia College, Kapelle-op-den-Bos. The same year he started studying nutrition and dietetics at the Catholic University of Jeuven. Ater 4 years he got his university degree and decided to add one more year to get his graduate degree in nutrition and dietetics. After 5 years of living in Leuven, it was time for something new and he started his $\mathrm{PhD}$. project, "daily physical activity and energy expenditure: measurement and intervention" at the University of Maastricht under the supervision of Prof. Klaas Westerterp. Now, 4 years later, the thesis is finished and the time has come for a new challenge. Starting from the 1 st of October 2004 , he will be working as 'associate lecturer' at the University of Wollongong, Australia. Whatever happens afterwards, ... is still unknown. 